\title{
RAL GTPases mediate EGFR-driven intestinal stem cell hyperproliferation and tumourigenesis.
}

Máté Nászai ${ }^{1,3,4}$, Karen Bellec ${ }^{1,3}$, Yachuan Yu1,2,3, Álvaro Román-Fernández ${ }^{2,3}$, Emma

Sandilands ${ }^{2,3}$, Joel Johansson ${ }^{2}$, Andrew D Campbell ${ }^{2}$, Jim C Norman ${ }^{2,3}$, Owen J Sansom ${ }^{2,3}$, David M Bryant ${ }^{2,3}$, Julia B Cordero ${ }^{1,2,3^{*}}$

${ }^{1}$ Wolfson Wohl Cancer Research Centre, Glasgow, G61 1QH, United Kingdom

${ }^{2}$ Cancer Research UK Beatson Institute, Glasgow, G61 1BD, United Kingdom

${ }^{3}$ Institute of Cancer Sciences, University of Glasgow, Glasgow, G61 1QH, United Kingdom

${ }^{4}$ Present address: St Peter's College, University of Oxford, Oxford OX1 2DL, United Kingdom

*Correspondence: Julia.Cordero@glasgow.ac.uk 


\section{Summary}

RAS-like (RAL) GTPases function in Wnt signalling-dependent intestinal stem cell proliferation and regeneration. Whether RAL proteins work as canonical RAS effectors in the intestine, and the mechanisms of how they contribute to tumourigenesis remain unclear. Here, we show that RAL GTPases are necessary and sufficient to activate EGFR/MAPK signalling in the intestine, via induction of EGFR internalisation. Knocking down Drosophila RalA from intestinal stem and progenitor cells leads to increased levels of plasma membrane-associated EGFR and decreased MAPK pathway activation. Importantly, in addition to impacting stem cell proliferation during damage-induced intestinal regeneration, this role of RAL GTPases impacts on EGFRdependent tumorigenic growth in the intestine and in human mammary epithelium. However, the effect of oncogenic RAS in the intestine is independent from RAL function. Altogether, our results reveal previously unrecognised cellular and molecular contexts where RAL GTPases become essential mediators of adult tissue homeostasis and malignant transformation.

Key words: RAL GTPase; EGFR/MAPK signalling; Intestinal Stem Cells; Regeneration; Cancer 


\section{Introduction}

The precise spatial and temporal regulation of signalling pathway activity is essential for organ development and adult tissue homeostasis. The latter is particularly important in stem cell maintained self-renewing epithelia, such as that of the gastrointestinal tract (Richardson et al., 2014), where cell loss needs to be counteracted by stem cell proliferation and differentiation while limiting the potential for unwanted overgrowth (Radtke and Clevers, 2005). Progressive loss of control over proliferative pathways either through loss of tumour suppressor genes or the activation of oncogenes are associated with tumour development and progression (Hanahan and Weinberg, 2011).

Regulation of intestinal homeostasis involves the coordinated action of multiple evolutionarily conserved signalling pathways, which relay environmental and nichederived signals to stem cells to ultimately determine their activity (Gehart and Clevers, 2019; Nászai et al., 2015; Scoville et al., 2008). Increasing understanding of how these pathways are regulated not only provides insight into basic stem cell biology, but also sheds light onto pathological conditions often associated with uncontrolled stem cell proliferation, such as cancer (Biteau et al., 2011; Sell, 2010).

Epidermal growth factor receptor (EGFR, also known as ErbB1 or HER1) is a member of the ErbB family of growth factor receptors, which play essential roles in regulating cell proliferation, differentiation and survival (Citri and Yarden, 2006; Wee and Wang, 2017). In the mammalian intestinal epithelium, EGFR is highly expressed in intestinal stem cells (ISC) and transit amplifying cells (Yang et al., 2017). EGFR ligands, such as EGF, are released by Paneth cells and the mesenchyme and are required for the maintenance and proliferation of ISCs (Dvořák et al., 1994; Jardé et al., 2020; Poulsen et al., 1986). Ectopic activation of EGFR signalling in the intestine by luminal 
application or genetic overexpression of pathway ligands (Bongers et al., 2012; Kitchen et al., 2005; Marchbank et al., 1995), or deletion of the negative regulator leucine-rich repeats and immunoglobulin-like domains protein 1 (Lrig1) (Powell et al., 2012; Wong et al., 2012), leads to elevated ISC proliferation. On the other hand, loss of EGFR signalling induces quiescence of Lgr5+ ISCs in vitro (Basak et al., 2017).

Gene amplification and activating point mutations of EGFR are highly prevalent in cancer (Santarius et al., 2010; Yarden and Pines, 2012). Ectopic EGFR/Ras/MAPK signalling is thought to be an early step in colorectal cancer (CRC) development (Calcagno et al., 2008). Hyperactivation of the pathway accelerates intestinal tumourigenesis driven by Adenomatous polyposis coli loss (Apc $\left.\mathrm{min} /+^{\mathrm{mice}}\right)$ (Luo et al., 2009), while a genetic background of partial loss-of-function of EGFR (Roberts et al., 2002) or small molecule inhibitor treatment reduce cancer incidence (Roberts et al., 2002; Torrance et al., 2000).

The Drosophila intestinal epithelium shares remarkable homology with its mammalian counterpart. The tissue is maintained by ISCs that replenish the epithelium through progenitor cells called enteroblasts (EB), which differentiate into either secretory enteroendocrine (EE) cells or absorptive enterocytes (ECs) (Micchelli and Perrimon, 2006; Ohlstein and Spradling, 2006). Importantly, signalling pathways governing intestinal proliferation and differentiation are highly conserved between fruit flies and mammals (Nászai et al., 2015; Miguel Aliaga et al., 2018). Activation of EGFR/Ras/MAPK within ISCs by niche-derived EGF-like ligands is essential to sustain homeostatic and regenerative proliferation of the adult fly midgut, while constitutive pathway activation in ISCs is sufficient to drive intestinal hyperplasia (Biteau and Jasper, 2011; Buchon et al., 2010; Jiang et al., 2011; Xu et al., 2011). 
Regulation of EGFR signalling activity is highly dependent on various modes of receptor trafficking throughout the endocytic pathway. Indeed, abnormal trafficking of receptor tyrosine kinases is linked to cancer (Lanzetti and Di Fiore, 2017; Mosesson et al., 2008). Following internalization through Clathrin-mediated (CME) or Clathrinindependent endocytosis (CIE) (Sorkin and Goh, 2009), EGF ligand/receptor complexes can either be targeted for recycling into the plasma membrane (PM), or ubiquitinated and targeted to late endosomes for lysosomal degradation (Sigismund et al., 2008, 2013). Most recently, autophagy has emerged as an important mechanism implicated in the termination of EGFR/MAPK signalling in the intestine (Zhang et al., 2019). While endocytosis is classically considered as a process to terminate pathway activity (Tomas et al., 2014), significant evidence suggests that receptors retain their ability to relay their signal even after internalisation, hence signalling is not limited to the PM (Sadowski et al., 2009). The relative contribution of PM versus intracellular EGFR to downstream signalling in vivo remains unclear (Sousa et al., 2012; Teis et al., 2006).

RAL small GTPases are best recognised for their role as effectors of Ras signalling, which has attracted basic and translational research into their potential in cancer development and progression (Moghadam et al., 2017). Mammalian RAL GTPases, RALA and RALB, have well characterized roles in membrane trafficking through their involvement in the exocyst complex (Bodemann and White, 2008; Chen et al., 2007; Chien et al., 2006) and in the regulation of clathrin (Jullien-Flores et al., 2000) and caveolar-dependent endocytosis (Jiang et al., 2016). RAL signalling is potentiated by RALGEFs, and negatively regulated by RALGAPs (Neel et al., 2011). RALGEF, such as RALGDS, can be activated upon association with oncogenic RAS (Koyama and 
Kikuchi, 2001) and mediate Ras-driven skin tumourigenesis (González-García et al., 2005).

We recently identified a novel role of RAL GTPases in the regulation of Wnt signalling activity in ISCs through the regulation of Wnt receptor trafficking into intracellular compartments (Johansson et al., 2019). The relevance of RAL GTPases in intestinal tumourigenesis remained unaddressed as their function in the intestine became redundant upon loss of $A p c$, a key driver of CRC (Johansson et al., 2019). Furthermore, whether RAL proteins (RALs) can impact intestinal biology beyond Wnt signalling and through their classical role as Ras effectors is unclear.

Here, using the Drosophila intestine and human lung and breast cancer cell lines we uncover an important role of RAL GTPases activating EGFR/MAPK signalling-driven cell proliferation, through induction of EGFR internalization. Our results show that, while RAL inhibition is an efficient means of attenuating intestinal hyperplasia caused by constitutively active forms of EGFR, the effect of oncogenic Ras in the intestine is insensitive to attenuation of RAL function. Our findings support a positive role of receptor tyrosine kinase internalization in signalling activation in vivo and identify physiological and pathological settings highly sensitive to the presence of RAL proteins, which may provide ideal platforms for the development of therapeutic approaches geared towards the modulation of RAL function. 


\section{Results}

\section{RAL GTPases are necessary for EGFR/MAPK signalling activation following damage to the intestinal epithelium}

We have previously demonstrated that RalA, the single Ral gene in Drosophila, is required for Wnt signalling activation in the developing Drosophila wing and adult midgut (Johansson et al., 2019). A canonical role of RalA as RAS effector remained unaddressed.

EGFR/Ras signalling is an important determinant of wing tissue patterning (Wang, 2000; Zecca and Struhl, 2002) and ISC proliferation in the adult Drosophila midgut (Biteau and Jasper, 2011; Buchon et al., 2010; Jiang et al., 2011; Xu et al., 2011). We observed that adult wings resulting from RNAi driven knockdown of RalA using the engrailed-gal4 driver (en>RalA-RNAi), showed a more severely dysmorphic phenotype than that caused by wingless knockdown (en>wg-RNAi) or EGFR knockdown (en>EGFR-RNAi) only (Figure 1A, B). Instead, adult wings from en>RalARNAi animals displayed a dysmorphic phenotype more similar to that resulting from combined knockdown of both $w g$ and EGFR downregulation (en>wg-RNAi + EGFR$R N A i$ ) (Figure 1A, B). These results led us to hypothesize that RalA may regulate pathways other than Wnt signalling, including EGFR/Ras signalling. To address this, we turned to the adult Drosophila midgut, a robust paradigm for the study of signal transduction in adult tissue homeostasis, where RalA plays a pivotal role (Johansson et al., 2019).

RaIA is required within ISCs to induce adult midgut regeneration following damage by oral infection with Erwinia carotovora carotovora 15 (Ecc15) (Johansson et al., 2019). To achieve a global view of intestinal pathways affected by RalA, we performed a 
transcriptomic analysis by RNAseq of whole midguts from vehicle treated (Mock) or damaged (Ecc15 fed) control animals or following adult restricted RalA knockdown in intestinal stem and progenitor cells using the escargot-gal4 driver (ISC/EB>) (Micchelli and Perrimon, 2006). Consistent with its effect on ISC proliferation (Johansson et al., 2019), RalA knockdown significantly impaired damage-induced upregulation of cell cycle genes in the midgut (Figure 1C). Additionally, levels of genes associated with the EGFR/MAPK pathway, such as argos (aos), rhomboid (rho), Sox21a and string (stg) appeared increased following Ecc15 infection in control midguts, in a RalA dependent manner (Figure 1C). RT-qPCR confirmed RNAseq results on rho, a wellcharacterized activator of EGFR/MAPK signalling in ISCs (Liang et al., 2017; Ngo et al., 2020), and two downstream targets of the pathway required for ISC proliferation, Sox21a and stg (Jin et al., 2015; Meng and Biteau, 2015) (Figure 1D). Furthermore, immunofluorescence staining for the transcription factor Sox21a (Meng and Biteau, 2015) and the activated form of the MAPK, phosphorylated ERK (pERK), in control animals and following RalA knockdown from ISCs/EBs confirmed the need for RalA for upregulation of MAPK signalling and downstream targets following damage to the midgut (Figure 1E-H and Figure 1-figure supplement 1A-D). Together, these results suggest that RalA is necessary for damage-induced EGFR/MAPK signalling activation in the Drosophila adult midgut.

Previously, we showed that the role of RAL proteins in Wnt signalling activation and intestinal regeneration is conserved between Drosophila and mice (Johansson et al., 2019). The mouse intestine has a robust capacity to regenerate following damage by gamma irradiation, as demonstrated by an increase in the number of regenerating crypts $72 \mathrm{~h}$ following irradiation (Cordero et al., 2014; Johansson et al., 2019). We next assessed whether MAPK activation in the regenerating mouse intestine required RAL 
GTPases. Single conditional knockout of either Rala $($ Rala $f / / f l)$ or Ralb $\left(\right.$ Rall $\left.^{f / f t}\right)$ in the murine intestinal epithelium using the Villin-CreER driver impaired ERK activation in regenerating intestines when compared to control (VillinCre ${ }^{E R}$ ) (Figure 1I, J and Figure 1-figure supplement 1E). Therefore, RAL GTPases' requirement for EGFR/MAPK pathway activation in the intestinal epithelia is evolutionarily conserved between fruit flies and mammals.

\section{RAL GTPases are sufficient for EGFR/MAPK signalling activation in the Drosophila midgut}

Ectopic expression of wild type RalA in ISC/EB is sufficient to induce Wnt pathway activation and intestinal proliferation in the Drosophila midgut (Johansson et al., 2019). To determine whether RalA is also sufficient to induce EGFR/MAPK signalling, we assessed Sox21a (Figure 1K, L), pERK (Figure 1M, N) and total ERK (Figure 1—figure supplement $1 F, G$ ) levels by immunostaining following RalA overexpression in midgut ISCs/EBs. While levels of Sox21a and pERK were increased in RalA overexpressing midguts compared to wild type control ones (Figure $1 \mathrm{~K}-\mathrm{N}$ ), total levels of ERK in the midgut remained unchanged across genotypes (Figure 1-figure supplement 1F, G). Immunostaining results for ERK and pERK were confirmed by western blot (Figure 1-figure supplement $1 \mathrm{H}$ ) and are consistent with ERK activation and not total protein levels being increased upon midgut injury (Figure 1-figure supplement $1 \mathrm{H}-\mathrm{J}$ ). Altogether, our data suggest that RAL GTPases are necessary and sufficient for EGFR/MAPK pathway activation within the intestinal epithelium. 


\section{RalA activation is necessary for ISC proliferation in Drosophila}

Small GTPases cycle between two alternative conformations: inactive (GDP-bound) and active (GTP-bound). The balance between these states is determined by the activity of guanine nucleotide exchange factors (GEF) and GTPase activating proteins (GAP), which activate and inactivate GTPases, respectively (Neel et al., 2011). There are seven Ral GEFs in the human genome, RALGDS, RALGPS1-2 and RGL1-4, which are often found misregulated in cancer (González-García et al., 2005; Koyama and Kikuchi, 2001; Rodriguez-Viciana and McCormick, 2005) and are considered emerging therapeutic targets (Neel et al., 2011; Vigil et al., 2010). However, the in vivo role of RAL GEFs in the intestine remains unknown. Several Ral GEFs are conserved in Drosophila (Gentry et al., 2014): Rgl, GEFmeso and CG5522 (RalGPS). $R g /$ is a close orthologue of mammalian RGL (Mirey et al., 2003), GEFmeso was identified in a yeast two hybrid screen using active RalA as bait (Blanke and Jäckle, 2006), while CG5522 was identified based on its close homology to mammalian RalGPS1 (Hu et al., 2011).

We next tested the functional role of each of these Ral GEFs in the fly midgut though RNAi-driven targeted knockdown and assessment of their impact on intestinal regeneration following oral infection with Ecc15 (Basset et al., 2000). The regenerative capacity of the adult posterior midgut (R4-R5) was quantified as per the number of proliferating ISCs, identified by staining with phosphorylated histone $\mathrm{H} 3$ antibody (pH3). As expected, Ecc15 infection induced significant increase in ISC proliferation relative to mock-treated control animals (Figure 2A-D). Knocking down either of the three Ral GEFs of interest significantly impaired regenerative ISC proliferation in the midgut (Figure 2A-D) to levels comparable to those observed upon RalA knockdown (Johansson et al., 2019). Furthermore, Ral GEF knockdown led to a significant 
reduction in MAPK activation in the midgut following damage (Figure 2E, F). These results provide evidence highlighting the importance of maintaining the active status of RalA for robust stem cell proliferation and MAPK activation in the intestine.

\section{RalA regulates EGFR- but not oncogenic Ras-driven hyperplasia in the intestine}

During our initial assessment of genetic interactions between EGFR signalling and RalA in adult wings, we observed that constitutive overexpression of EGFR under engrailed-gal4 (en>EGFR ${ }^{w t}$ ) caused sever organismal lethality, which was greatly suppressed by concomitant knockdown of RalA (Figure 3-figure supplement 1A). Wing vein patterning defects observed in rare en>EGFR ${ }^{w t}$ adult escapers, was also suppressed by RalA knockdown (Figure 3-figure supplement 1B). These results reinforced the importance of RalA as a broad mediator of EGFR signalling.

EGFR is overexpressed in $\sim 20 \%$ of breast and $\sim 80 \%$ of CRCs (Rimawi et al., 2010; Spano et al., 2005), and activating mutations of Ras are one of the most common cancer-associated genetic alterations (Prior et al., 2012). Activation of the EGFR/MAPK pathway in the adult Drosophila midgut by ISC/EB-specific overexpression of wild type EGFR $\left(E G F R^{W T}\right)$ or constitutively active Ras $\left(\operatorname{Ras}^{V 12}\right)$ was sufficient to induce intestinal hyperproliferation (Figure 3A, B) (Jiang et al., 2011; Zhang et al., 2019). Downregulation of RalA suppressed EGFRWT - but not Ras V12_ driven ISC hyperproliferation (Figure 3A, B and Figure 3-figure supplement 1C, D). Consistently, RalA knockdown impaired activation of ERK following EGFR ${ }^{\text {wt }}$, but not $\operatorname{Ras}^{V 12}$ overexpression (Figure 3C, D and Figure 3-figure supplement 1E, F).

\section{RalA potentiates EGFR signalling activity downstream of ligand binding}


Increasing the pool of receptors available for ligand binding, such as through recycling of intracellular receptor towards the plasma membrane or inhibition of receptor degradation, favours activation of receptor tyrosine kinase signalling, including EGFR (von Zastrow and Sorkin, 2007; Zhang et al., 2019). Therefore, one possible mechanism by which RAL proteins may potentiate EGFR signalling in the intestine is by facilitating ligand/receptor interactions. In that case, ligand-independent, constitutively active forms of EGFR, which are linked to cancer (Endres et al., 2014), should be insensitive to RAL deficiency. To test this prediction, we co-expressed RalARNAi with two active mutant forms of EGFR - EGFR $R^{\text {גtop }}$ and $E G F R^{A 887 T}$ - in Drosophila intestinal stem and progenitor cells (Figure 3E, F). EGFR $R^{\lambda t o p}$ includes an extracellular dimerization domain that causes receptor activation even in the absence of ligand (Queenan et al., 1997), and EGFR ${ }^{A 887 T}$ contains an activating point mutation in the receptor kinase domain (Lesokhin et al., 1999). Importantly, overexpression of $E G F R^{\text {גtop }}$ or $E G F R^{A 887 T}$ led to ISC hyperproliferation levels comparable to those observed following $\operatorname{Ras}^{\mathrm{V} 12}$ overexpression (Figure 3E, F compare with Figure 3A, B and Figure 3-figure supplement 1C, D). However, unlike in the case of Ras ${ }^{V 12}$, knocking down RalA significantly impaired $E G F R^{\text {גtop }}$ or $E G F R^{A 887 T}$-driven ISC proliferation (Figure 3E, F). Consistently, EGFR $R^{\lambda t o p_{-}}$or $E G F R^{A 887 T}$-dependent ERK activation was also suppressed by RalA-RNAi (Figure 3G, H). These results suggest that RalA influences EGFR signalling activity downstream of ligand/receptor binding.

\section{RAL GTPases are required for EGFR internalisation}

RAL GTPases are key mediators of Ras-regulated membrane trafficking (Bodemann and White, 2008; Chen et al., 2007; Chien et al., 2006; Jiang et al., 2016; Jullien-Flores et al., 2000). We next asked whether, as in the case of the Wnt receptor Frizzled 
(Johansson et al., 2019), RAL GTPases may induce EGFR/MAPK signalling through regulation of EGFR cellular localisation in the intestine. We used a well-established immunostaining approach (Cordero et al., 2014; Kim-Yip and Nystul, 2018; Zhang et al., 2019) and a custom developed macro to visualise EGFR cellular localization in the adult Drosophila midgut (Figure 4-figure supplement 1). Firstly, we assessed EGFR localisation in control adult Drosophila midguts or following genetic manipulation of RalA expression. Knocking down RalA in ISCs/EBs led to significantly increased levels of PM-associated EGFR wild type (Figure 4A, B) and A887T mutant (Figure 4C, D). Conversely, overexpression of wild type RalA decreased membrane localisation of EGFR (Figure 4E, F). We were unable to assess impact of knocking down RalA on $E G F R^{\text {גtop }}$ localization as our antibody, designed to bind the extracellular domain of EGFR, failed to recognise this mutant version of the receptor. Consistent with the role of RAL GTPases as effectors of Ras, knocking down endogenous Ras from ISCs/EBs caused a similar effect on EGFR localization than that observed upon RaIA downregulation (Figure 4-figure supplement 2). Altogether, these results strongly suggest that activation of RalA induces EGFR/MAPK signalling in the intestine by increasing the intracellular pool of EGFR. Consequently, oncogenic Ras, whose activation is independent of EGFR signalling, is refractory to RalA function in the intestine (Figure 3A-D and Figure3-figure supplement 1C, D).

Next, we used a surface biotinylation-based biochemical assay to directly quantify the rate of EGFR internalization in $\mathrm{H} 1299$, a human non-small cell lung cancer (NSCLC) cell line with intact EGFR signalling (Amann et al., 2005). To obtain a measure of endocytosis that was not influenced by the rate at which the receptor returns, or 'recycles', to the cell surface from endosomes, we performed the surface biotinylationbased assay in the presence of the receptor recycling inhibitor, primaquine. This 
clearly indicated that EGF-driven (but not EGF-independent) endocytosis of EGFR was significantly reduced by combined knockdown of Rala and Ralb (Figure 4G and Figure 4-figure supplement 3A, B). By contrast, integrin $\alpha 5 \beta 1$, transferrin (hTfnR) or ligand-induced c-Met receptor internalization, were not affected by Rala/b knockdown (Figure 4-figure supplement 3C-F). These results suggest that the effect of RAL GTPases on EGFR cellular localisation is conserved between Drosophila and mammals, and that RAL proteins function in a context-dependent manner, as opposed to being generally required for transmembrane or tyrosine kinase receptor trafficking dynamics.

\section{RAL proteins are necessary for EGFR dependent tumorigenesis}

Given that intestinal hyperplasia caused by hyperactivation of $\beta$-Catenin or oncogenic RAS is independent of RAL proteins (Johansson et al., 2019) (Figure 3A, B; Figure 3-figure supplement 1C,D), the importance of RAL GTPases in intestinal malignancy remains unaddressed. The effect of RalA knockdown on intestinal hyperproliferation caused by overexpression of wild type or constitutively active mutants of EGFR in the intestine (Figure 3) suggests that other pathological settings driven by exacerbated EGFR activity might also be sensitive to RAL function.

c-Src is a conserved non-receptor tyrosine kinase whose expression is necessary and sufficient to drive regeneration and tumourigenesis of both the Drosophila and mouse intestine through EGFR/MAPK activation (Cordero et al., 2014; Kohlmaier et al., 2015) (Figure 5A, B). Consistently, Src overexpression in ISCs/EBs $\left(e s g^{t s}>S r c 64^{w t}\right)$ induced expression of the MAPK pathway transcriptional target Sox21a (Figure 5C, D) and pERK levels (Figure 5E, F) (Cordero et al., 2014; Kohlmaier et al., 2015). Importantly, knocking down RalA (ISC/EB>Src64wt; RalA-RNAi) suppressed Src-driven ISC 
hyperproliferation and MAPK signalling activation in the Drosophila midgut (Figure 5AF), which correlated with an increase in membrane versus intracellular levels of EGFR in ISC/EB $>$ Src64wt; RalA-RNAi midguts when compared to ISC/EB $>\operatorname{Src} 64^{w t}$ counterparts (Figure 5G, H).

As a proof of principle in an orthogonal mammalian system dependent on EGFR for morphogenesis, we employed the human breast tumour cell line HMT3522 T4-2 (henceforth referred to as 'T4-2') as a paradigm to test the role of mammalian RAL GTPases in malignant growth. T4-2 is a subline obtained after spontaneous malignant transformation of the benign breast tumour cell line HMT3522 S1 (henceforth 'S1'). Compared to the S1 predecessor, T4-2 cells grow as disorganised aggregates of cells when cultured in 3Dimensional (3D) Extracellular Matrix gels such as Matrigel. This growth and morphogenesis in 3D of T4-2 cells is EGFR-dependent: T4-2 show robustly upregulated EGFR levels and activation, their growth is independent of exogenous EGF, and they are acutely sensitive to EGFR inhibitors (Madsen et al., 1992; Wang et al., 1998). Thus, we hypothesised that T4-2 growth would be dependent on RAL function.

Consistent with previous reports (Madsen et al., 1992; Wang et al., 1998), treating T42 cells with two structurally independent EGFR inhibitors, Tyrphostin (AG1478) and Erlotinib, resulted in defective growth as determined by a reduction in 3D acinus size (Figure 5I, J). Importantly, stable depletion of Rala or Ralb in T4-2 by shRNA (Figure 5K, L-figure supplement 1A, B) phenocopied EGFR inhibition, as determined by a significant reduction in $3 \mathrm{D}$ acinus size (Figure $5 \mathrm{~K}, \mathrm{~L}$ ). Therefore, RALA/B function is similarly required for a mammalian morphogenetic function that is dependent on EGFR. Altogether, our results uncover a conserved role of RAL GTPases mediating EGFR/MAPK-dependent tissue homeostasis and transformation. 


\section{Discussion}

Spatial and temporal regulation of signal transduction by the endocytic pathway plays a key role in health and pathophysiology (Casaletto and McClatchey, 2012; von Zastrow and Sorkin, 2007). The impact of this process in adult stem cells and tissue homeostasis is only recently becoming evident from reports on the effect of endocytosis and autophagy on ISC proliferation through modulation of Wnt/ß-Catenin and EGFR/MAPK activity, respectively (Johansson et al., 2019; Zhang et al., 2019).

In this study, we identify a role for the Ras-related protein RAL in the activation of EGFR/MAPK signalling activity through regulation of EGFR internalisation (Figure 6). Preventing RAL function in Drosophila intestinal stem/progenitor cells reduces the intracellular pool of EGFR, leading to decreased MAPK activation and downstream signalling. This role of RAL proteins impacts stem cell proliferation and regeneration of the intestinal epithelium and has implications in pathological settings that depend on active EGFR signalling, including intestinal hyperplasia and breast cancer cell growth. However, oncogenic Ras expression in the intestine escapes the antiproliferative effect of Ral knockdown.

\section{RAL GTPases as regulators of signal transduction}

While internalization is recognised as the initial means to attenuate signal transduction through reduction of plasma membrane receptors available for activation by extracellular ligands (Goh et al., 2010; Sousa et al., 2012; Vieira et al., 1996; von Zastrow, 2003), the subsequent outcome of endocytosis on signalling is dependent on the trafficking pathway followed by internalised receptors. Internalisation of membrane EGFR through Clathrin-mediated endocytosis results in prolonged EGFR signalling by favouring receptor recycling back to the plasma membrane, while Clathrin- 
independent endocytosis leads to EGFR degradation and signalling attenuation (Sigismund et al., 2008). The differential effect of endocytic trafficking on EGFR has therapeutic implications as Clathrin inhibition can divert a tyrosine kinase inhibitorresistant forms of EGFR from Clathrin-mediated endocytosis and recycling to pinocytosis and degradation in non-small cell lung carcinoma (Ménard et al., 2018).

Here, we provide robust evidence of physiological and pathological contexts in the intestine where the internalisation of EGFR mediated by RAL GTPases directly correlates with potentiation of downstream MAPK signalling (Figure 6). We recently reported a similar effect of RAL proteins on the seven transmembrane class receptor, Frizzled, leading to high threshold of Wnt signalling activity (Johansson et al., 2019). In both cases, the ultimate outcome of RAL action is an efficient acute proliferative response of intestinal stem cells during tissue regeneration following damage. Therefore, RAL GTPases are effectors of two pivotal signal transduction pathways within the intestinal epithelium (Biteau and Jasper, 2011; Buchon et al., 2010; Jardé et al., 2020; Jiang et al., 2011; Perochon et al., 2018; Sato et al., 2009; Xu et al., 2011). The effect of knocking down RalA in the Drosophila midgut is, however, milder than that observed upon individual or combined impairment of Wnt/ß-Catenin and EGFR/MAPK signalling reception in ISCs (Xu et al., 2011). This suggests that RalA is only partly responsible for the activation of these signalling pathways and its effect is only evident in the regenerative response to damage, which requires high thresholds of signalling activity to allow acute stem cell proliferation for tissue regeneration. The scenario is different in the mammalian intestine, where combined knockout of Rala and Ralb leads to complete disruption of intestinal epithelial homeostasis (Johansson et al., 2019). This may relate to inherent differences in the signalling activity levels needed to maintain homeostatic ISC proliferation in the fly midgut versus the mouse 
intestine. Compared to its murine counterpart, basal proliferation in the adult fly midgut is relatively low and there is no transit amplifying proliferative zone (Micchelli and Perrimon, 2006; Ohlstein and Spradling, 2006). Alternatively, the difference could lie in the different experimental approaches taken, namely the use of gene knockout in the mouse versus partial knockdown in the fly. Our efforts to generate FRT mediated Rala knockout clones in the adult Drosophila midgut were unsuccessful (data not shown) and full mutant animals are not viable. Therefore, any potential residual activity due to incomplete knockdown could lead to milder Drosophila phenotypes.

RAL GTPases have been linked to Clathrin-mediated endocytosis via interaction of their effector protein, RAL binding protein (RALBP1), with the Clathrin adaptor AP2 (Jullien-Flores et al., 2000). More recently, RAL proteins have also been shown to engage in Caveolin-mediated endocytosis (Jiang et al., 2016). While the potentiating effect of RALs on EGFR signalling activity would favour a role of the small GTPases in Clathrin-mediated endocytosis in the system, this needs to be directly assessed. Experiments to functionally connect RalA with specific endocytic trafficking pathways using Drosophila genetics have been unsuccessful as, consistent with recently published work (Zhang et al., 2019), global perturbation of the trafficking machinery within ISCs leads to very severe disruption of intestinal homeostasis (data not shown), precluding the establishment of meaningful genetic interactions.

Future research will need to be done to better elucidate the place of action of RAL GTPases within the endocytic trafficking pathway and its connection with EGF and Wnt receptors in the intestine. The use of fluorescently tagged endocytic proteins (Dunst et al., 2015) combined with recently developed live imaging approaches in the adult Drosophila intestine (Koyama et al., 2020; Martin et al., 2018) offers a clear opportunity to visualise spatial and temporal receptor/endosome interactions in vivo. 


\section{RAL GTPases as potential therapeutic targets in cancer}

EGFR function is frequently altered in cancer (Santarius et al., 2010; Yarden and Pines, 2012). Excessive protein levels due to gene amplification or increasedtranscription are the most common EGFR perturbations found in gastrointestinal and lung adenocarcinoma as well as in cholangiocarcinoma (Birkman et al., 2016; Jung et al., 2017; Li et al., 2008). On the other hand, EGFR kinase domain activating point mutations are associated with non-small cell lung carcinoma and glioblastoma, but are rarely seen in other types of cancer (Li et al., 2008; Siegelin and Borczuk, 2014; Zhang et al., 2016). Extracellular domain truncating mutations yielding to constitutively active receptor through ligand-independent dimerization have also been observed in glioblastomas (Furnari et al., 2015; Guo et al., 2015; Huang et al., 1997). We have utilised Drosophila genetic constructs that mimic all three main classes of EGFR common to human cancers and which lead to intestinal hyperplasia when overexpressed in intestinal stem/progenitor cells (Figure 3). Genetic inhibition of Ral GTPase activity consistently prevented hyperproliferation in these models, suggesting that targeting RAL function could be a potentially effective therapeutic approach in the treatment of multiple highly aggressive cancer types.

Current EGFR-targeted therapies include small molecule tyrosine kinase inhibitors $(\mathrm{TKI})$ and monoclonal antibodies $(\mathrm{mAb})$ against the extracellular domain of the receptor (Xu et al., 2017). A number of resistance mechanisms arise secondary to treatment. Specific kinase domain mutations desensitize cells against TKI (Sequist et al., 2011; Yu et al., 2015), while alterations of the antibody binding site are observed in CRC (Arena et al., 2015). There is also a tendency for downstream mutations (Raf, Ras, MAPK, MET) to uncouple pathway activity from the receptor (Camidge et al., 
2014; Mancini and Yarden, 2016). The most common form of resistance to EGFRtargeted therapies is believed to be innate rather than adaptive (Parseghian et al., 2019). Indeed, about $80 \%$ of CRCs are refractive to EGFR therapy (Bardelli and Siena, 2010). Several reports highlight how cancer cells co-opt the endocytic pathway for growth and survival benefits (Mosesson et al., 2008). In fact, these have been proposed as a potential venue for drug development (Mellman and Yarden, 2013). However, based on the current evidence, we propose that targeting RAL function versus a broader component of the endocytic machinery may prove a more refined approach leading to lower toxic effects (Zhang et al., 2019).

RAL effector proteins, including RALGEFs and RALBP1 have emerged as important mediators of malignant growth in pancreatic, colorectal, prostate, bladder and other tumour cell lines characterized by the presence of oncogenic RAS mutations (Neel et al., 2011). Furthermore, genetic knockout of the RALGEF, RALGDS, ameliorates tumour growth in a mouse model of Ras-driven skin tumourigenesis (González-García et al., 2005). Unexpectedly, our results show that, at least in the intestine, oncogenic mutations in Ras are refractory to Ral GTPase inhibition. These apparently discrepant results could be due to context dependent requirements for RAL function in malignancy, differences between in vitro and in vivo experimental settings and/or a potential promiscuous role of RAL effectors on small GTPase signalling.

Previously, we have shown that fly and murine intestines bearing loss of Apc, a key initiating event in up to $80 \%$ of human CRC, also overcome the need for RAL GTPases to proliferate (Johansson et al., 2019). Taken together, our results argue against an effective role of anti-RAL therapies to treat CRCs carrying Apc loss of function and/or hyperactivating Ras mutations. On the other hand, tumours with overexpression or activating mutations in EGFR, such as carcinomas of the upper gastrointestinal tract, 
lung and mammary tissue or glioblastomas (Birkman et al., 2016; Furnari et al., 2015; Guo et al., 2015; Huang et al., 1997; Li et al., 2008; Siegelin and Borczuk, 2014; Zhang et al., 2016) might be responsive to impairment of RAL function. Ultimately, taking into consideration the genetic composition of the tumour is of outmost importance when considering the use of RAL inhibition as a therapeutic approach. 


\section{Materials and Methods}

Key resources table is included as an Appendix.

\section{Experimental models and organisms}

Species used: Drosophila melanogaster, Mus musculus

Cell lines used: HMT-3522 T4-2 (human breast cancer derived), NCl-H1299 (human lung cancer derived)

Only mated females were used for Drosophila experiments.

\section{Drosophila breeding and maintenance}

Flies were maintained in humidity and temperature-controlled incubators with a 12-12hour light-dark cycle. Crosses were kept at $18^{\circ} \mathrm{C}$. F1s of the desired genotype were collected 2-3 days after adult eclosion and aged at $29^{\circ} \mathrm{C}$ for the time needed to allow for transgene activation. Only female midguts were used. Standard rearing medium used: $10 \mathrm{~g}$ agar, $15 \mathrm{~g}$ sucrose, $30 \mathrm{~g}$ glucose, $15 \mathrm{~g}$ maize meal, $10 \mathrm{~g}$ wheat germ, $30 \mathrm{~g}$ treacle and $10 \mathrm{~g}$ soya flour per litre of distilled water.

Exact genotypes for all figure panels are listed in Supplementary Table 1.

\section{Mouse work}

Mouse experiments were performed as described in (Johansson et al., 2019), according to the UK Home Office regulations and designed in accordance with the ARRIVE guidelines. Animals were fed on standard diet and water ad libitum, and under non-barrier conditions. Genotypes used are indicated in the key resources table. VilCreER recombinase was induced using $80 \mathrm{mg} / \mathrm{kg}$ Tamoxifen (Sigma) IP. 
Regeneration was induced using caesium-137 y-radiation sources delivering 0.423 Gy $\min -1$ to a total of $10 \mathrm{~Gy}$. Mice were sampled 3 days following irradiation damage. No distinction was made between males and females in the mouse experiments. All animals used in experiments were above $20 \mathrm{~g}$ of weight. Experiments were performed on a C57BL/6 background and using a minimum of 3 mice per condition/genotype.

\section{IHC of mouse tissue}

Formalin-fixed paraffin embedded (FFPE) tissues were cut into $4 \mu \mathrm{m}$ sections and mounted onto adhesive slides, followed by a 2-hour long oven-incubation step at $60^{\circ} \mathrm{C}$. Samples were dewaxed in xylene for 5 minutes before rehydration through serial washes in decreasing concentrations of alcohol followed by washing with $\mathrm{H}_{2} \mathrm{O}$ for 5 minutes. For heat-induced epitope retrieval sections were heated for 20 minutes at $97^{\circ} \mathrm{C}$ in Sodium Citrate pH6 retrieval buffer (Thermo, TA-250-PM1X) before cooling to $65^{\circ} \mathrm{C}$. This was followed by washing in Tris Buffered Saline with Tween (TBT) (Thermo, TA-999-TT). Sections were loaded onto the Dako autostainer link48 platform, washed with TBT then peroxidase blocking solution (Agilent, S2023) for 5 minutes. Sections were washed with TBT then appropriate antibody was applied to specific slides. Phospho-p44/42 MAPK (Erk1/2) (Cell Signalling, 9101) was applied at 1/400 dilution and p44/42 MAPK (Erk1/2) (Cell Signalling 9102) was applied at 1/40 dilution for 30 minutes. After another TBT wash, secondary antibody (Rabbit Envision, Agilent, K4003) was applied for 30 minutes before washing with TBT again. 3,3' diaminobenzidine (Agilent, K3468) was then applied for 10 minutes before washing in $\mathrm{H}_{2} \mathrm{O}$ to terminate the reaction. Finally, slides were counterstained with haematoxylin and dehydrated in increasing concentrations of alcohol, then taken through 3 changes 
of xylene prior to sealing with glass coverslips using DPX mounting media for microscopy.

\section{Quantification of pERK and total ERK staining in mouse tissues}

A minimum of 12 and up to 30 randomly selected crypts per animal from at least three mice per genotype, per condition were quantified. Data is expressed as the percentage of crypt cells positively stained for a marker of interest per crypt. Finally, the percentage of positively stained cells was averaged for each animal.

\section{Brightfield microscopy and scoring of adult wing patterning}

Drosophila wings were mounted onto glass slides (VWR) with $13 \mathrm{~mm} \times 0.12 \mathrm{~mm}$ spacers (Electron Microscopy Science). Images were obtained on the Zeiss Axio Observer system. Images were focus stacked using the ZEN 2 software (Zeiss). Wing dysmorphia was blindly scored on a scale from 1 to 5 using a previously developed macro https://github.com/emltwc/TracheaProject/blob/master/Blind_scoring.ijm, where 1 is a normal, wild type wing and 5 refers to the most severely disrupted adult wings.

\section{Immunofluorescence of Drosophila tissues}

Immunofluorescent staining was performed as described in (Johansson et al., 2019). Briefly, tissues were dissected in PBS and immediately fixed in 4\% paraformaldehyde (PFA, Polysciences Inc) at room temperature for a minimum of $30 \mathrm{~min}$. Once fixed, 20-minute-long washes in PBS $+0.2 \%$ Triton $\mathrm{X}-100$ (PBST) were repeated three times, followed by overnight incubation at $4^{\circ} \mathrm{C}$ with primary antibodies in PBST $+0.5 \%$ Bovine Serum Albumin (BSA) (PBT). Prior to applying the secondary antibodies 
tissues were washed in PBST 3 times 20 minutes and then incubated with the appropriate antibodies in PBT for $3 \mathrm{~h}$ at room temperature, followed by washing and mounting.

Midguts stained for $p E R K$ and tERK included a methanol fixation step between PFA fixation and PBST washing steps of the standard protocol. Following PFA fixation methanol was added dropwise to the solution, with the tissues in it until the volume of the liquid is at least double. Tissues were transferred into $100 \%$ methanol for minimum 1 minute. PBS was added to the methanol dropwise to rehydrate the tissues after which the samples were subjected to the standard staining protocol.

All samples were mounted onto glass slides (VWR) with $13 \mathrm{~mm} \times 0.12 \mathrm{~mm}$ spacers (Electron Microscopy Science) and Vectashield antifade mounting medium containing DAPI (Vector Laboratories, Inc). Confocal images were obtained on a Zeiss LSM 780 and processed in the Zeiss ZEN software.

Antibody concentrations used: anti-GFP (1:2000), anti-pERK (1:100), anti-tERK (1:100), anti-EGFR (1:50), anti-Sox21a (1:2000), anti-pH3S10 (1:100). Secondary antibodies were used as follows: anti-chicken-lgY-488 (1:200), anti-rabbit-lgG-594 (1:100), anti-mouse-lgG-594 (1:100).

\section{Drosophila midgut regeneration assay}

Drosophila intestinal regeneration was induced through oral infection using Erwinia carotovora subsp. carotovora 15 (Ecc15) (Basset et al., 2000), as described in (Neyen et al., 2014). Briefly, bacteria were cultured overnight in LB medium in an orbital shaker incubator at $29^{\circ} \mathrm{C}, 200 \mathrm{rpm}$. Samples were pelleted (Beckman Coulter JS-4.2 rotor, 10 min @3000rpm) and adjusted to $O D_{600}=200$. Flies used for regeneration experiments 
were starved in empty vials for 2 hours prior to infection to synchronize feeding. Animals were moved into vials containing filter paper (Whatman) soaked into vehicle control, $5 \%$ sucrose solution (Mock) or the prepared bacterial solution mixed with $5 \%$ sucrose 1:1. Flies were dissected 12-16 hours after infection.

\section{Staining quantification}

pERK and tERK intensity were quantified in 16-bit z-stack confocal images as the average staining intensity within the GFP positive compartment. Sox21a staining was quantified in 16-bit z-stack confocal images as the average staining intensity within the entire DAPI positive compartment. pERK, tERK and Sox21a were quantified using the custom ImageJ macro: BatchQuantify (https://github.com/emltwc/2018-Cell-StemCell). EGFR membrane/cytoplasmic staining was quantified in 16-bit z-stack confocal images using the custom ImageJ macro: EGFR_quant (https://github.com/emltwc/EGFRProject).

\section{Survival quantification}

Relative survival was calculated by counting the proportion of adult flies emerging from crosses, which carried the desired experimental genotypes, as per the expected Mendelian ratio. When the proportion of animals of a given genotype emerged at the expected Mendelian ratio, this genotype was demed to be $100 \%$ viable.

\section{Drosophila RNA extraction, RNA-sequencing and RT-qPCR}

Total RNA from a minimum of 25 midguts was extracted using QIAGEN RNAeasy kit, following the manufacturer's instructions, including the on-column DNase digestion step. For RNA-seq, an RNA integrity score was determined (average $=9.4, \mathrm{SD}=0.6$, 
lowest score used = 8.2; Agilent technologies 2200 Tapestation, RNA Screen Tape). Libraries for cluster generation and DNA sequencing were prepared following (Fisher et al., 2011), using Illumina TruSeq RNA library Preparation Kit v2. Libraries were run on the Next Seq 500 platform (Illumina) using the High Output 75 cycles kit (2x36 cycles, paired end reads, single index).

For RT-qPCR, RNA was quantified using a NanoDrop 2000c Spectrophotometer. cDNA was synthesised using the High-Capacity cDNA reverse transcription kit (Applied Biosystems), according to the manufacturer's recommendations using a maximum of $2 \mu \mathrm{g}$ RNA per $20 \mu \mathrm{L}$ final volume. Quanta SYBR green Master Mix (Low ROX, Fermentas) was used following the manufacturer's instructions. Data were obtained and analysed using the Applied Biosystems 7500 software. Results represent four independent replicates \pm SEM. Expression of target genes was measured and normalized to rp/32 using standard curves.

\section{Western blot}

Protein was extracted from 12 adult female Drosophila midguts dissected in ice cold PBS. The tissues were lysed in $20 \mu \mathrm{L}$ RIPA buffer (Sigma) using a microcentrifuge pestle. Samples were spun down at $13,000 \mathrm{rpm}$ for 10 minutes at $4^{\circ} \mathrm{C}$ and the supernatant was collected. Protein concentration was determined using Bradford reaction (Abcam) following the manufacturer's recommendations. $40 \mu \mathrm{g}$ of total protein was loaded onto NuPAGE 10\% Bis-Tris gel (Thermo Fisher Scientific) and run using NuPAGE MOPS buffer (Thermo Fisher Scientific). Protein was transferred to a membrane (Bio-Rad) using the Trans-Blot Turbo system (Bio-Rad) following the manufacturer's instructions. Membranes were blocked overnight at $4^{\circ} \mathrm{C}$ in $5 \%$ BSA (Sigma) then probed using pERK and tERK antibodies (Cell signalling) at 1:1000 
concentration. Antibody signal was detected using the SuperSignal West Pico Chemiluminescent Substrate (Thermo Fisher Scientific) system.

\section{Cell culture}

HMT-3522 T4-2 (V. Weaver, UCSF) cells were cultured in precoated collagen plates using DMEM / Ham's F12 (1:1) medium supplemented with 2mM Glutamine (Life Technologies), $250 \mathrm{ng} / \mathrm{ml}$ insulin solution from bovine pancreas (Sigma-Aldrich), 10 $\mu \mathrm{g} / \mathrm{ml}$ transferrin (Sigma-Aldrich), $2.6 \mathrm{ng} / \mathrm{mL}$ Sodium selenite (Sigma-Aldrich), $10^{-10} \mathrm{M}$ 17 beta-estradiol (Sigma-Aldrich), $1.4 \times 10^{-6} \mathrm{M}$ hydrocortisone (Sigma-Aldrich), and 10 $\mathrm{ng} / \mathrm{ml}$ human prolactin (Miltenyi Biotec).

$3 \mathrm{D}$ acini were grown as follows: single cell suspensions $\left(1.5 \times 10^{4}\right.$ cells per $\left.\mathrm{ml}\right)$ were plated in the appropriate medium supplemented with $2 \%$ Growth Factor Reduced Matrigel (GFRM; BD Biosciences). 100 $\mu$ l of this mix were added per well in a 96 well ImageLock plate (Essen Biosciences) precoated with $10 \mu$ l of pure GFRM for 15 minutes at $37^{\circ} \mathrm{C}$. Cells were incubated at $37^{\circ} \mathrm{C}$ for 5 days, changing the media every two days, before IF.

For inhibitor studies, cells were treated from the time of plating with TyrphostinAG1478 (80 nM in ethanol, Sigma-Aldrich), Erlotinib (100 nM in DMSO), and Ethanol or DMSO as appropriate controls, respectively.

HEK293-FT (Thermo Fisher Scientific) were cultured in DMEM supplemented with 10\% FBS, 6mM L-glutamine and 0.1mM Non-Essential Amino Acids (NEAA) (all reagents from Life Technologies/Thermo Fisher). 


\section{Generation of stable cell lines}

Stable cell lines were performed by co-transfecting HEK293-FT packaging cells with a pLKO.1-puromycin shRNA plasmid with VSVG and SPAX2 lentiviral packaging vectors using Lipofectamine 2000 according to the manufacturer's instructions (Invitrogen). Viral supernatants were collected; filtered using PES $0.45 \mu \mathrm{m}$ syringe filters (Starlab), and concentrated using Lenti-X Concentrator (Clontech) as per the manufacturer's instructions. Cells were then transduced with the lentivirus for 3 days before selection with $1 \mu \mathrm{g} / \mathrm{ml}$ puromycin (Thermo Fisher Scientific). shRNA target sequences: non-targeting control shScr (5'CCGCAGGTATGCACGCGT3'), shRalA (5'GGAGGAAGTCCAGATCGATAT3'), and shRalB

CAAGGTGTTCTTTGACCTAAT3'). To knockdown RAL protein expression in H1229 cells, cells were transfected with Dharmacon ON-TARGETplus siRNAs using the Amaxa Nucleofector system (Lonza).

\section{RNA extraction and RT-qPCR in cell culture samples}

RT-qPCR on human samples was performed following the same protocol used for Drosophila samples, except using human $\beta$-actin or GAPDH to normalise transcript levels using the delta-delta- $\mathrm{C}_{\mathrm{T}}$ method.

\section{Cyst growth assay}

Acini labelling was adapted from previously described protocols. Briefly, cultures were fixed in 4\% paraformaldehyde (PFA, Affimetrix) for $10 \mathrm{~min}$ at room temperature (RT), washed twice in PBS, blocked for $1 \mathrm{~h}$ in PFS buffer (PBS, 0.7\% w/v fish skin gelatin (Sigma-Aldrich), 0.5\% saponin (Sigma-Aldrich), and incubated with primary antibodies diluted in PFS at $4^{\circ} \mathrm{C}$ overnight with gentle rocking. Then, cyst cultures were washed 
three times with PFS and incubated with secondary antibodies diluted in PFS for $1 \mathrm{~h}$ at RT, followed by washing twice in PFS and twice in PBS. Labelling was performed using Phalloidin (1:200) (Invitrogen) and Hoescht to label nuclei (10 $\left.\mathrm{mg} \mathrm{ml}^{-1}\right)$.

Acquisition of confocal images was performed using Opera Phenix Z9501 high-content imaging system (PerkinElmer), imaging at least 10 optical sections every $2 \mu \mathrm{M}$, imaging 25 fields at 20x. Images were analysed using Harmony imaging analysis software (PerkinElmer).

\section{Internalisation assay}

Internalisation assays were performed as described in (Roberts et al., 2001). Briefly, cells were surface labelled at $4^{\circ} \mathrm{C}$ with $0.13 \mathrm{mg} / \mathrm{ml}$ NHS-SS-biotin (Pierce) in PBS for $30 \mathrm{~min}$. Following surface labelling, cells were transferred to complete medium at $37^{\circ} \mathrm{C}$ to allow internalization in the presence of $0.6 \mathrm{mM}$ primaquine for the indicated times. Biotin was then removed from the cell surface by treatment with the cell-impermeable reducing agent MesNa. Cells were then lysed and the quantity of biotinylated receptors determined using a capture-ELISA. The following antibodies were used for captureELISA; clone VC5 (BDPharmingen, Cat 555651) for a5ß1, anti-CD71 (BDPharmingen, Cat 555534) for the TfnR, anti-HGFR (R\&D Systems, Cat AF276) and anti-EGFR1 (BDPharmingen, Cat 555996).

\section{Statistical analysis}

GraphPad Prism 8 software was used for statistical analyses. Information on sample size, and statistical tests used for each experiment are indicated in the figure legends. 


\section{Data availability}

All raw data underlying the findings of this paper will be available at the time of publication through http://dx.doi.org/10.5525/gla.researchdata.1142. RNA sequencing data has been deposited in GEO (accession GSE162421) and can be accessed through (https://www.ncbi.nlm.nih.gov/geo/query/acc.cgi?acc=GSE162421). Custom scripts used for quantification are available at https://github.com/emltwc/TracheaProject/blob/master/Blind scoring.ijm;

https://github.com/emltwc/2018-Cell-Stem-Cell

and https://github.com/emltwc/EGFRProject . Further information, reagents and resources should be directed to and will be fulfilled by Julia B. Cordero (julia.cordero@glasgow.ac.uk) upon reasonable request.

\section{Author contributions}

M.N. performed and analysed most experiments; K.B. perform and analysed experiments required for the revision of the manuscript; Y.Y. provided technical assistance throughout the study; A.R.F and E.S. performed the 3D mammary tumour cell growth assays; J.J. and A.D.C., performed the mouse intestinal regeneration experiment; J.C.N. designed, performed and analysed the EGFR internalization experiments; D.M.B. designed and supervised 3D mammary tumour cell growth assays; O.J.S. designed and supervised the mouse intestinal regeneration experiment; JBC conceptualized the study, designed the experiments with M.N. and K.B., supervised the work and analysed the data. M.N. and J.B.C. wrote the manuscript with contributions from the rest of the authors. 


\section{Acknowledgements}

We would like to thank Björn Kruspig, Sergi Marco, Martha Maria Zarou, Gaiti Hasan, Valerie Weaver and Benoit Biteau for reagents and Ann Hedley (CRUK Beatson) for help with bioinformatic analysis of the RNAseq data. We thank the Vienna Drosophila RNAi Center, the Bloomington Drosophila Stock Center, and the Developmental Studies Hybridoma Bank for providing Drosophila lines and reagents.

\section{Funding sources}

M.N. was supported by a Leadership Fellowship from the University of Glasgow to (J.B.C.). Y.Y. is supported by CRUK core funding to the CRUK Beatson Institute (A17196). The work from the Norman laboratory was funded by CRUK core funding for his laboratory (A18277), and J.C.N acknowledges the CRUK Glasgow Centre (C596/A18076). J.J, A.D.C. and O.J.S are funded by CRUK core funding for O.J.S. laboratory (A21139). D.M.B., A.R.F. and E.S. are supported by the University of Glasgow and CRUK core funding (A17196). J.B.C. is a Sir Henry Dale Fellow jointly funded by the Wellcome Trust and the Royal Society (Grant number 104103/Z/14/Z).

\section{Conflicts of interest}

O.J.S. has received funding from Novartis to examine RAL and RAL GEFs in malignancy. 


\section{Figure legends}

Figure 1. Ral GTPases are necessary and sufficient to induce EGFR/MAPK signalling in intestinal stem cells.

A. Adult Drosophila wings from control animals and with posterior compartment knockdown of wg (wg-RNAi), Egfr (Egfr-RNAi) or RalA using one of two previously validated RNAi lines (RalA-RNAi(1)) or combined wg and Egfr knockdown (wg-RNAi+Egfr-RNAi). Scale bar $=500 \mu \mathrm{m}$

B. Blind scoring of wing dysmorphia on a scale of 1-5. Numbers inside bars represent the total number of wings scored. Kruskal-Wallis test followed by Dunn's multiple comparisons test.

C. Heat map from transcriptomic analysis of adult whole midguts from mock treated and Ecc15 infected control animals $(+)$ or following adult restricted knockdown of RalA (RalA-RNAi(1)) using the escargot-gal4, UAS-gfp driver (ISC/EB $>$ ). RNA was extracted from $>25$ whole midguts per replicate and 4 biological replicates per genotype/per condition were processed for sequencing.

D. RT-qPCR confirmation of genes associated with EGFR/MAPK signalling in whole midguts from genotypes and conditions as in $\mathrm{C}$ expressed relative to rp/32 levels. $\mathrm{n}$ (number of biological replicates) $=4$, each dot represents an independent RNA sample from $>25$ midguts per sample. Two-way ANOVA followed by Sidak's multiple comparisons test.

E. Representative confocal images of Sox21a immunofluorescence staining (red/grey) of adult posterior midguts from Mock treated or Ecc15 infected wild 
type control animals or following knockdown of $\operatorname{RalA}(\operatorname{RalA-RNAi(1))}$ in stem/progenitor cells using escargot-gal4, UAS-gfp (ISC/EB>; green).

F. Quantification of average Sox21a staining intensity, within the nuclear compartment (DAPI positive) in midguts as in E. Two-way ANOVA followed by Sidak's multiple comparisons test; $n=$ number of z-stack confocal images quantified, each from an independent posterior midgut.

G. Representative confocal images of pERK immunofluorescence staining (red/grey) of adult posterior midguts from Mock treated or Ecc15 infected control animals or following knockdown of RalA (RalA-RNAi(1)) within stem/progenitor cells (ISC/EB>; green).

H. Quantification of average pERK staining intensity within the ISC/EB compartment (GFP positive) of midguts as in G. Two-way ANOVA followed by Sidak's multiple comparisons test; $n=$ number of z-stack confocal images quantified, each from an independent posterior midgut.

I. Immunohistochemistry images of total (bottom panels) and pERK (top panels) in small intestinal regenerating crypts 3 days after whole body irradiation of control mice (left panels) or mice following conditional intestinal epithelial knockout of Rala or Ralb. Scale bar $=50 \mu \mathrm{m}$

J. Quantification of the percentage of cells with pERK staining in regenerating small intestinal crypts as in I. n=number of mice, with $>12$ crypts quantified per animal, each dot represents the average percentage from a given mouse. Oneway ANOVA followed by Tukey's multiple comparisons test.

K. Representative confocal images of Sox21a immunofluorescence staining (red/grey) of adult posterior midguts from control animals or animals 
overexpressing wild type Rala within stem/progenitor cells (ISC/EB>; green). Scale bar $=50 \mu \mathrm{m}$

L. Quantification of average Sox21a staining intensity, within the nuclear compartment (DAPI positive; blue) of midguts as in K. Student's t-test; $\mathrm{n}=$ number of $\mathrm{z}$-stack confocal images quantified, each from an independent posterior midgut.

M. Representative confocal images of pERK immunofluorescence staining (red/grey) in control animals or animals overexpressing wild type Rala within stem/progenitor cells (ISC/EB>; green).

N. Quantification of average pERK staining intensity, within the ISC/EB compartment (GFP positive) of midguts as in M. Student's t-test; $n=$ number of z-stack confocal images quantified, each from an independent posterior midgut.

Where indicated: ${ }^{*} p<0.05,{ }^{* *} p<0.01,{ }^{* * *} p<0.001,{ }^{* * * *} p<0.0001$, ns: not significant. All error bars represent SD. Scale bars $=20 \mu \mathrm{m}$, unless otherwise stated.

Figure 1-figure supplement 1. Ral GTPases are necessary and sufficient to induce EGFR/MAPK signalling in intestinal stem cells.

A. Representative confocal images of Sox21a immunofluorescence staining (red/grey) of adult posterior midguts from Mock treated or Ecc15 infected control animals or following knockdown of RalA using an independent RNAi line from that in Figure $1(\operatorname{Ral} A-R N A i(2))$ in stem/progenitor cells using escargot-gal4, UAS-gfp (ISC/EB>; green). Scale bar $=50 \mu \mathrm{m}$

B. Quantification of average Sox21a staining intensity, within the nuclear compartment (DAPI positive; blue) in midguts as in A. Two-way ANOVA 
followed by Sidak's multiple comparisons test; $n=$ number of $z$-stack confocal images quantified, each from an independent posterior midgut.

C. Representative confocal images of pERK immunofluorescence staining (red/grey) of adult posterior midguts from Mock treated or Ecc15 infected control animals or following knockdown of RalA using an independent RNAi line from that in Figure $1(\operatorname{RalA}-R N A i(2))$ within stem/progenitor cells (ISC/EB>; green).

D. Quantification of average pERK staining intensity within the ISC/EB compartment (GFP positive) of midguts as in C. Two-way ANOVA followed by Sidak's multiple comparisons test; $n=$ number of z-stack confocal images quantified, each from an independent posterior midgut.

E. Quantification of the percentage of cells with total ERK staining (tERK) in regenerating small intestinal crypts as in Figure 1I. n=number of mice, with $>12$ crypts quantified per animal, each dot represents the average percentage from a given mouse. One-way ANOVA followed by Tukey's multiple comparisons test.

F. Representative confocal images of tERK immunofluorescence staining (red/grey) in control animals or animals overexpressing wild type Rala within stem/progenitor cells (ISC/EB>; green).

G. Quantification of average tERK staining intensity, within the ISC/EB compartment (GFP positive) of midguts as in F. Student's t-test; n=number of z-stack confocal images quantified, each from an independent posterior midgut. 
H. Western blot of pERK and tERK from Control (Mock treated), wild type Rala overexpressing (Mock treated) and Ecc15 infected midguts and whole fly lysates.

I. Representative confocal images of tERK immunofluorescence staining (red/grey) in mock treated wild type control animals or animals infected with Ecc15.

J. Quantification of average tERK staining intensity, within the ISC/EB compartment (GFP positive) of midguts as in I. Student's t-test; n=number of z-stack confocal images quantified, each from an independent posterior midgut.

Where indicated: ${ }^{*} p<0.05,{ }^{* *} p<0.01,{ }^{* * *} p<0.001,{ }^{* * *} p<0.0001$, ns: not significant. All error bars represent SD. Scale bars $=20 \mu \mathrm{m}$, unless otherwise stated.

Figure 2. Ral GTPase activation is necessary for EGFR/MAPK signalling in regenerating ISCs/EBs.

A. Representative confocal images of $\mathrm{pH} 3$ staining (red) within the ISC/EB compartment (green) in mock-treated or regenerating posterior midguts. Scale bar $=50 \mu \mathrm{m}$.

B. Quantification of $\mathrm{pH} 3$ positive nuclei in control or GEFmeso-RNAi posterior midguts as in A. Two-way ANOVA followed by Sidak's multiple comparisons test. $\mathrm{n}=$ number of midguts.

C. Quantification of $\mathrm{pH} 3$ positive nuclei in control or RalGPS-RNAi posterior midguts as in A. Two-way ANOVA followed by Sidak's multiple comparisons test. $n=$ number of midguts. 
D. Quantification of $\mathrm{pH} 3$ positive nuclei in control or Rgl-RNAi posterior midguts as in A. Two-way ANOVA followed by Sidak's multiple comparisons test. $\mathrm{n}=$ number of midguts.

E. Representative confocal images of pERK staining (red/grey) in mock-treated or regenerating control animals or animals with knockdown of GEFmeso, RalGPS or $\mathrm{Rg} /$ within the ISC/EB compartment (green). Scale bar $=20 \mu \mathrm{m}$.

F. Quantification of average $p E R K$ staining intensity within the ISC/EB compartment (GFP positive) as in E. Two-way ANOVA followed by Sidak's multiple comparisons test; n=number of z-stack confocal images quantified, each from an independent posterior midgut.

Where indicated: ${ }^{*} p<0.05,{ }^{* *} p<0.01,{ }^{* * *} p<0.001, \quad{ }^{* * * *} p<0.0001$, ns: not significant. All error bars represent SD. Scale bars $=20 \mu \mathrm{m}$, unless otherwise stated.

Figure 3. Ral GTPases are required for EGFR/MAPK signalling upstream of Ras.

A. Representative confocal images of $\mathrm{pH} 3$ staining (red) within the ISC/EB compartment (green) of control animals or animals overexpressing wild type Egfr $\left(E G F R^{W T}\right)$ or one of two constitutive Ras constructs used in this paper $\left(\operatorname{Ras}^{V 12}(2)\right)$ with or without RalA knock-down within stem/progenitor cells (ISC/EB>; green). Scale bar $=50 \mu \mathrm{m}$.

B. Quantification of $\mathrm{pH} 3$ positive nuclei in posterior midguts, as in A. Two-way ANOVA followed by Sidak's multiple comparisons test. $n=$ number of midguts.

C. Representative confocal images of pERK staining (red/grey) of control animals or animals overexpressing wild type Egfr $\left(E G F R^{W T}\right)$ or one of two constitutive Ras constructs used in this paper $\left(\operatorname{Ras}^{V 12}(2)\right)$ with or without RalA knock-down within stem/progenitor cells (ISC/EB>; green). 
D. Quantification of average pERK staining intensity, as seen in $(C)$, within the ISC/EB compartment (GFP positive). Two-way ANOVA followed by Sidak's multiple comparisons test; n=number of z-stack confocal images quantified, each from an independent posterior midgut.

E. Representative confocal images of $\mathrm{pH} 3$ staining (red) within the ISC/EB compartment (green) of control animals or animals overexpressing two types of constitutively active Egfr constructs ( $E G F R^{\text {גtop }}$ or $\left.E G F R^{A 887 T}\right)$ with or without RalA knock-down within stem/progenitor cells (ISC/EB>; green). Scale bar $=50$ $\mu \mathrm{m}$.

F. Quantification of $\mathrm{pH} 3$ positive nuclei in posterior midguts, as in E. Two-way ANOVA followed by Sidak's multiple comparisons test. Error bars represent SEM. $\mathrm{n}=$ number of midguts.

G. Representative confocal images of $\mathrm{pERK}$ staining (red/grey) within the ISC/EB compartment (green) of control animals or animals overexpressing two types of constitutively active Egfr constructs $\left(E G F R^{\text {גtop }}\right.$ or $\left.E G F R^{A 887 T}\right)$ with or without RalA knock-down within stem/progenitor cells (ISC/EB>; green).

$H$. Quantification of average pERK staining intensity, as in $G$, within the ISC/EB compartment (GFP positive). Two-way ANOVA followed by Sidak's multiple comparisons test; $n=$ number of $z$-stack confocal images quantified, each from an independent posterior midgut.

Where indicated: ${ }^{*} p<0.05,{ }^{* *} p<0.01, \quad{ }^{* * *} p<0.001, \quad{ }^{* * * *} p<0.0001$, ns: not significant. All error bars represent SD. Scale bars $=20 \mu \mathrm{m}$, unless otherwise stated. 
Figure 3-figure supplement 1. Ral GTPases are required for EGFR/MAPK signalling upstream of Ras.

A. Percentage survival of adult flies eclosing with the desired experimental genotype. Fisher's exact test.

B. Adult Drosophila wings from control animals and with posterior compartment overexpression of wild type Egfr $\left(E G F R^{W T}\right)$ with or without knockdown of RalA $(\operatorname{RalA}-R N A i(1))$. Scale bar $=500 \mu \mathrm{m}$

C. Representative confocal images of $\mathrm{pH} 3$ staining (red/grey; white arrows) within the ISC/EB compartment (green) in animals overexpressing a constitutively active Ras transgene independent from that in Figure $3\left(\operatorname{Ras}^{V 12}(1)\right)$ with or without RalA knock-down (RalA-RNAi(2)) within stem/progenitor cells (ISC/EB >; green). Scale bar $=50 \mu \mathrm{m}$.

D. Quantification of pH3 positive nuclei in posterior midguts, as in C. Data were analysed by Student's t-test. $n=$ number of midguts.

E. Representative confocal images of tERK staining (red/grey) in animals overexpressing wild type Egfr $\left(E G F R^{W T}\right)$ with or without RalA knock-down within stem/progenitor cells (ISC/EB>; green). Scale bar= $20 \mu \mathrm{m}$

F. Quantification of average tERK staining intensity within the ISC/EB compartment (GFP positive) of midguts as in E. Student's t-test. n=number of z-stack confocal images quantified, each from an independent posterior midgut. Where indicated: ${ }^{* * *} p<0.0001$, ns: not significant. All error bars represent SD. 
Figure 4. Ral GTPases are required for EGFR internalisation.

A. Representative images of wild type EGFR staining (red/turbo colourmap) in adult Drosophila midgut stem/progenitor cells (ISC/EB>; green) without (Control) or with RalA knock-down (RalA-RNAi).

B. Quantification of EGFR plasma membrane staining localisation in midguts as in A, relative to the cytoplasm. Data is presented as Tukey's box and whiskers plot. Data were analysed by Student's t-test. $n=$ number of z-stack confocal images quantified, each from an independent posterior midgut.

C. Representative images of EGFR ${ }^{\mathrm{A} 887 T}$ staining (red/turbo colourmap) in adult Drosophila midgut stem/progenitor cells (ISC/EB>; green) without (control) or with RalA knock-down (RalA-RNAi).

D. Quantification of EGFR ${ }^{\text {A887T }}$ plasma membrane staining localisation as in C, relative to the cytoplasm presented as Tukey's box and whiskers plot. Student's t-test. $n=$ number of $z$-stack confocal images quantified, each from an independent posterior midgut.

E. Representative images of EGFR staining in (red/turbo colourmap) in adult Drosophila midgut stem/progenitor cells (ISC/EB>; green) without (control) or with wild type RalA overexpression $\left(R a l A^{w t}\right)$.

F. Quantification of EGFR plasma membrane staining localisation in midguts as in E, relative to the cytoplasm. Data is presented as Tukey's box and whiskers plot. Student's t-test. $n=$ number of $z$-stack confocal images quantified, each from an independent posterior midgut.

G. Internalisation of EGFR over time determined by a surface biotinylation ELISA based assay in H1299 human non-small cell lung cancer cells transfected with a non-targeting (Control) or combined Rala and Ralb knockdown constructs 
$($ siRala $+b)$ and incubated in the presence or absence of EGF ligand. Data from one experiment with three technical replicates and representative of three independently performed experiments is presented. Two-way ANOVA followed by Bonferroni's multiple comparisons test. Error bars represent SEM.

Where indicated: ${ }^{*} p<0.05,{ }^{* *} p<0.01,{ }^{* * *} p<0.001,{ }^{* * *} p<0.0001$. All error bars represent SD. Scale bars $=20 \mu \mathrm{m}$.

Figure 4-figure supplement 1. Demonstration of method used to quantify EGFR cellular localisation.

A. Example of a single confocal plane from a Z-stack confocal image used for the quantification of EGFR localisation. Stem/progenitor cells are identified using escargot-gal4, UAS-gfp (ISC/EB>; green), nuclei are highlighted by DAPI staining (blue). These layers are converted to binary masks based on the triangle method to determine the threshold value and subjected to morphological operations to yield masks for the quantification of EGFR intensity in the various subcellular locations. The membrane compartment (red) is defined as the dilated outline of the ISC/EB compartment. The cytoplasmic compartment (green) is defined as the ISC/EB compartment minus the membrane and nuclear (blue) compartments.

B. Coloured bar representing the colour of pixels with a given 16-bit intensity in the turbo colourmap. 
Figure 4-figure supplement 2. Ras is required for EGFR internalisation.

A. Representative images of wild type EGFR staining (red/turbo colourmap) in adult Drosophila midgut stem/progenitor cells (ISC/EB>; green) without (Control) or with Ras knock-down (Ras-RNAi).

B. Quantification of EGFR plasma membrane staining localisation in midguts as in A, relative to the cytoplasm. Data is presented as Tukey's box and whiskers plot. Student's t-test. $n=$ number of $z$-stack confocal images quantified, each from an independent posterior midgut.

Where indicated: ${ }^{*} p<0.05,{ }^{* *} p<0.01,{ }^{* * *} p<0.001,{ }^{* * * *} p<0.0001$. All scale bars $=$ $20 \mu \mathrm{m}$.

Figure 4-figure supplement 3. RAL GTPases are required for EGFR internalisation.

A. Confirmation of knock-down of Rala in H1299 human non-small cell lung cancer cells transfected with a non-targeting (Control) or combined Rala and Ralb knockdown constructs $($ siRala $+b)$. Data expressed as Delta $\mathrm{C}_{\mathrm{T}}$ using GAPDH as a reference. $\mathrm{n}=3$ repeat knockdown cultures. Student's t-test. Error bars represent SEM.

B. Confirmation of knock-down of Ralb in H1299 human non-small cell lung cancer cells transfected with a non-targeting (Control) or combined Rala and Ralb knockdown constructs $($ siRala $+b)$. Data expressed as Delta $\mathrm{C}_{\mathrm{T}}$ using GAPDH as a reference. $\mathrm{n}=3$ repeat knockdown cultures. Student's t-test. Error bars represent SEM.

C. Internalisation of cMet over time as determined by a surface biotinylation ELISA based assay in H1299 human non-small cell lung cancer cells 
transfected with a non-targeting (Control) or combined Rala and Ralb knockdown constructs (siRala+b) and incubated in the presence or absence of HGF ligand. Data from one representative experiment is shown with three technical replicates. Experiment was repeated three times. Two-way ANOVA followed by Bonferroni's multiple comparisons test. Error bars represent SEM.

D. Internalisation of cMet over time as determined by a surface biotinylation ELISA based assay in H1299 human non-small cell lung cancer cells transfected with a non-targeting (Control) or combined Rala and Ralb knockdown constructs (siRala+b) and incubated in the presence or absence of EGF ligand. Data from one representative experiment is shown with three technical replicates. Experiment was repeated three times. Two-way ANOVA followed by Bonferroni's multiple comparisons test. Error bars represent SEM.

E. Internalisation of human Transferrin receptor (hTfnR) over time as determined by a surface biotinylation ELISA based assay in H1299 human non-small cell lung cancer cells transfected with a non-targeting (Control) or combined Rala and Ralb knockdown constructs (siRala+b) and incubated in the presence or absence of EGF ligand. Data from one representative experiment is shown with three technical replicates. Experiment was repeated three times. Two-way ANOVA followed by Bonferroni's multiple comparisons test. Error bars represent SEM.

F. Internalisation of $\alpha 5 \beta 1$ integrin over time as determined by a surface biotinylation ELISA based assay in H1299 human non-small cell lung cancer cells transfected with a non-targeting (Control) or combined Rala and Ralb 
knockdown constructs $($ siRala $+b)$ and incubated in the presence or absence of EGF ligand. Data from one representative experiment is shown with three technical replicates. Experiment was repeated three times. Two-way ANOVA followed by Bonferroni's multiple comparisons test. Error bars represent SEM.

Where indicated: ${ }^{* * *} p<0.001$

Figure 5. Ral GTPases mediate malignant transformation of the intestinal and mammary epithelium.

A. Representative confocal images of $\mathrm{pH} 3$ staining (red/grey) in midguts overexpressing Src-kinase $\left(\operatorname{Src64}{ }^{w t}\right)$ with or without Rala knock-down (RalA$R N A i(2))$ in stem/progenitor cells (ISC/EB>; green). White arrows indicate $\mathrm{pH} 3$ positive nuclei.

B. Quantification of $\mathrm{pH} 3$ positive nuclei in posterior midguts as in A. Data were analysed by Student's t-test. $n=$ number of midguts.

C. Representative confocal images of Sox21a staining (red/grey) in midguts overexpressing Src-kinase $\left(\operatorname{Src64}{ }^{w t}\right)$ with or without Rala knock-down (RalA$R N A i(2))$ in stem/progenitor cells (ISC/EB>; green). Scale bar $=50 \mu \mathrm{m}$.

D. Quantification of average Sox21a staining intensity within the nuclear compartment (DAPI positive) as in C. Two-way ANOVA followed by Sidak's multiple comparisons test; $n=$ number of z-stack confocal images quantified, each from an independent posterior midgut.

E. Representative confocal images of $\mathrm{pERK}$ staining (red/grey) in midguts overexpressing Src-kinase $\left(\operatorname{Src6} 64^{w t}\right)$ with or without Rala knock-down (RalARNAi(2)) in stem/progenitor cells (ISC/EB>; green). 
F. Quantification of average pERK staining intensity within the ISC/EB compartment (GFP positive) as in E. Two-way ANOVA followed by Sidak's multiple comparisons test; n=number of z-stack confocal images quantified, each from an independent posterior midgut. Error bars represent SD.

G. Representative images of EGFR staining (red/grey) in midguts overexpressing Src-kinase $\left(\operatorname{Src64}{ }^{w t}\right)$ and EGFR wt with or without Rala knock-down (RalA$R N A i(2))$ in stem/progenitor cells (ISC/EB>; green).

$H$. Quantification of EGFR plasma membrane staining localisation relative to the cytoplasm as in G presented as Tukey's box and whiskers plot. Data were analysed by Student's t-test. n=number of z-stack confocal images quantified, each from an independent posterior midgut.

I. Confocal fluorescence microscopy images of HMT3522 T4-2 3D cultures, treated with EGFR inhibitors (tyrphostin AG1478 and erlotinib) or corresponding vehicle controls (ethanol and DMSO, respectively) followed by fixation after 5 days and staining for F-actin (yellow) and nuclei (blue, Hoechst). Scale bar $=40 \mu \mathrm{m}$.

J. Quantification of area of 5 -days T4-2 cysts treated as in I. $n \geq 1214$ cysts assessed from four wells/condition/experiment, two independent experiments. One-way ANOVA, Tukey's multiple comparisons test.

K. Confocal fluorescence microscopy images of HMT3522 T4-2 cysts of 5-days expressing either scramble, RalA or RalB shRNA. Cysts were fixed and stained for F-actin (yellow) and nuclei (blue, Hoechst). Scale bar $=40 \mu \mathrm{m}$.

L. Quantification of 5-days T4-2 cysts as in $K . n \geq 468$ cysts assessed from four wells/condition/experiment, three independent experiments. One-way ANOVA, Tukey's multiple comparisons test. 
Where indicated: ${ }^{*} p<0.05,{ }^{* *} p<0.01,{ }^{* * *} p<0.001,{ }^{* * * *} p<0.0001$, ns: not significant. All error bars represent SD. Scale bars $=20 \mu \mathrm{m}$, unless otherwise stated.

Figure 5-figure supplement 1. Ral knockdown in human mammary cell lines.

A. Confirmation of knock-down of Rala in HMT3522 T4-2 3D cultures in parental lines or following shScr, shRala and shRalb transfection. Data expressed as Delta $\mathrm{C}_{\mathrm{T}}$ using $A C T B$ as a reference. $\mathrm{n}=3$ independent samples, Error bars represent SEM. Data was analysed using One-way ANOVA followed by Tukey's multiple comparisons test.

B. Confirmation of knock-down of Ralb in HMT3522 T4-2 3D cultures in parental lines or following shScr, shRala and shRalb transfection. Data expressed as Delta $\mathrm{C}_{\mathrm{T}}$ using $A C T B$ as a reference. $\mathrm{n}=3$ independent samples, Error bars represent SEM. Data was analysed using One-way ANOVA followed by Tukey's multiple comparisons test.

Where indicated: ${ }^{* * *} p<0.001,{ }^{* * * *} p<0.0001$

Figure 6. Working model depicting the role of RAL GTPases in EGFR/MAPK signalling.

A. Experimental contexts used. Most results were acquired from Drosophila intestinal epithelial stem-progenitor cells. Key findings were confirmed using mammalian intestine and human lung and breast cancer cell lines.

B. RalA is necessary for EGFR internalisation and MAPK activation leading to mitogenic signalling. 


\section{References}

Amann, J., Kalyankrishna, S., Massion, P.P., Ohm, J.E., Girard, L., Shigematsu, H., Peyton, M., Juroske, D., Huang, Y., Stuart Salmon, J., et al. (2005). Aberrant epidermal growth factor receptor signaling and enhanced sensitivity to EGFR inhibitors in lung cancer. Cancer Res. 65, 226-235.

Arena, S., Bellosillo, B., Siravegna, G., Martinez, A., Canadas, I., Lazzari, L., Ferruz, N., Russo, M., Misale, S., Gonzalez, I., et al. (2015). Emergence of Multiple EGFR Extracellular Mutations during Cetuximab Treatment in Colorectal Cancer. Clin. Cancer Res. 21, 2157-2166.

Bardelli, A., and Siena, S. (2010). Molecular Mechanisms of Resistance to Cetuximab and Panitumumab in Colorectal Cancer. J. Clin. Oncol. 28, 1254-1261.

Basak, O., Beumer, J., Wiebrands, K., Seno, H., van Oudenaarden, A., and Clevers, H. (2017). Induced Quiescence of Lgr5+ Stem Cells in Intestinal Organoids Enables Differentiation of Hormone-Producing Enteroendocrine Cells. Cell Stem Cell 20, 177190.e4.

Basset, a, Khush, R.S., Braun, a, Gardan, L., Boccard, F., Hoffmann, J. a, and Lemaitre, B. (2000). The phytopathogenic bacteria Erwinia carotovora infects Drosophila and activates an immune response. Proc. Natl. Acad. Sci. U. S. A. 97, $3376-3381$.

Birkman, E.-M., Ålgars, A., Lintunen, M., Ristamäki, R., Sundström, J., and Carpén, O. (2016). EGFR gene amplification is relatively common and associates with outcome in intestinal adenocarcinoma of the stomach, gastro-oesophageal junction and distal oesophagus. BMC Cancer 16, 406. 
Biteau, B., and Jasper, H. (2011). EGF signaling regulates the proliferation of intestinal stem cells in Drosophila. Development 138, 1045-1055.

Biteau, B., Hochmuth, C.E., and Jasper, H. (2011). Maintaining tissue homeostasis: dynamic control of somatic stem cell activity. Cell Stem Cell 9, 402-411.

Blanke, S., and Jäckle, H. (2006). Novel guanine nucleotide exchange factor GEFmeso of Drosophila melanogaster interacts with Ral and Rho GTPase Cdc42. FASEB J. 20, 683-691.

Bodemann, B.O., and White, M. a (2008). Ral GTPases and cancer: linchpin support of the tumorigenic platform. Nat. Rev. Cancer 8, 133-140.

Bongers, G., Muniz, L.R., Pacer, M.E., luga, A.C., Thirunarayanan, N., Slinger, E., Smit, M.J., Reddy, E.P., Mayer, L., Furtado, G.C., et al. (2012). A role for the epidermal growth factor receptor signaling in development of intestinal serrated polyps in mice and humans. Gastroenterology 143, 730-740.

Buchon, N., Broderick, N.A., Kuraishi, T., and Lemaitre, B. (2010). Drosophila EGFR pathway coordinates stem cell proliferation and gut remodeling following infection. BMC Biol. 8, 152.

Calcagno, S.R., Li, S., Colon, M., Kreinest, P.A., Thompson, E.A., Fields, A.P., and Murray, N.R. (2008). Oncogenic K-ras promotes early carcinogenesis in the mouse proximal colon. Int. J. Cancer 122, 2462-2470.

Camidge, D.R., Pao, W., and Sequist, L. V. (2014). Acquired resistance to TKIs in solid tumours: learning from lung cancer. Nat. Rev. Clin. Oncol. 11, 473-481.

Casaletto, J.B., and McClatchey, A.I. (2012). Spatial regulation of receptor tyrosine 
kinases in development and cancer. Nat. Rev. Cancer 12, 387-400.

Chen, X.-W., Leto, D., Chiang, S.-H., Wang, Q., and Saltiel, A.R. (2007). Activation of RalA Is Required for Insulin-Stimulated Glut4 Trafficking to the Plasma Membrane via the Exocyst and the Motor Protein Myo1c. Dev. Cell 13, 391-404.

Chien, Y., Kim, S., Bumeister, R., Loo, Y.-M., Kwon, S.W., Johnson, C.L., Balakireva, M.G., Romeo, Y., Kopelovich, L., Gale, M., et al. (2006). RalB GTPase-Mediated Activation of the IKB Family Kinase TBK1 Couples Innate Immune Signaling to Tumor Cell Survival. Cell 127, 157-170.

Citri, A., and Yarden, Y. (2006). EGF-ERBB signalling: towards the systems level. Nat. Rev. Mol. Cell Biol. 7, 505-516.

Cordero, J.B., Ridgway, R.A., Valeri, N., Nixon, C., Frame, M.C., Muller, W.J., Vidal, M., and Sansom, O.J. (2014). c-Src drives intestinal regeneration and transformation. EMBO J. 33, 1474-1491.

Dunst, S., Kazimiers, T., von Zadow, F., Jambor, H., Sagner, A., Brankatschk, B., Mahmoud, A., Spannl, S., Tomancak, P., Eaton, S., et al. (2015). Endogenously Tagged Rab Proteins: A Resource to Study Membrane Trafficking in Drosophila. Dev. Cell 33, 351-365.

Dvořák, B., Holubec, H., LeBouton, A. V., Wilson, J.M., and Koldovský, O. (1994). Epidermal growth factor and transforming growth factor- $\alpha$ mRNA in rat small intestine: In situ hybridization study. FEBS Lett. 352, 291-295.

Endres, N.F., Barros, T., Cantor, A.J., and Kuriyan, J. (2014). Emerging concepts in the regulation of the EGF receptor and other receptor tyrosine kinases. Trends Biochem. Sci. 39, 437-446. 
Fisher, S., Barry, A., Abreu, J., Minie, B., Nolan, J., Delorey, T.M., Young, G., Fennell, T.J., Allen, A., Ambrogio, L., et al. (2011). A scalable, fully automated process for construction of sequence-ready human exome targeted capture libraries. Genome Biol. 12, R1.

Furnari, F.B., Cloughesy, T.F., Cavenee, W.K., and Mischel, P.S. (2015). Heterogeneity of epidermal growth factor receptor signalling networks in glioblastoma. Nat. Rev. Cancer 15, 302-310.

Gehart, H., and Clevers, H. (2019). Tales from the crypt: new insights into intestinal stem cells. Nat. Rev. Gastroenterol. Hepatol. 16, 19-34.

Gentry, L.R., Martin, T.D., Reiner, D.J., and Der, C.J. (2014). Ral small GTPase signaling and oncogenesis: More than just 15minutes of fame. Biochim. Biophys. Acta 1843, 2976-2988.

Goh, L.K., Huang, F., Kim, W., Gygi, S., and Sorkin, A. (2010). Multiple mechanisms collectively regulate clathrin-mediated endocytosis of the epidermal growth factor receptor. J. Cell Biol. 189, 871-883.

González-García, A., Pritchard, C.A., Paterson, H.F., Mavria, G., Stamp, G., and Marshall, C.J. (2005). RalGDS is required for tumor formation in a model of skin carcinogenesis. Cancer Cell 7, 219-226.

Guo, G., Gong, K., Wohlfeld, B., Hatanpaa, K.J., Zhao, D., and Habib, A.A. (2015). Ligand-Independent EGFR Signaling. Cancer Res. 75, 3436-3441.

Hanahan, D., and Weinberg, R.A. (2011). Hallmarks of cancer: the next generation. Cell 144, 646-674. 
Hu, Y., Flockhart, I., Vinayagam, A., Bergwitz, C., Berger, B., Perrimon, N., and Mohr, S.E. (2011). An integrative approach to ortholog prediction for disease-focused and other functional studies. BMC Bioinformatics 12, 357.

Huang, H.-J.S., Nagane, M., Klingbeil, C.K., Lin, H., Nishikawa, R., Ji, X.-D., Huang, C.-M., Gill, G.N., Wiley, H.S., and Cavenee, W.K. (1997). The Enhanced Tumorigenic Activity of a Mutant Epidermal Growth Factor Receptor Common in Human Cancers Is Mediated by Threshold Levels of Constitutive Tyrosine Phosphorylation and Unattenuated Signaling. J. Biol. Chem. 272, 2927-2935.

Jardé, T., Chan, W.H., Rossello, F.J., Kaur Kahlon, T., Theocharous, M., Kurian Arackal, T., Flores, T., Giraud, M., Richards, E., Chan, E., et al. (2020). Mesenchymal Niche-Derived Neuregulin-1 Drives Intestinal Stem Cell Proliferation and Regeneration of Damaged Epithelium. Cell Stem Cell.

Jiang, H., Grenley, M.O., Bravo, M.-J., Blumhagen, R.Z., and Edgar, B. a (2011). EGFR/Ras/MAPK signaling mediates adult midgut epithelial homeostasis and regeneration in Drosophila. Cell Stem Cell 8, 84-95.

Jiang, Y., Sverdlov, M.S., Toth, P.T., Huang, L.S., Du, G., Liu, Y., Natarajan, V., and Minshall, R.D. (2016). Phosphatidic Acid Produced by RalA-activated PLD2 Stimulates Caveolae-mediated Endocytosis and Trafficking in Endothelial Cells. J. Biol. Chem. 291, 20729-20738.

Jin, Y., Ha, N., Forés, M., Xiang, J., Gläßer, C., Maldera, J., Jiménez, G., and Edgar, B.A. (2015). EGFR/Ras Signaling Controls Drosophila Intestinal Stem Cell Proliferation via Capicua-Regulated Genes. PLOS Genet. 11, e1005634.

Johansson, J., Naszai, M., Hodder, M.C., Pickering, K.A., Miller, B.W., Ridgway, R.A., 
Yu, Y., Peschard, P., Brachmann, S., Campbell, A.D., et al. (2019). RAL GTPases

Drive Intestinal Stem Cell Function and Regeneration through Internalization of WNT Signalosomes. Cell Stem Cell 24, 592-607.e7.

Jullien-Flores, V., Mahé, Y., Mirey, G., Leprince, C., Meunier-Bisceuil, B., Sorkin, A., and Camonis, J.H. (2000). RLIP76, an effector of the GTPase Ral, interacts with the AP2 complex: involvement of the Ral pathway in receptor endocytosis. J. Cell Sci. 113 (Pt 1, 2837-2844.

Jung, M.J., Woo, C.G., Lee, S., Chin, S., Kim, H.K., Kwak, J.J., Koh, E.S., Lee, B., Jang, K.-T., and Moon, A. (2017). Gene copy number variation and protein overexpression of EGFR and HER2 in distal extrahepatic cholangiocarcinoma. Pathology 49, 582-588.

Kim-Yip, R.P., and Nystul, T.G. (2018). Wingless promotes EGFR signaling in follicle stem cells to maintain self-renewal. Development 145.

Kitchen, P.A., Goodlad, R.A., FitzGerald, A.J., Mandir, N., Ghatei, M.A., Bloom, S.R., Berlanga-Acosta, J., Playford, R.J., Forbes, A., and Walters, J.R.F. (2005). Intestinal Growth in Parenterally-Fed Rats Induced by the Combined Effects of Glucagon-like Peptide 2 and Epidermal Growth Factor. J. Parenter. Enter. Nutr. 29, 248-254.

Kohlmaier, A., Fassnacht, C., Jin, Y., Reuter, H., Begum, J., Dutta, D., and Edgar, B.A. (2015). Src kinase function controls progenitor cell pools during regeneration and tumor onset in the Drosophila intestine. Oncogene 34, 2371-2384.

Koyama, S., and Kikuchi, A. (2001). Ras interaction with Ra1GDS effector targets. pp. $127-138$.

Koyama, L.A.J., Aranda-Díaz, A., Su, Y.-H., Balachandra, S., Martin, J.L., Ludington, 
W.B., Huang, K.C., and O'Brien, L.E. (2020). Bellymount enables longitudinal, intravital imaging of abdominal organs and the gut microbiota in adult Drosophila. PLOS Biol. 18, e3000567.

Lanzetti, L., and Di Fiore, P.P. (2017). Behind the Scenes: Endo/Exocytosis in the Acquisition of Metastatic Traits. Cancer Res. 77, 1813-1817.

Lesokhin, A.M., Yu, S.-Y., Katz, J., and Baker, N.E. (1999). Several Levels of EGF Receptor Signaling during Photoreceptor Specification in Wild-Type,Ellipse,and Null MutantDrosophila. Dev. Biol. 205, 129-144.

Li, A.R., Chitale, D., Riely, G.J., Pao, W., Miller, V.A., Zakowski, M.F., Rusch, V., Kris, M.G., and Ladanyi, M. (2008). EGFR Mutations in Lung Adenocarcinomas. J. Mol. Diagnostics 10, 242-248.

Liang, J., Balachandra, S., Ngo, S., and O'Brien, L.E. (2017). Feedback regulation of steady-state epithelial turnover and organ size. Nature 548, 588-591.

Luo, F., Brooks, D.G., Ye, H., Hamoudi, R., Poulogiannis, G., Patek, C.E., Winton, D.J., and Arends, M.J. (2009). Mutated K-ras(Asp12) promotes tumourigenesis in Apc(Min) mice more in the large than the small intestines, with synergistic effects between K-ras and Wnt pathways. Int. J. Exp. Pathol. 90, 558-574.

Madsen, M.W., Lykkesfeldt, A.E., Laursen, I., Nielsen, K. V, and Briand, P. (1992). Altered gene expression of c-myc, epidermal growth factor receptor, transforming growth factor-alpha, and c-erb-B2 in an immortalized human breast epithelial cell line, HMT-3522, is associated with decreased growth factor requirements. Cancer Res. 52, $1210-1217$.

Mancini, M., and Yarden, Y. (2016). Mutational and network level mechanisms 
underlying resistance to anti-cancer kinase inhibitors. Semin. Cell Dev. Biol. 50, 164176.

Marchbank, T., Goodlad, R.A., Lee, C.Y., and Playford, R.J. (1995). Luminal Epidermal Growth Factor is Trophic to the Small Intestine of Parenterally Fed Rats. Clin. Sci. 89, 117-120.

Martin, J.L., Sanders, E.N., Moreno-Roman, P., Jaramillo Koyama, L.A., Balachandra, S., Du, X., and O'Brien, L.E. (2018). Long-term live imaging of the Drosophila adult midgut reveals real-time dynamics of division, differentiation and loss. Elife 7.

Mellman, I., and Yarden, Y. (2013). Endocytosis and Cancer. Cold Spring Harb. Perspect. Biol. 5, a016949-a016949.

Ménard, L., Floc'h, N., Martin, M.J., and Cross, D.A. (2018). Reactivation of mutantEGFR degradation through clathrin inhibition overcomes resistance to EGFR tyrosine kinase inhibitors. Cancer Res. canres.2195.2017.

Meng, F.W., and Biteau, B. (2015). A Sox Transcription Factor Is a Critical Regulator of Adult Stem Cell Proliferation in the Drosophila Intestine. Cell Rep. 13, 906-914.

Micchelli, C.A., and Perrimon, N. (2006). Evidence that stem cells reside in the adult Drosophila midgut epithelium. Nature 439, 475-479.

Mirey, G., Balakireva, M., L'Hoste, S., Rosse, C., Voegeling, S., and Camonis, J. (2003). A Ral Guanine Exchange Factor-Ral Pathway Is Conserved in Drosophila melanogaster and Sheds New Light on the Connectivity of the Ral, Ras, and Rap Pathways. Mol. Cell. Biol. 23, 1112-1124.

Moghadam, A.R., Patrad, E., Tafsiri, E., Peng, W., Fangman, B., Pluard, T.J., Accurso, 
A., Salacz, M., Shah, K., Ricke, B., et al. (2017). Ral signaling pathway in health and cancer. Cancer Med. 6, 2998-3013.

Mosesson, Y., Mills, G.B., and Yarden, Y. (2008). Derailed endocytosis: an emerging feature of cancer. Nat. Rev. Cancer 8, 835-850.

Nászai, M., Carroll, L.R., and Cordero, J.B. (2015). Intestinal stem cell proliferation and epithelial homeostasis in the adult Drosophila midgut. Insect Biochem. Mol. Biol. $67,9-14$.

Neel, N.F., Martin, T.D., Stratford, J.K., Zand, T.P., Reiner, D.J., and Der, C.J. (2011). The RalGEF-Ral Effector Signaling Network: The Road Less Traveled for Anti-Ras Drug Discovery. Genes Cancer 2, 275-287.

Neyen, C., Bretscher, A.J., Binggeli, O., and Lemaitre, B. (2014). Methods to study Drosophila immunity. Methods 68, 116-128.

Ngo, S., Liang, J., Su, Y.-H., and O’Brien, L.E. (2020). Disruption of EGF Feedback by Intestinal Tumors and Neighboring Cells in Drosophila. Curr. Biol. 30, 15371546.e3.

Ohlstein, B., and Spradling, A. (2006). The adult Drosophila posterior midgut is maintained by pluripotent stem cells. Nature $439,470-474$.

Parseghian, C.M., Napolitano, S., Loree, J.M., and Kopetz, S. (2019). Mechanisms of Innate and Acquired Resistance to Anti-EGFR Therapy: A Review of Current Knowledge with a Focus on Rechallenge Therapies. Clin. Cancer Res. 25, 68996908.

Perochon, J., Carroll, L.R., and Cordero, J.B. (2018). Wnt Signalling in Intestinal Stem 
Cells: Lessons from Mice and Flies. Genes (Basel). 9.

Perochon, J., Yu, Y., Aughey, G. N., Medina, A. B., Southall, T. D., \& Cordero, J. B. (2021). Dynamic adult tracheal plasticity drives stem cell adaptation to changes in intestinal homeostasis in Drosophila. Nature Cell Biology, 23(5), 485-496. https://doi.org/10.1038/s41556-021-00676-z

Poulsen, S.S., Nexo, E., Skov Olsen, P., Hess, J., and Kirkegaard, P. (1986). Immunohistochemical localization of epidermal growth factor in rat and man. Histochemistry 85, 389-394.

Powell, A.E., Wang, Y., Li, Y., Poulin, E.J., Means, A.L., Washington, M.K., Higginbotham, J.N., Juchheim, A., Prasad, N., Levy, S.E., et al. (2012). The Pan-ErbB Negative Regulator Lrig1 Is an Intestinal Stem Cell Marker that Functions as a Tumor Suppressor. Cell 149, 146-158.

Prior, I.A., Lewis, P.D., and Mattos, C. (2012). A Comprehensive Survey of Ras Mutations in Cancer. Cancer Res. 72, 2457-2467.

Queenan, A.M., Ghabrial, A., and Schupbach, T. (1997). Ectopic activation of torpedo/Egfr, a Drosophila receptor tyrosine kinase, dorsalizes both the eggshell and the embryo. Development 124, 3871 LP - 3880.

Radtke, F., and Clevers, H. (2005). Self-renewal and cancer of the gut: two sides of a coin. Science 307, 1904-1909.

Richardson, R.B., Allan, D.S., and Le, Y. (2014). Greater organ involution in highly proliferative tissues associated with the early onset and acceleration of ageing in humans. Exp. Gerontol. 55, 80-91. 
Rimawi, M.F., Shetty, P.B., Weiss, H.L., Schiff, R., Osborne, C.K., Chamness, G.C., and Elledge, R.M. (2010). Epidermal growth factor receptor expression in breast cancer association with biologic phenotype and clinical outcomes. Cancer 116, 12341242.

Roberts, M., Barry, S., Woods, A., van der Sluijs, P., and Norman, J. (2001). PDGFregulated rab4-dependent recycling of alphavbeta3 integrin from early endosomes is necessary for cell adhesion and spreading. Curr. Biol. 11, 1392-1402.

Roberts, R.B., Min, L., Washington, M.K., Olsen, S.J., Settle, S.H., Coffey, R.J., and Threadgill, D.W. (2002). Importance of epidermal growth factor receptor signaling in establishment of adenomas and maintenance of carcinomas during intestinal tumorigenesis. Proc. Natl. Acad. Sci. U. S. A. 99, 1521-1526.

Rodriguez-Viciana, P., and McCormick, F. (2005). RalGDS comes of age. Cancer Cell 7, 205-206.

Sadowski, L., Pilecka, I., and Miaczynska, M. (2009). Signaling from endosomes: Location makes a difference. Exp. Cell Res. 315, 1601-1609.

Santarius, T., Shipley, J., Brewer, D., Stratton, M.R., and Cooper, C.S. (2010). A census of amplified and overexpressed human cancer genes. Nat. Rev. Cancer 10, 59-64.

Sato, T., Vries, R.G., Snippert, H.J., van de Wetering, M., Barker, N., Stange, D.E., van Es, J.H., Abo, A., Kujala, P., Peters, P.J., et al. (2009). Single Lgr5 stem cells build crypt-villus structures in vitro without a mesenchymal niche. Nature 459, 262-265.

Scoville, D.H., Sato, T., He, X.C., and Li, L. (2008). Current View: Intestinal Stem Cells and Signaling. Gastroenterology 134, 849-864. 
Sell, S. (2010). On the Stem Cell Origin of Cancer. Am. J. Pathol. 176, 2584-2594.

Sequist, L. V., Waltman, B.A., Dias-Santagata, D., Digumarthy, S., Turke, A.B., Fidias, P., Bergethon, K., Shaw, A.T., Gettinger, S., Cosper, A.K., et al. (2011). Genotypic and Histological Evolution of Lung Cancers Acquiring Resistance to EGFR Inhibitors. Sci. Transl. Med. 3, 75ra26-75ra26.

Siegelin, M.D., and Borczuk, A.C. (2014). Epidermal growth factor receptor mutations in lung adenocarcinoma. Lab. Investig. 94, 129-137.

Sigismund, S., Argenzio, E., Tosoni, D., Cavallaro, E., Polo, S., and Di Fiore, P.P. (2008). Clathrin-Mediated Internalization Is Essential for Sustained EGFR Signaling but Dispensable for Degradation. Dev. Cell 15, 209-219.

Sigismund, S., Algisi, V., Nappo, G., Conte, A., Pascolutti, R., Cuomo, A., Bonaldi, T., Argenzio, E., Verhoef, L.G.G.C., Maspero, E., et al. (2013). Threshold-controlled ubiquitination of the EGFR directs receptor fate. EMBO J. 32, 2140-2157.

Sorkin, A., and Goh, L.K. (2009). Endocytosis and intracellular trafficking of ErbBs. Exp. Cell Res. 315, 683-696.

Sousa, L.P., Lax, I., Shen, H., Ferguson, S.M., De Camilli, P., Schlessinger, J., Camilli, P.D., and Schlessinger, J. (2012). Suppression of EGFR endocytosis by dynamin depletion reveals that EGFR signaling occurs primarily at the plasma membrane. Proc. Natl. Acad. Sci. 109, 4419-4424.

Spano, J.-P., Lagorce, C., Atlan, D., Milano, G., Domont, J., Benamouzig, R., Attar, A., Benichou, J., Martin, A., Morere, J.-F., et al. (2005). Impact of EGFR expression on colorectal cancer patient prognosis and survival. Ann. Oncol. 16, 102-108. 
Teis, D., Taub, N., Kurzbauer, R., Hilber, D., de Araujo, M.E., Erlacher, M., Offterdinger, M., Villunger, A., Geley, S., Bohn, G., et al. (2006). p14-MP1-MEK1 signaling regulates endosomal traffic and cellular proliferation during tissue homeostasis. J. Cell Biol. 175, 861-868.

Tomas, A., Futter, C.E., and Eden, E.R. (2014). EGF receptor trafficking: consequences for signaling and cancer. Trends Cell Biol. 24, 26-34.

Torrance, C.J., Jackson, P.E., Montgomery, E., Kinzler, K.W., Vogelstein, B., Wissner, A., Nunes, M., Frost, P., and Discafani, C.M. (2000). Combinatorial chemoprevention of intestinal neoplasia. Nat. Med. 6, 1024-1028.

Vieira, A. V, Lamaze, C., and Schmid, S.L. (1996). Control of EGF receptor signaling by clathrin-mediated endocytosis. Science 274, 2086-2089.

Vigil, D., Cherfils, J., Rossman, K.L., and Der, C.J. (2010). Ras superfamily GEFs and GAPs: validated and tractable targets for cancer therapy? Nat. Rev. Cancer 10, 842857.

Wang, S.-H. (2000). Dual role for Drosophila epidermal growth factor receptor signaling in early wing disc development. Genes Dev. 14, 2271-2276.

Wang, F., Weaver, V.M., Petersen, O.W., Larabell, C.A., Dedhar, S., Briand, P., Lupu, R., and Bissell, M.J. (1998). Reciprocal interactions between beta1-integrin and epidermal growth factor receptor in three-dimensional basement membrane breast cultures: a different perspective in epithelial biology. Proc. Natl. Acad. Sci. U. S. A. 95, $14821-14826$.

Wee, P., and Wang, Z. (2017). Epidermal Growth Factor Receptor Cell Proliferation Signaling Pathways. Cancers (Basel). 9, 52. 
Wong, V.W.Y., Stange, D.E., Page, M.E., Buczacki, S., Wabik, A., Itami, S., van de Wetering, M., Poulsom, R., Wright, N.A., Trotter, M.W.B., et al. (2012). Lrig1 controls intestinal stem-cell homeostasis by negative regulation of ErbB signalling. Nat. Cell Biol. 14, 401-408.

Xu, M.J., Johnson, D.E., and Grandis, J.R. (2017). EGFR-targeted therapies in the post-genomic era. Cancer Metastasis Rev. 36, 463-473.

Xu, N., Wang, S.Q., Tan, D., Gao, Y., Lin, G., and Xi, R. (2011). EGFR, Wingless and JAK/STAT signaling cooperatively maintain Drosophila intestinal stem cells. Dev. Biol. $354,31-43$.

Yang, Y.-P., Ma, H., Starchenko, A., Huh, W.J., Li, W., Hickman, F.E., Zhang, Q., Franklin, J.L., Mortlock, D.P., Fuhrmann, S., et al. (2017). A Chimeric Egfr Protein Reporter Mouse Reveals Egfr Localization and Trafficking In Vivo. Cell Rep. 19, 12571267.

Yarden, Y., and Pines, G. (2012). The ERBB network: at last, cancer therapy meets systems biology. Nat. Rev. Cancer 12, 553-563.

Yu, H.A., Tian, S.K., Drilon, A.E., Borsu, L., Riely, G.J., Arcila, M.E., and Ladanyi, M. (2015). Acquired Resistance of EGFR- Mutant Lung Cancer to a T790M-Specific EGFR Inhibitor. JAMA Oncol. 1, 982.

von Zastrow, M. (2003). Mechanisms regulating membrane trafficking of G proteincoupled receptors in the endocytic pathway. Life Sci. 74, 217-224.

von Zastrow, M., and Sorkin, A. (2007). Signaling on the endocytic pathway. Curr. Opin. Cell Biol. 19, 436-445. 
Zecca, M., and Struhl, G. (2002). Control of growth and patterning of the Drosophila wing imaginal disc by EGFR-mediated signaling. Development 129, 1369-1376.

Zhang, P., Holowatyj, A.N., Roy, T., Pronovost, S.M., Marchetti, M., Liu, H., Ulrich, C.M., and Edgar, B.A. (2019). An SH3PX1-Dependent Endocytosis-Autophagy Network Restrains Intestinal Stem Cell Proliferation by Counteracting EGFR-ERK Signaling. Dev. Cell 49, 574-589.e5.

Zhang, Y.-L., Yuan, J.-Q., Wang, K.-F., Fu, X.-H., Han, X.-R., Threapleton, D., Yang, Z.-Y., Mao, C., and Tang, J.-L. (2016). The prevalence of EGFR mutation in patients with non-small cell lung cancer: a systematic review and meta-analysis. Oncotarget 7. 
Key resources table

\begin{tabular}{|c|c|c|c|c|}
\hline $\begin{array}{c}\text { Reagent type } \\
\text { (species) or } \\
\text { resource }\end{array}$ & Designation & $\begin{array}{l}\text { Source or } \\
\text { reference }\end{array}$ & Identifiers & $\begin{array}{l}\text { Additional } \\
\text { information }\end{array}$ \\
\hline $\begin{array}{l}\text { strain, strain } \\
\text { background } \\
\text { (Mus } \\
\text { musculus) }\end{array}$ & VillinCreER & $\begin{array}{l}\text { (el Marjou et al., } \\
2004 \text { ) } \\
10.1002 \text { /gene.2004 } \\
2\end{array}$ & NA & \\
\hline $\begin{array}{l}\text { strain, strain } \\
\text { background } \\
\text { (Mus } \\
\text { musculus) }\end{array}$ & Rala $a^{f \mid / f l}$ & $\begin{array}{l}\text { (Peschard et al., } \\
2012) \\
10.1016 / j . c u b .2012 . \\
09.013 \\
\end{array}$ & $\begin{array}{l}\text { RRID:MGI:5 } \\
505291\end{array}$ & \\
\hline $\begin{array}{l}\text { strain, strain } \\
\text { background } \\
\text { (Mus } \\
\text { musculus) }\end{array}$ & Ralb $b^{f l / f l}$ & $\begin{array}{l}\text { (Peschard et al., } \\
\text { 2012) } \\
\text { 10.1016/j.cub.2012. } \\
09.013\end{array}$ & $\begin{array}{l}\text { RRID:MGI:5 } \\
505291\end{array}$ & \\
\hline $\begin{array}{l}\text { strain, strain } \\
\text { background } \\
\text { (Erwinia } \\
\text { carotovora } \\
\text { carotovora 15) }\end{array}$ & Ecc15 & $\begin{array}{l}\text { B. Lemaitre; } \\
\text { (Basset et al., } \\
2000 \text { ) } \\
10.1073 \text { /pnas.97.7. } \\
3376 \\
\end{array}$ & NA & \\
\hline $\begin{array}{l}\text { genetic } \\
\text { reagent } \\
\text { (Drosophila } \\
\text { melanogaster) }\end{array}$ & en> & BDSC & $\begin{array}{l}\text { RRID:BDSC } \\
-30564\end{array}$ & $\begin{array}{l}y 1 w^{*} \\
P\{w+m W . h s=e n 2.4- \\
\text { GAL4\}e16E }\end{array}$ \\
\hline $\begin{array}{l}\text { genetic } \\
\text { reagent } \\
\text { (Drosophila } \\
\text { melanogaster) }\end{array}$ & ISC/EB> & $\begin{array}{l}\text { S. Hayashi; (Goto } \\
\text { and Hayashi, 1999) } \\
\text { PMID: } 10393119\end{array}$ & NA & $\begin{array}{l}\text { yw;esg- } \\
\text { Gal4NP5130,UAS- } \\
\text { GFP,UAS- } \\
\text { GFPnLacZ/Cyo;tub- } \\
\text { Gal80ts/Tm6B }\end{array}$ \\
\hline $\begin{array}{l}\text { genetic } \\
\text { reagent } \\
\text { (Drosophila } \\
\text { melanogaster) } \\
\end{array}$ & Control & R. Cagan & NA & $w[1118]$ \\
\hline $\begin{array}{l}\text { genetic } \\
\text { reagent } \\
\text { (Drosophila } \\
\text { melanogaster) }\end{array}$ & $\begin{array}{l}\text { RalA- } \\
\text { RNAi(1) }\end{array}$ & VDRC & $\begin{array}{l}\text { RRID:FlyBas } \\
\text { e_FBst0477 } \\
1 \overline{24}\end{array}$ & $\begin{array}{l}\text { P }\{\text { KK 108989\}VIE- } \\
260 B\end{array}$ \\
\hline $\begin{array}{l}\text { genetic } \\
\text { reagent } \\
\text { (Drosophila } \\
\text { melanogaster) }\end{array}$ & $\begin{array}{l}\text { RalA- } \\
\text { RNAi(2) }\end{array}$ & BDSC & $\begin{array}{l}\text { RRID:BDSC } \\
29580\end{array}$ & $\begin{array}{l}\text { y1 v1; } \\
P\{y+t 7.7 v+t 1.8=T R i P . \\
\text { JF03259\}attP2 }\end{array}$ \\
\hline $\begin{array}{l}\text { genetic } \\
\text { reagent } \\
\text { (Drosophila } \\
\text { melanogaster) } \\
\end{array}$ & $w g-R N A i$ & VDRC & $\begin{array}{l}\text { RRID:FlyBas } \\
\text { e_FBst0476 } \\
4 \overline{3} 7\end{array}$ & $\begin{array}{l}\mathrm{P}\{\mathrm{KK} 108857\} \mathrm{VIE}- \\
260 \mathrm{~B}\end{array}$ \\
\hline
\end{tabular}




\begin{tabular}{|c|c|c|c|c|}
\hline \begin{tabular}{|l} 
genetic \\
reagent \\
(Drosophila \\
melanogaster)
\end{tabular} & $w g-R N A i$ & VDRC & $\begin{array}{l}\text { RRID:FlyBas } \\
\text { e_FBst0450 } \\
965\end{array}$ & $P\{G D 5007\} \vee 13351$ \\
\hline $\begin{array}{l}\text { genetic } \\
\text { reagent } \\
\text { (Drosophila } \\
\text { melanogaster) } \\
\end{array}$ & EGFR-RNAi & VDRC & $\begin{array}{l}\text { RRID:FlyBas } \\
\text { e_FBst0478 } \\
9 \overline{5} 3\end{array}$ & $\begin{array}{l}\text { P }\{\text { KK100051\}VIE- } \\
260 B\end{array}$ \\
\hline \begin{tabular}{|l} 
genetic \\
reagent \\
(Drosophila \\
melanogaster) \\
\end{tabular} & RalAwt & $\begin{array}{l}\text { G. Hasan; } \\
\text { (Richhariya et al., } \\
2017 \text { ) } \\
\text { 10.1038/srep42586 }\end{array}$ & NA & $P\{U A S-R a l A\} 3$ \\
\hline \begin{tabular}{|l} 
genetic \\
reagent \\
(Drosophila \\
melanogaster) \\
\end{tabular} & $\begin{array}{l}\text { GEFmeso- } \\
R N A i\end{array}$ & BDSC & $\begin{array}{l}\text { RRID:BDSC } \\
-42545\end{array}$ & $\begin{array}{l}\mathrm{y}[1] \mathrm{v}[1] ; \mathrm{P}\{\mathrm{y}[+\mathrm{t} 7.7] \\
\mathrm{v}[+\mathrm{t} 1.8]=\mathrm{R}[\mathrm{PiP} . \mathrm{HMJ02} \\
\text { 116\}attP40 }\end{array}$ \\
\hline $\begin{array}{l}\text { genetic } \\
\text { reagent } \\
\text { (Drosophila } \\
\text { melanogaster) }\end{array}$ & $\begin{array}{l}\text { RalGPS- } \\
\text { RNAi }\end{array}$ & VDRC & $\begin{array}{l}\text { RRID:FlyBas } \\
\text { e_FBst0463 } \\
6 \overline{50}\end{array}$ & $\begin{array}{l}\text { w[1118]; } \\
\text { P\{GD11683\}v40596/T } \\
\text { M3 }\end{array}$ \\
\hline \begin{tabular}{|l} 
genetic \\
reagent \\
(Drosophila \\
melanogaster) \\
\end{tabular} & $R g l-R N A i$ & BDSC & $\begin{array}{l}\text { RRID:BDSC } \\
28938\end{array}$ & $\begin{array}{l}\mathrm{y}[1] \mathrm{v}[1] ; \mathrm{P}\{\mathrm{y}[+\mathrm{t} 7.7] \\
\mathrm{v}[+\mathrm{t} 1.8]=\mathrm{R} \text { iP.HM051 } \\
\text { 49\}attP2 }\end{array}$ \\
\hline $\begin{array}{l}\text { genetic } \\
\text { reagent } \\
\text { (Drosophila } \\
\text { melanogaster) } \\
\end{array}$ & $E G F R^{w t}$ & BDSC & $\begin{array}{l}\text { RRID:BDSC } \\
-5368\end{array}$ & $\begin{array}{l}y[1] \mathrm{w}\left[^{\star}\right] ; \\
\mathrm{P}\{\mathrm{w}[+\mathrm{+mc}]=\mathrm{UAS}- \\
\text { Egfr.B }\} 32-26-1\end{array}$ \\
\hline $\begin{array}{l}\text { genetic } \\
\text { reagent } \\
\text { (Drosophila } \\
\text { melanogaster) } \\
\end{array}$ & $E G F R^{A 887 T}$ & BDSC & $\begin{array}{l}\text { RRID:BDSC } \\
\text { _9533 }\end{array}$ & $\begin{array}{l}\mathrm{w}\left[^{*}\right] \\
\mathrm{P}\{\mathrm{w}[+\mathrm{mC}]=\text { Egfr. } 2 . \text { A88 } \\
\text { 7T.UAS }\} 8-2\end{array}$ \\
\hline \begin{tabular}{|l|} 
genetic \\
reagent \\
(Drosophila \\
melanogaster) \\
\end{tabular} & $E G F R^{\lambda t o p}$ & BDSC & $\begin{array}{l}\text { RRID:BDSC } \\
-59843\end{array}$ & $\begin{array}{l}\mathrm{w}\left[^{\star}\right] ; \mathrm{P}\{\mathrm{w}[+\mathrm{mC}]=\mathrm{UAS}- \\
\text { Egfr.lambdatop }\} 3 / \mathrm{TM} 6 \\
\mathrm{C}, \mathrm{Sb}[1]\end{array}$ \\
\hline \begin{tabular}{|l} 
genetic \\
reagent \\
(Drosophila \\
melanogaster) \\
\end{tabular} & $\operatorname{Ras}^{V 12}(1)$ & BDSC & $\begin{array}{l}\text { RRID:BDSC } \\
64196\end{array}$ & $\begin{array}{l}\mathrm{w}\left[^{\star}\right] ; \mathrm{P}\{\mathrm{w}[+\mathrm{mC}]=\mathrm{UAS}- \\
\text { Ras85D.V12\}2 }\end{array}$ \\
\hline $\begin{array}{l}\text { genetic } \\
\text { reagent } \\
\text { (Drosophila } \\
\text { melanogaster) }\end{array}$ & $\operatorname{Ras}^{V 12}(2)$ & BDSC & $\begin{array}{l}\text { RRID:BDSC } \\
64195\end{array}$ & $\begin{array}{l}\mathrm{w}\left[{ }^{*}\right] ; \mathrm{P}\{\mathrm{w}[+\mathrm{mC}]=\mathrm{UAS}- \\
\text { Ras85D.V12\}TL1 }\end{array}$ \\
\hline \begin{tabular}{|l} 
genetic \\
reagent \\
(Drosophila \\
melanogaster) \\
\end{tabular} & Ras-RNAi & VDRC & $\begin{array}{l}\text { RRID:FlyBas } \\
\text { e_FBst0478 } \\
466\end{array}$ & $\begin{array}{l}\mathrm{P}\{\mathrm{KK} 108029\} \mathrm{VIE}- \\
260 \mathrm{~B}\end{array}$ \\
\hline $\begin{array}{l}\text { genetic } \\
\text { reagent }\end{array}$ & Src64wt & BDSC & $\begin{array}{l}\text { RRID:BDSC } \\
8477\end{array}$ & $\begin{array}{l}\mathrm{w}\left[{ }^{*}\right] ; \mathrm{P}\{\mathrm{w}[+\mathrm{mC}]=\mathrm{UAS}- \\
\text { Src64B.C }\} 2\end{array}$ \\
\hline
\end{tabular}




\begin{tabular}{|c|c|c|c|c|}
\hline \multicolumn{5}{|c|}{$\begin{array}{l}\text { (Drosophila } \\
\text { melanogaster) }\end{array}$} \\
\hline $\begin{array}{l}\text { cell line } \\
\text { (Homo } \\
\text { sapiens) }\end{array}$ & H1299 & ATCC & $\begin{array}{l}\text { RRID:CVCL } \\
0060\end{array}$ & ATCC CRL-5803 \\
\hline $\begin{array}{l}\text { cell line } \\
\text { (Homo } \\
\text { sapiens) }\end{array}$ & $\begin{array}{l}\text { HMT3522 } \\
\text { T4-2 }\end{array}$ & V. Weaver, UCSF & $\begin{array}{l}\text { RRID:CVCL } \\
-2501\end{array}$ & \\
\hline $\begin{array}{l}\text { cell line } \\
\text { (Homo } \\
\text { sapiens) } \\
\end{array}$ & HEK293-FT & $\begin{array}{l}\text { Thermo Fisher } \\
\text { Scientific }\end{array}$ & $\begin{array}{l}\text { RRID:CVCL } \\
6911\end{array}$ & \\
\hline \multirow[t]{11}{*}{ antibody } & GFP & AbCam & $\begin{array}{l}\text { RRID:AB_30 } \\
0798\end{array}$ & $\begin{array}{l}\text { chicken polyclonal } \\
\text { anti GFP; 1:2000 }\end{array}$ \\
\hline & Sox21a & $\begin{array}{l}\text { B. Biteau; (Meng } \\
\text { and Biteau, 2015) } \\
\text { 10.1016/j.celrep.20 } \\
\text { 15.09.061 }\end{array}$ & NA & $\begin{array}{l}\text { rabbit polyclonal anti } \\
\text { Sox21a; } 1: 2000\end{array}$ \\
\hline & pERK & $\begin{array}{l}\text { Cell Signalling } \\
\text { Technology }\end{array}$ & $\begin{array}{l}\text { RRID:AB_33 } \\
1646\end{array}$ & $\begin{array}{l}\text { rabbit polyclonal anti } \\
\text { pERK1/2; 1:100 in } \\
\text { Drosophila IF, 1:400 } \\
\text { in mouse IHC, 1:1000 } \\
\text { in Western blot }\end{array}$ \\
\hline & tERK & $\begin{array}{l}\text { Cell Signalling } \\
\text { Technology }\end{array}$ & $\begin{array}{l}\text { RRID:AB_39 } \\
0779\end{array}$ & $\begin{array}{l}\text { Rabbit monoclonal } \\
\text { anti ERK1/2; 1:100 } \\
\text { Drosophila IF, 1:1000 } \\
\text { in Western blot }\end{array}$ \\
\hline & tERK & $\begin{array}{l}\text { Cell Signalling } \\
\text { Technology }\end{array}$ & $\begin{array}{l}\text { RRID:AB_33 } \\
0744\end{array}$ & $\begin{array}{l}\text { Rabbit polyclonal anti } \\
\text { ERK1/2; } 1: 40 \text { in } \\
\text { mouse IHC } \\
\end{array}$ \\
\hline & $\begin{array}{l}\text { anti-rabbit } \\
\text { lgG HRP- } \\
\text { linked } \\
\text { antibody } \\
\end{array}$ & $\begin{array}{l}\text { Cell Signalling } \\
\text { Technology }\end{array}$ & $\begin{array}{l}\text { RRID:AB_20 } \\
99233\end{array}$ & $\begin{array}{l}\text { Goat polyclonal anti- } \\
\text { rabbit lgG, HRP- } \\
\text { linked 1:10,000 in } \\
\text { Western blot }\end{array}$ \\
\hline & $\mathrm{pH} 3$ & $\begin{array}{l}\text { Cell Signalling } \\
\text { Technology }\end{array}$ & $\begin{array}{l}\text { RRID:AB_33 } \\
1535\end{array}$ & $\begin{array}{l}\text { rabbit polyclonal anti } \\
\text { Phospho-Histone H3 } \\
\text { (Ser10); } 1: 100 \\
\end{array}$ \\
\hline & $\begin{array}{l}\text { EGFR } \\
\text { (Drosophila } \\
\text { IF) }\end{array}$ & Sigma Aldrich & $\begin{array}{l}\text { RRID:AB_60 } \\
9900\end{array}$ & $\begin{array}{l}\text { mouse monoclonal } \\
\text { anti Drosophila EGFR } \\
\text { extracellular domain; } \\
1: 50\end{array}$ \\
\hline & $\begin{array}{l}\text { EGFR1 } \\
\text { (capture- } \\
\text { ELISA) }\end{array}$ & BDPharmingen & $\begin{array}{l}\text { RRID:AB_20 } \\
96589\end{array}$ & $\begin{array}{l}\text { mouse anti-EGF } \\
\text { Receptor monoclonal }\end{array}$ \\
\hline & c-MET & R\&D Systems & $\begin{array}{l}\text { RRID:AB_35 } \\
5289\end{array}$ & $\begin{array}{l}\text { Goat anti-HGFR } \\
\text { polyclonal }\end{array}$ \\
\hline & $\begin{array}{l}\text { alpha5 beta1 } \\
\text { integrin }\end{array}$ & BDPharmingen & $\begin{array}{l}\text { RRID:AB_39 } \\
6007\end{array}$ & $\begin{array}{l}\text { Mouse Anti-CD49e } \\
\text { Monoclonal Antibody, } \\
\text { Unconjugated, Clone } \\
\text { VC5 }\end{array}$ \\
\hline
\end{tabular}




\begin{tabular}{|c|c|c|c|c|}
\hline & $\begin{array}{l}\text { Transferrin } \\
\text { receptor }\end{array}$ & BDPharmingen & \begin{tabular}{|l} 
RRID:AB_39 \\
5918
\end{tabular} & $\begin{array}{l}\text { CD71 human } \\
\text { monoclonal antibody }\end{array}$ \\
\hline & $\begin{array}{l}\text { anti-chicken- } \\
\lg Y-488\end{array}$ & Invitrogen & $\begin{array}{l}\text { RRID:AB_14 } \\
2924\end{array}$ & $\begin{array}{l}\text { goat anti-chicken- } \\
\lg \mathrm{Y}(\mathrm{H}+\mathrm{L}) \text {-Alexa Fluor } \\
488\end{array}$ \\
\hline & $\begin{array}{l}\text { anti-rabbit- } \\
\lg \text { G-594 }\end{array}$ & $\begin{array}{l}\text { Thermo Fisher } \\
\text { Scientific }\end{array}$ & $\begin{array}{l}\text { RRID:AB_25 } \\
34095\end{array}$ & $\begin{array}{l}\text { goat anti-rabbit- } \\
\text { lgG(H+L)-Alexa Fluor } \\
594\end{array}$ \\
\hline & $\begin{array}{l}\text { anti-mouse- } \\
\lg \text { lg-594 }\end{array}$ & Molecular Probes & $\begin{array}{l}\text { RRID:AB_14 } \\
1672\end{array}$ & $\begin{array}{l}\text { goat anti-mouse- } \\
\text { lgG }(\mathrm{H}+\mathrm{L}) \text {-Alexa Fluor } \\
594\end{array}$ \\
\hline \multirow[t]{3}{*}{$\begin{array}{l}\text { recombinant } \\
\text { DNA reagent }\end{array}$} & $\begin{array}{l}\text { pLKO.1- } \\
\text { puromycin }\end{array}$ & $\begin{array}{l}\text { Moffat et al Cell. } \\
2006 \text { Mar 24. } \\
\text { 124(6):1283-98 }\end{array}$ & $\begin{array}{l}\text { RRID:Addge } \\
\text { ne_10878 }\end{array}$ & \\
\hline & VSVG & $\begin{array}{l}\text { Trono lab, } \\
\text { unpublished, } \\
\text { donated to } \\
\text { Addgene }\end{array}$ & $\begin{array}{l}\text { RRID:Addge } \\
\text { ne_12259 }\end{array}$ & \\
\hline & SPAX2 & $\begin{array}{l}\text { Trono lab, } \\
\text { unpublished, } \\
\text { donated to } \\
\text { Addgene }\end{array}$ & $\begin{array}{l}\text { RRID:Addge } \\
\text { ne_12260 }\end{array}$ & \\
\hline \multirow[t]{13}{*}{$\begin{array}{l}\text { sequence- } \\
\text { based reagent }\end{array}$} & Rho_Fwd & This paper & NA & $\begin{array}{l}\text { TTGTCATCTTTGTCT } \\
\text { CCTGCGA }\end{array}$ \\
\hline & Rho_Rev & This paper & NA & $\begin{array}{l}\text { GTCAGGTGGGCAAT } \\
\text { GTACGA } \\
\end{array}$ \\
\hline & Stg_Fwd & This paper & NA & $\begin{array}{l}\text { CAGTAATAACACCA } \\
\text { GCAGTTCGAG }\end{array}$ \\
\hline & Stg_Rev & This paper & NA & $\begin{array}{l}\text { GTAGAACGACAGCT } \\
\text { CCTCCT }\end{array}$ \\
\hline & Sox21a_Fwd & This paper & NA & $\begin{array}{l}\text { AGACAATTAATACA } \\
\text { GAGCTCGAGG }\end{array}$ \\
\hline & Sox21a_Rev & This paper & NA & $\begin{array}{l}\text { GAGATGCTCGTCAT } \\
\text { GATGCC }\end{array}$ \\
\hline & Rp/32_Fwd & This paper & NA & $\begin{array}{l}\text { AGGCCCAAGATCGT } \\
\text { GAAGAA }\end{array}$ \\
\hline & Rpl32_Rev & This paper & NA & $\begin{array}{l}\text { TGTGCACCAGGAAC } \\
\text { TTCTTGAA }\end{array}$ \\
\hline & Rala_Fwd & PrimerBank & $\begin{array}{l}\text { ID\#3240727 } \\
\text { 95c2 }\end{array}$ & $\begin{array}{l}\text { GCAGACAGCTATCG } \\
\text { GAAGAAG }\end{array}$ \\
\hline & Rala_Rev & PrimerBank & $\begin{array}{l}\text { ID\#3240727 } \\
\text { 95c2 } \\
\end{array}$ & $\begin{array}{l}\text { TCTCTAATTGCAGC } \\
\text { GTAGTCCT } \\
\end{array}$ \\
\hline & Ralb_Fwd & PrimerBank & \begin{tabular}{|l|} 
ID\#4876292 \\
7c1
\end{tabular} & $\begin{array}{l}\text { AGCCCTGACGCTTC } \\
\text { AGTTC }\end{array}$ \\
\hline & Ralb_Rev & PrimerBank & \begin{tabular}{|l|} 
ID\#4876292 \\
7c1
\end{tabular} & $\begin{array}{l}\text { AGCGGTGTCCAGAA } \\
\text { TATCTATCT }\end{array}$ \\
\hline & ActB_Fwd & $\begin{array}{l}\text { (Liu et al., 2015) } \\
\text { 10.1371/journal.pon } \\
\text { e.0117058 }\end{array}$ & NA & $\begin{array}{l}\text { TGACGTGGACATCC } \\
\text { GCAAAG }\end{array}$ \\
\hline
\end{tabular}




\begin{tabular}{|c|c|c|c|c|}
\hline & $A c t B \_R e v$ & \begin{tabular}{|l|} 
(Liu et al., 2015) \\
$10.1371 /$ journal.pon \\
e.0117058
\end{tabular} & NA & $\begin{array}{l}\text { CTGGAAGGTGGAC } \\
\text { AGCGAGG }\end{array}$ \\
\hline & shScr & This paper & NA & $\begin{array}{l}\text { CCGCAGGTATGCAC } \\
\text { GCGT }\end{array}$ \\
\hline & shRala & This paper & NA & $\begin{array}{l}\text { GGAGGAAGTCCAG } \\
\text { ATCGATAT } \\
\end{array}$ \\
\hline & shRalb & This paper & NA & $\begin{array}{l}\text { CAAGGTGTTCTTTG } \\
\text { ACCTAAT }\end{array}$ \\
\hline & $\begin{array}{l}\text { SiRNA Rala } \\
\text { (human) }\end{array}$ & Dharmacon & $\begin{array}{l}\text { ONTARGET } \\
\text { plus - Cat\# } \\
\text { L-009235- } \\
00-0005\end{array}$ & \\
\hline & $\begin{array}{l}\text { SiRNA Ralb } \\
\text { (human) }\end{array}$ & Dharmacon & $\begin{array}{l}\text { ONTARGET } \\
\text { plus - Ca\# L- } \\
008403-00- \\
0005\end{array}$ & \\
\hline \multirow[t]{2}{*}{$\begin{array}{l}\text { peptide, } \\
\text { recombinant } \\
\text { protein }\end{array}$} & EGF & Sigma & \begin{tabular}{|l|} 
Cat\# \\
1137645400 \\
1 \\
\end{tabular} & \\
\hline & HGF & Sigma & Cat\# H9661 & \\
\hline \multirow[t]{7}{*}{$\begin{array}{l}\text { commercial } \\
\text { assay or kit }\end{array}$} & $\begin{array}{l}\text { High } \\
\text { Capacity } \\
\text { cDNA } \\
\text { Reverse } \\
\text { Transcription } \\
\text { Kit }\end{array}$ & Applied Biosystems & $\begin{array}{l}\text { Cat\# } \\
4368813\end{array}$ & \\
\hline & $\begin{array}{l}\text { PerfeCTa } \\
\text { SYBR Green } \\
\text { FastMix } \\
\text { (Low ROX) }\end{array}$ & Quanta Bio & $\begin{array}{l}\text { Cat\# 95074- } \\
012\end{array}$ & \\
\hline & $\begin{array}{l}\text { VECTASHIE } \\
\text { LD Mounting } \\
\text { Medium with } \\
\text { DAPI }\end{array}$ & $\begin{array}{l}\text { Vector } \\
\text { Laboratories, Inc }\end{array}$ & $\begin{array}{l}\text { RRID:AB_23 } \\
36790\end{array}$ & \\
\hline & $\begin{array}{l}\text { SuperSignal } \\
\text { West Pico } \\
\text { Chemilumine } \\
\text { scent } \\
\text { Substrate }\end{array}$ & $\begin{array}{l}\text { Thermo Fisher } \\
\text { Scientific }\end{array}$ & Cat\# 34077 & \\
\hline & \begin{tabular}{|l|} 
RNAeasy \\
Mini Kit (50) \\
\end{tabular} & Qiagen & Cat\# 74104 & \\
\hline & $\begin{array}{l}\text { Growth } \\
\text { Factor } \\
\text { Reduced } \\
\text { Matrigel }\end{array}$ & BD Biosciences & 354230 & \\
\hline & $\begin{array}{l}\text { Lipofectamin } \\
\text { e } 2000\end{array}$ & $\begin{array}{l}\text { Thermo Fisher } \\
\text { Scientific }\end{array}$ & \begin{tabular}{|l|} 
Cat\# \\
11668027
\end{tabular} & \\
\hline
\end{tabular}




\begin{tabular}{|c|c|c|c|c|}
\hline & \begin{tabular}{|l} 
Lenti-X \\
Concentrator
\end{tabular} & Clonetech & & \\
\hline \multirow{19}{*}{$\begin{array}{l}\text { chemical } \\
\text { compound, } \\
\text { drug }\end{array}$} & Glutamine & $\begin{array}{l}\text { Thermo Fisher } \\
\text { Scientific }\end{array}$ & 25030081 & \\
\hline & DMEM & $\begin{array}{l}\text { Thermo Fisher } \\
\text { Scientific }\end{array}$ & 12491015 & \\
\hline & FBS & $\begin{array}{l}\text { Thermo Fisher } \\
\text { Scientific }\end{array}$ & 26140079 & \\
\hline & L-Glutamine & $\begin{array}{l}\text { Thermo Fisher } \\
\text { Scientific }\end{array}$ & 25030081 & \\
\hline & $\begin{array}{l}\text { Non- } \\
\text { Essential } \\
\text { Amino Acids }\end{array}$ & $\begin{array}{l}\text { Thermo Fisher } \\
\text { Scientific }\end{array}$ & 11140050 & \\
\hline & Insulin & Sigma Aldrich & 10516 & $\begin{array}{l}\text { Insulin solution from } \\
\text { bovine pancreas, } 10 \\
\mathrm{mg} / \mathrm{mL} \text { insulin in } 25 \\
\mathrm{~mm} \text { HEPES, pH } 8.2 \text {, } \\
\text { BioReagent, sterile- } \\
\text { filtered, suitable for } \\
\text { cell culture }\end{array}$ \\
\hline & Transferrin & Sigma Aldrich & T2252 & \\
\hline & $\begin{array}{l}\text { Sodium } \\
\text { selenite }\end{array}$ & Sigma Aldrich & S5261 & \\
\hline & \begin{tabular}{|l|} 
beta- \\
estradiol
\end{tabular} & Sigma Aldrich & E2758 & \\
\hline & $\begin{array}{l}\text { hydrocortiso } \\
\text { ne }\end{array}$ & Sigma Aldrich & H0888 & \\
\hline & Prolactin & Miltenyi Biotech & $130-093-985$ & \\
\hline & $\begin{array}{l}\text { Tyrphostin- } \\
\text { AG1478 }\end{array}$ & Sigma Aldrich & T4182 & \\
\hline & $\begin{array}{l}\text { Erlotinib, } \\
\mathrm{HCL}\end{array}$ & Sigma Aldrich & SML2156 & \\
\hline & puromycin & $\begin{array}{l}\text { Thermo Fisher } \\
\text { Scientific }\end{array}$ & A1113803 & \\
\hline & Phalloidin & Invitrogen & $\begin{array}{l}\text { A12380, } \\
\text { A22287 }\end{array}$ & \\
\hline & Hoechst & & $\mathrm{H} 21486$ & \\
\hline & RIPA buffer & Sigma & R0278 & \\
\hline & $\begin{array}{l}\text { Bradford } \\
\text { reagent }\end{array}$ & Abcam & AB119216 & \\
\hline & $\begin{array}{l}\text { NuPAGE } \\
10 \% \text { Bis-Tris } \\
\text { gel }\end{array}$ & $\begin{array}{l}\text { Thermo Fisher } \\
\text { Scientific }\end{array}$ & NP0301BOX & \\
\hline
\end{tabular}




\begin{tabular}{|c|c|c|c|c|}
\hline & $\begin{array}{l}\text { NuPAGE } \\
\text { MOPS SDS } \\
\text { running } \\
\text { buffer }\end{array}$ & & & \\
\hline & $\begin{array}{l}\text { Trans-Blot } \\
\text { Turbo PVDF } \\
\text { membrane }\end{array}$ & Bio-Rad & 1704157 & \\
\hline & BSA & Sigma & A3294 & \\
\hline & $\begin{array}{l}\text { Super Signal } \\
\text { West Pico } \\
\text { Chemilumine } \\
\text { scent } \\
\text { Substrate } \\
\end{array}$ & $\begin{array}{l}\text { Thermo Fisher } \\
\text { Scientific }\end{array}$ & 34077 & \\
\hline \multirow{8}{*}{$\begin{array}{l}\text { software, } \\
\text { algorithm }\end{array}$} & Fiji & $\mathrm{NIH}$ & & 1.51n; https://fiji.sc/ \\
\hline & \begin{tabular}{|l|} 
GraphPad \\
Prism 6
\end{tabular} & GraphPad & $\begin{array}{l}\text { RRID:SCR_ } \\
002798\end{array}$ & \\
\hline & ZEN 2 lite & ZEISS & $\begin{array}{l}\text { RRID:SCR_ } \\
013672\end{array}$ & \\
\hline & $\begin{array}{l}7500 \text { Real- } \\
\text { Time PCR } \\
\text { Software }\end{array}$ & Applied Biosystems & $\begin{array}{l}\text { RRID:SCR_ } \\
014596\end{array}$ & \\
\hline & Harmony & PerkinElmer & & \\
\hline & $\begin{array}{l}\text { BatchQuantif } \\
\text { y }\end{array}$ & $\begin{array}{l}\text { (Johansson et al., } \\
2019) \\
10.1016 / \text { j.stem.201 } \\
9.02 .002\end{array}$ & NA & $\begin{array}{l}\text { https://github.com/eml } \\
\text { twc/2018-Cell-Stem- } \\
\text { Cell }\end{array}$ \\
\hline & EGFR_quant & This paper & NA & $\begin{array}{l}\text { https://github.com/eml } \\
\text { twc/EGFRProject }\end{array}$ \\
\hline & Blind scoring & $\begin{array}{l}\text { (Perochon et al., } \\
\text { 2021) } \\
\text { https://doi.org/10.10 } \\
\text { 38/s41556-021- } \\
00676-z\end{array}$ & N/A & $\begin{array}{l}\text { https://github.com/eml } \\
\text { twc/TracheaProject/bl } \\
\text { ob/master/Blind_scori } \\
\text { ng.ijm }\end{array}$ \\
\hline \multirow[t]{4}{*}{ other } & $\begin{array}{l}\text { Axio } \\
\text { Observer }\end{array}$ & ZEISS & & \\
\hline & $\begin{array}{l}\text { LSM780 } \\
\text { microscope }\end{array}$ & ZEISS & & \\
\hline & $\begin{array}{l}\text { BX51 } \\
\text { microscope }\end{array}$ & Olympus & & \\
\hline & $\begin{array}{l}\text { Opera } \\
\text { Phenix } \\
\text { Z9501 }\end{array}$ & PerkinElmer & & \\
\hline
\end{tabular}




\begin{tabular}{|l|l|l|l|l|} 
& $\begin{array}{l}\text { 7500 Fast } \\
\text { Real-Time } \\
\text { PCR System }\end{array}$ & Applied Biosystems & & \\
\hline & $\begin{array}{l}\text { Trans-Blot } \\
\text { Turbo } \\
\text { system }\end{array}$ & Bio-Rad & 1704150 & \\
\hline & HiSeq 2000 & Illumina & & \\
\hline $\begin{array}{l}\text { ImageLock } \\
\text { plate }\end{array}$ & Essen Biosciences & & \\
\hline
\end{tabular}




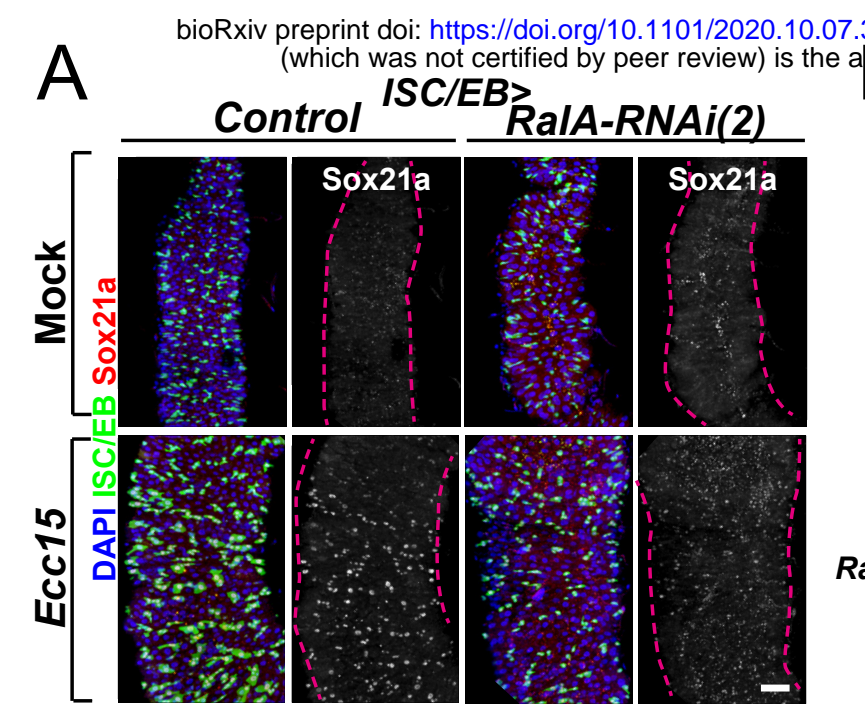

$E$ Irradiation 10 Gy $F$

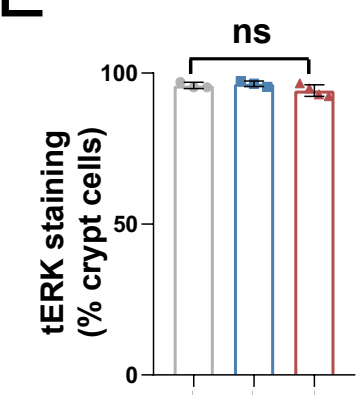

Villin Cre $e^{E R}+$

Ralafl/fl

Ralb $^{\text {flffl }}+$

$n=3 \quad 34$

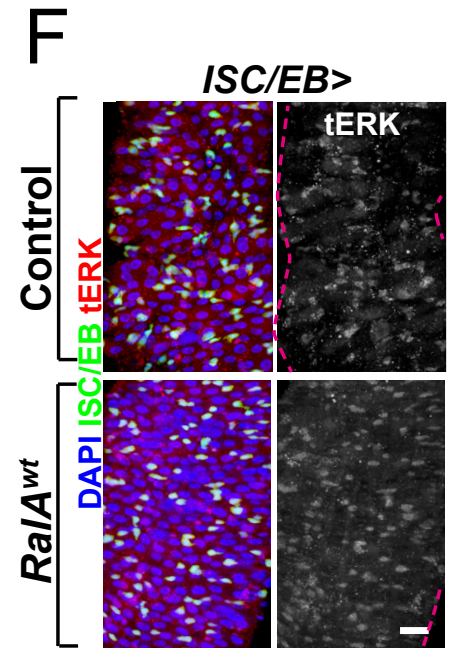

The copyright holder for this preprint
flowed without permission.

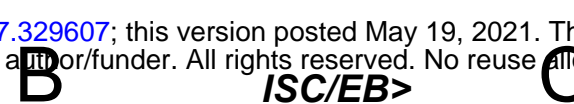

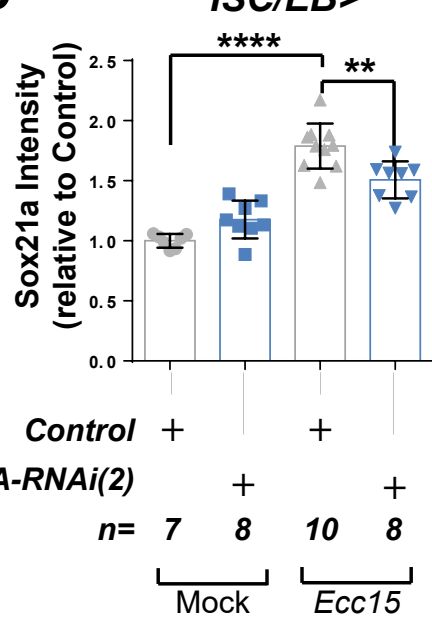

$\mathrm{D}$

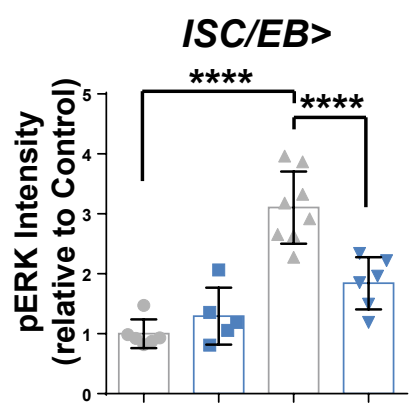

Control + RalA-RNAi(2)

$$
\begin{array}{lllll}
n= & & + & & + \\
\cline { 1 - 2 } & \mathbf{6} & \mathbf{8} & \mathbf{6} \\
\cline { 1 - 2 } & & & \\
\text { Mock } & & \text { Ecc15 }
\end{array}
$$
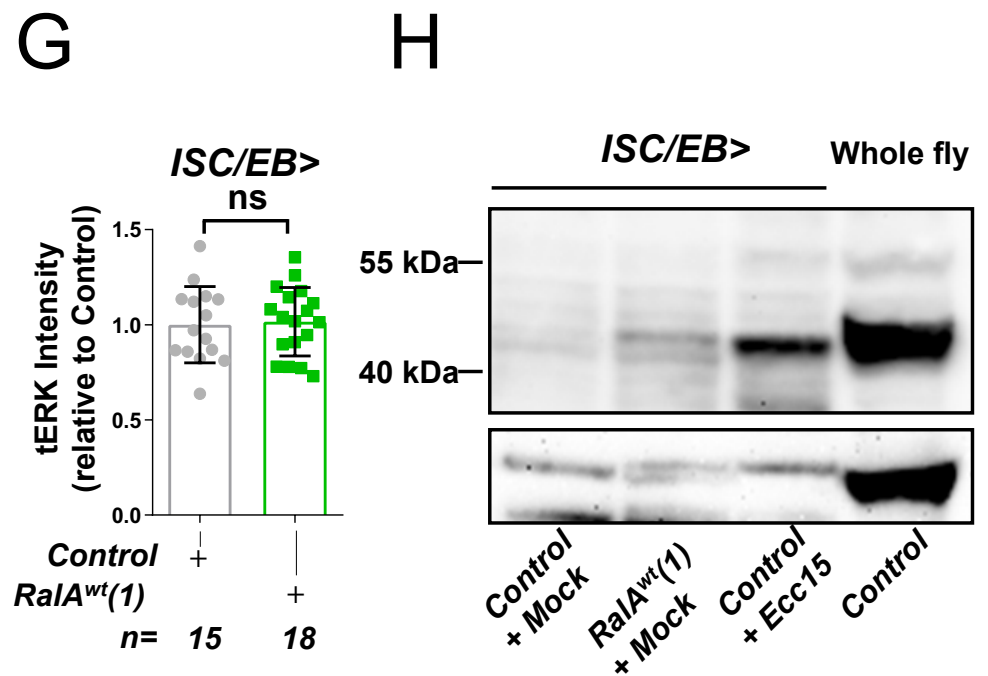

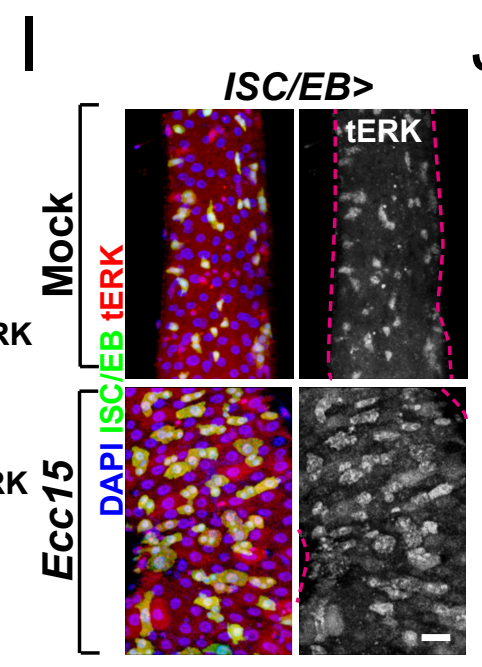

$\mathrm{J}$

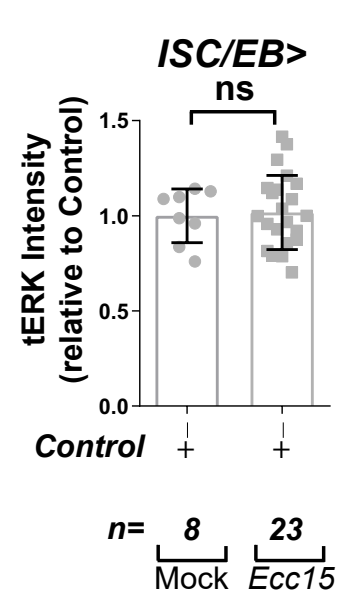

Fig 1-Supplement 1 
bioRxiv preprint doi: https://doi.org/10.1101/2020.10.07.329607; this version posted May 19, 2021. The copyright holder for this preprint
(which whS
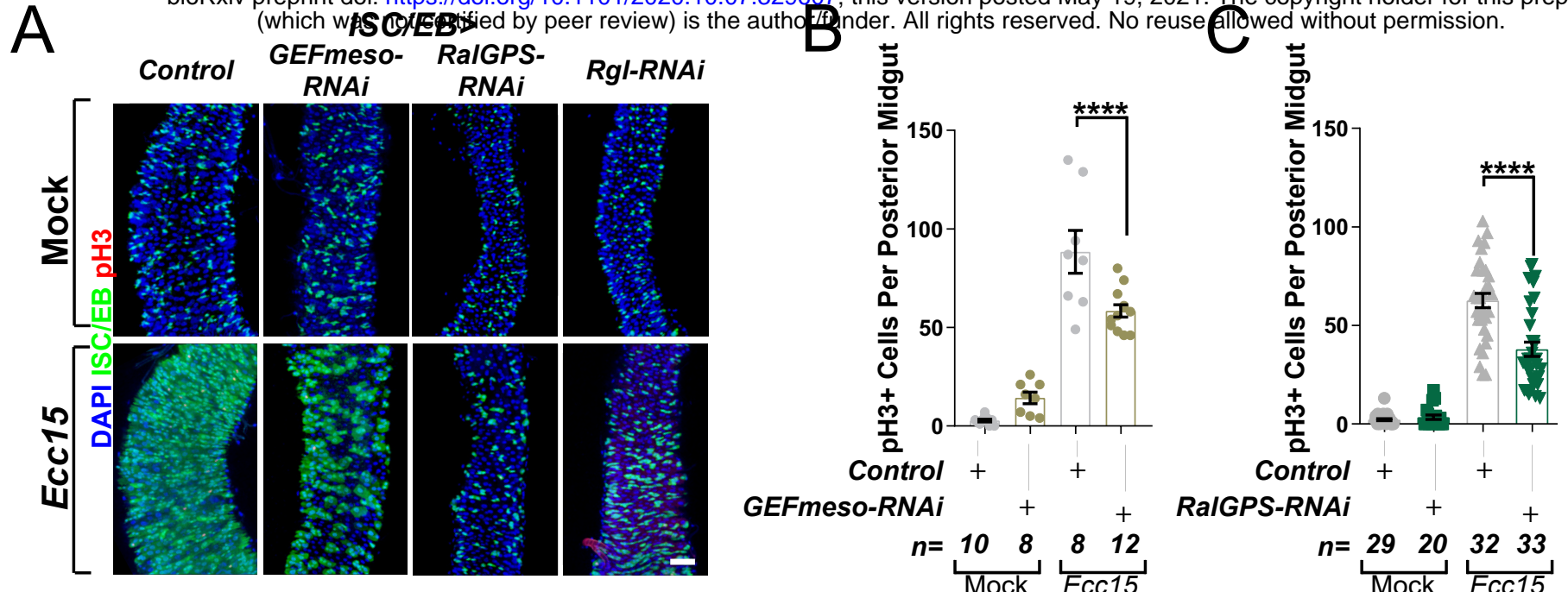

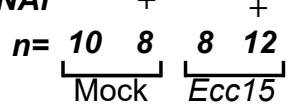

$$
n=\frac{29 \quad 20}{232} 33
$$

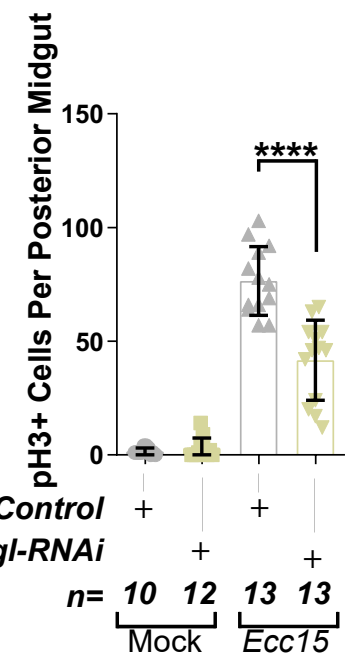

E

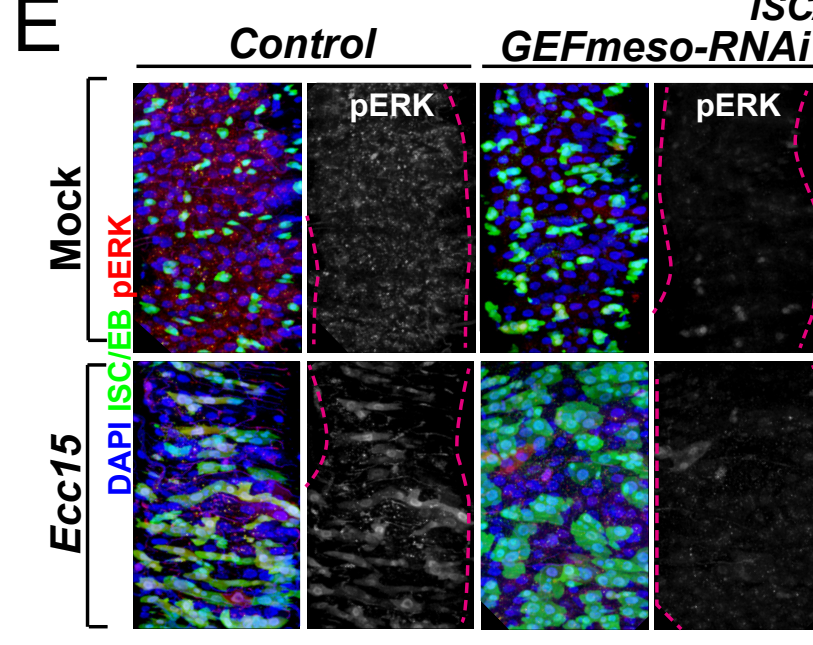

ISC/EB>

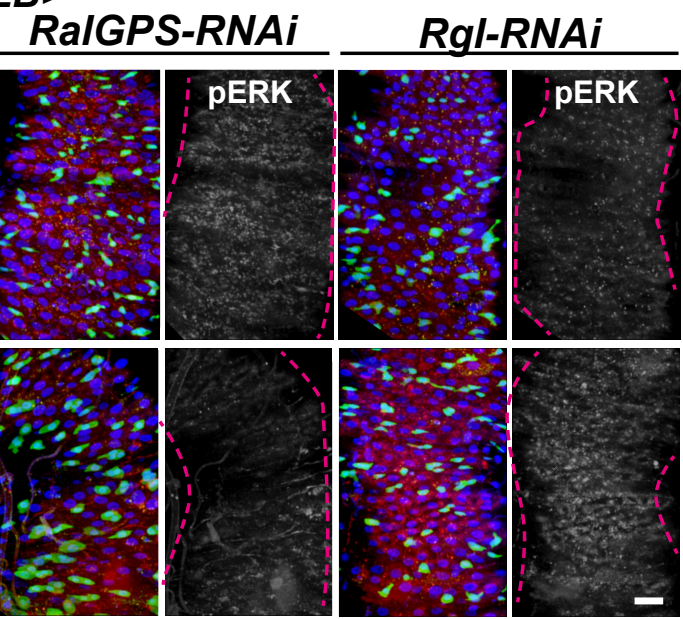

F

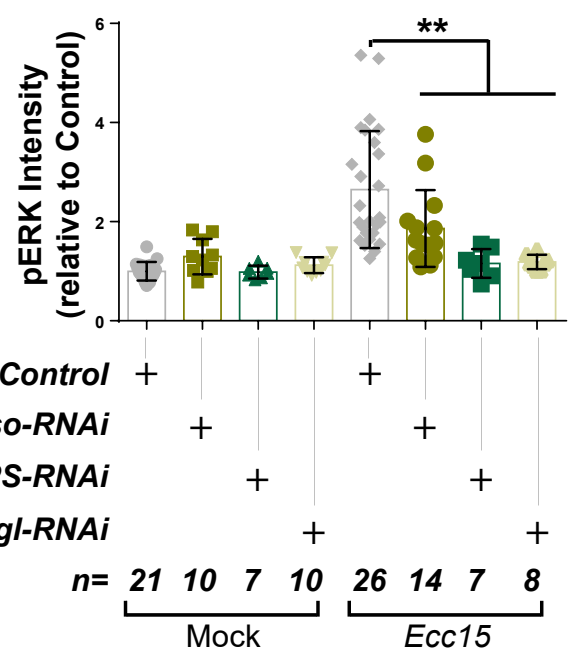

Fig2 


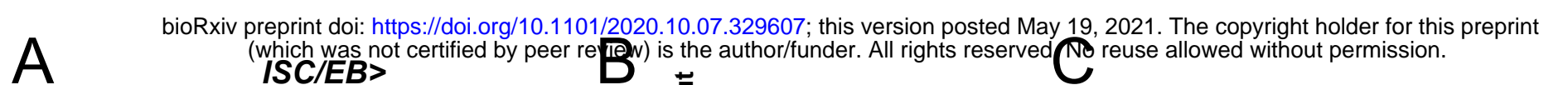

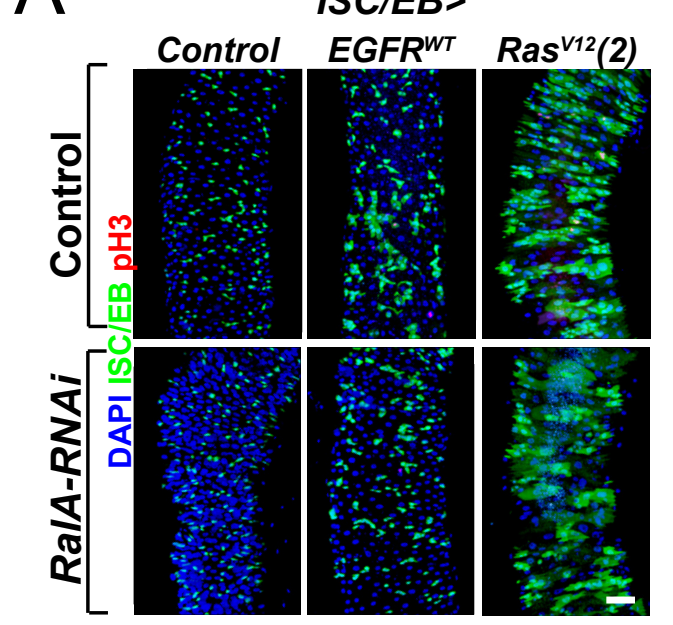

E

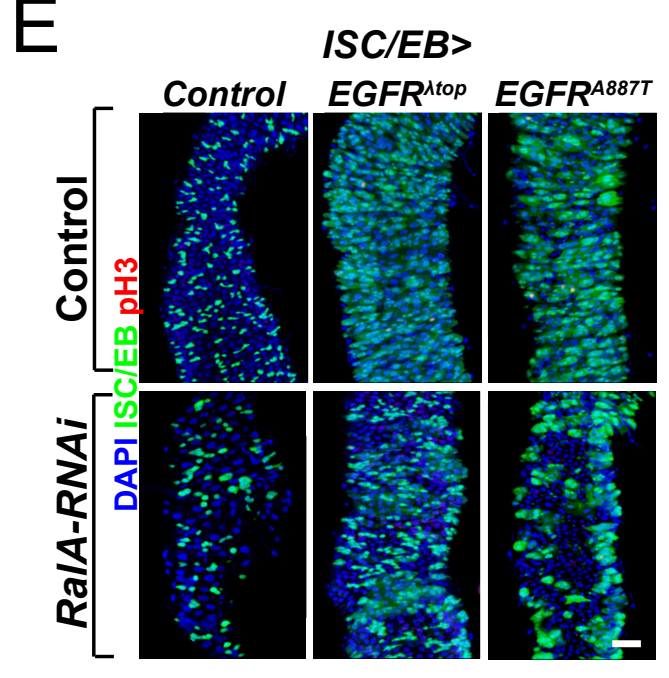

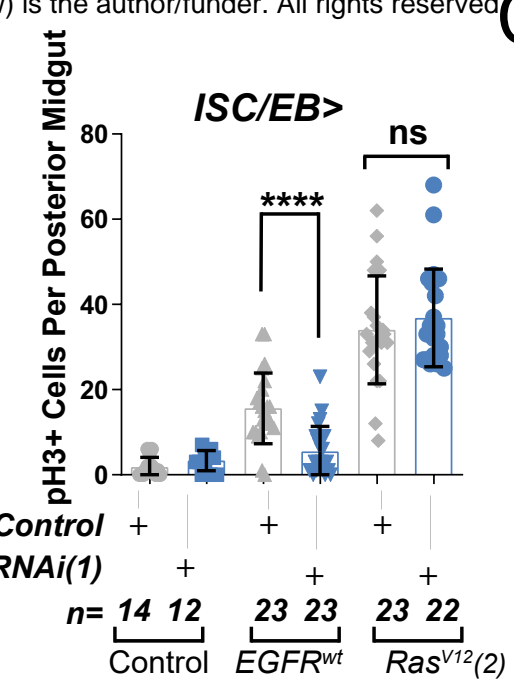

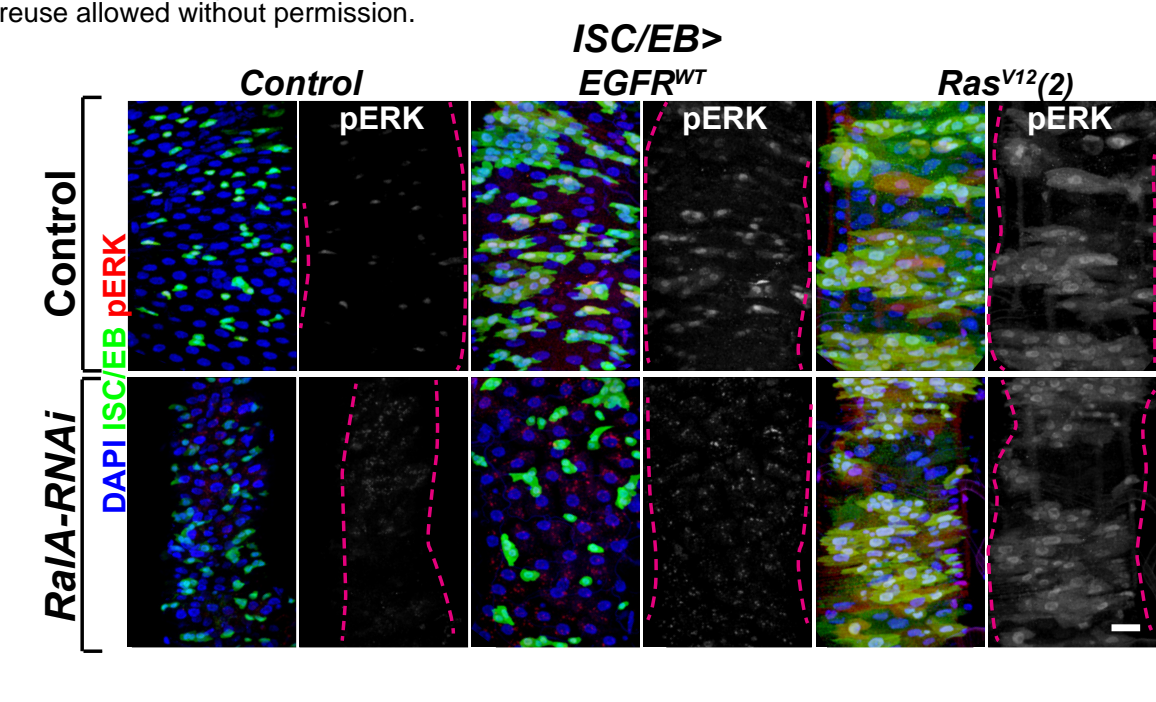

$\mathrm{F}$

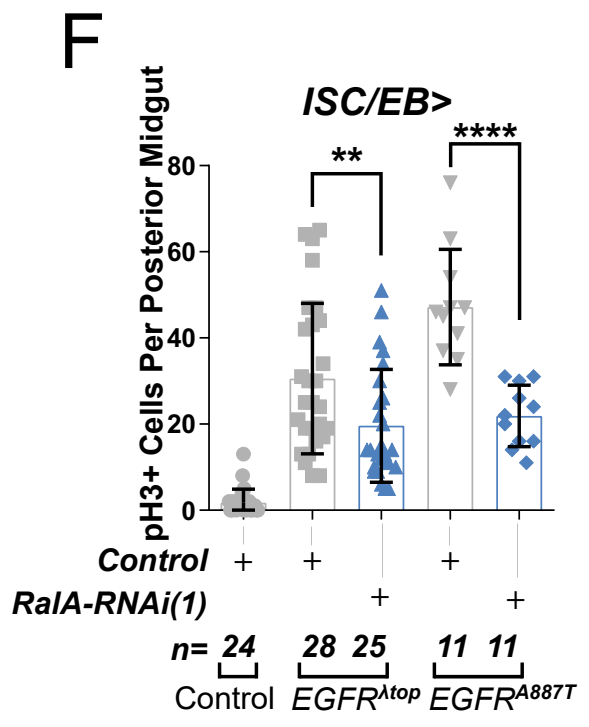

G

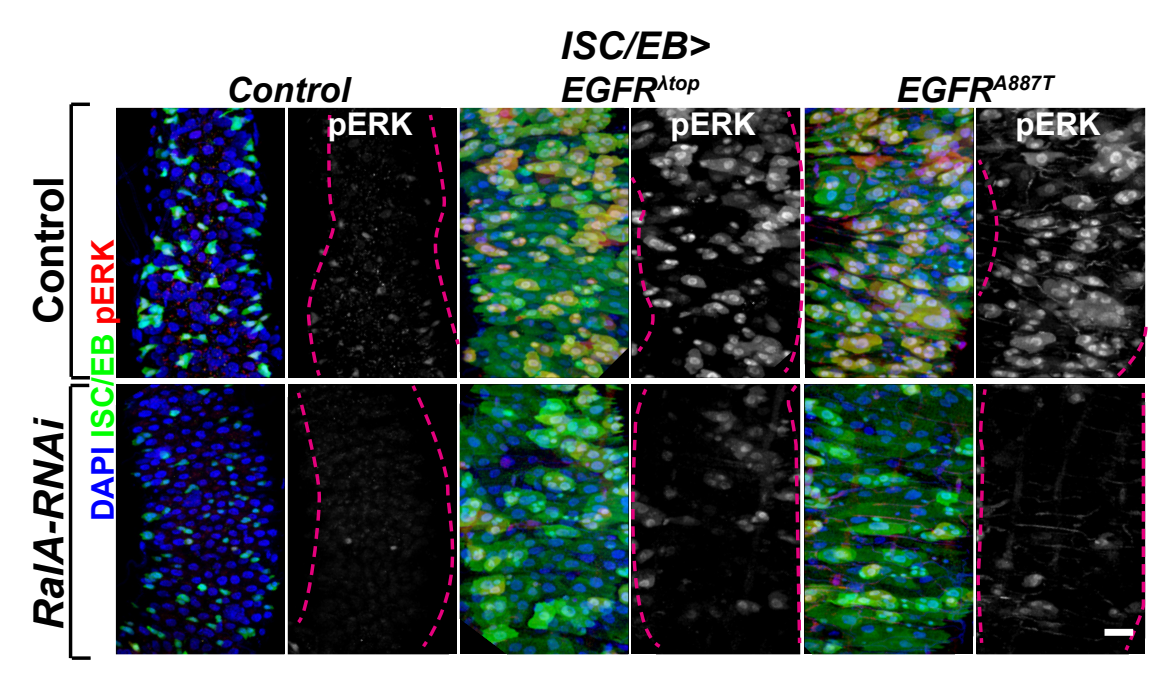

D

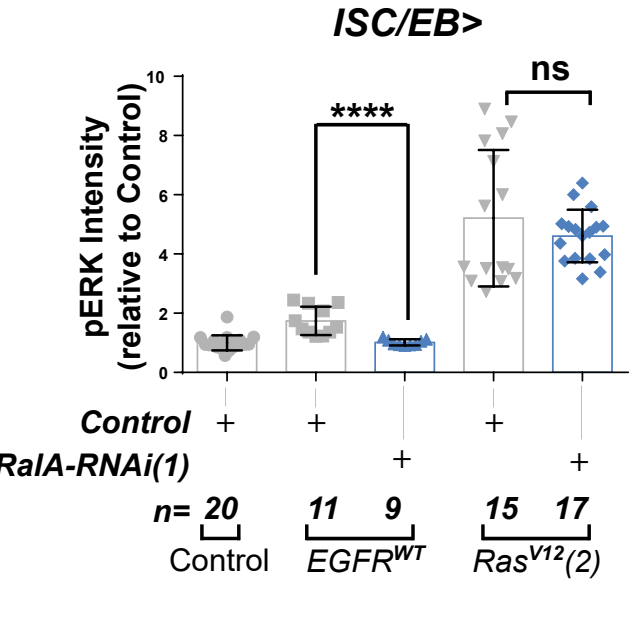

$H$

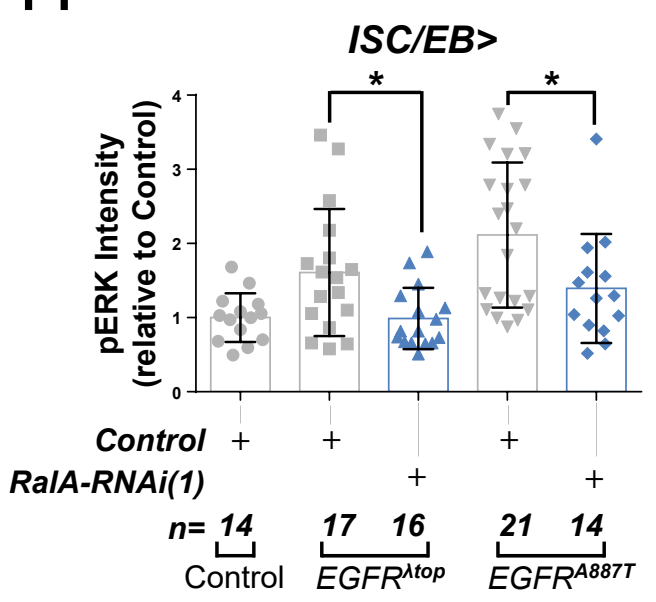

Fig 3 
bioRxiv preprint doi: https://doi.org/10.1121/2020.10.07.329607; this version posted May 19, 2021. The copyright holder for this preprint
(which was not certified by peed

A

en>
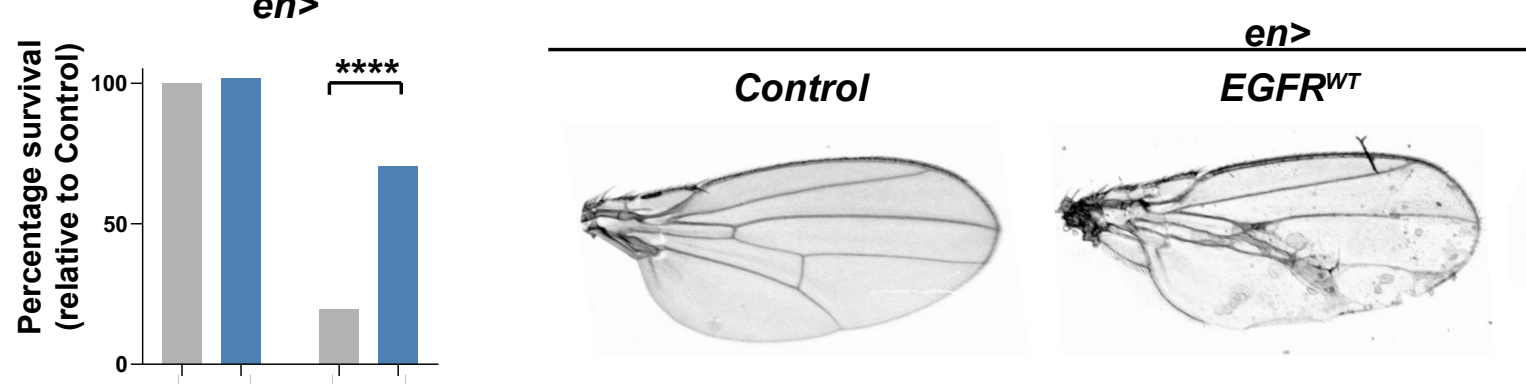

RaIA-RNAi;EGFR ${ }^{W T}$

Control +

RalA-RNAi(1)

$$
\begin{aligned}
& \begin{array}{llll}
n=157 & 99 & 75 & 87
\end{array} \\
& \text { Control } \overleftarrow{E G F R^{W T}}
\end{aligned}
$$

C

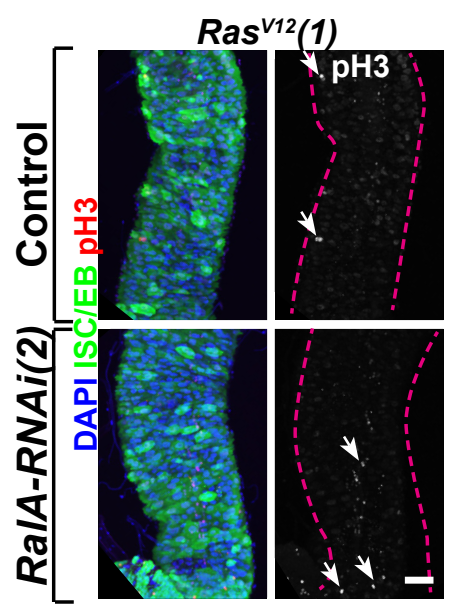

D

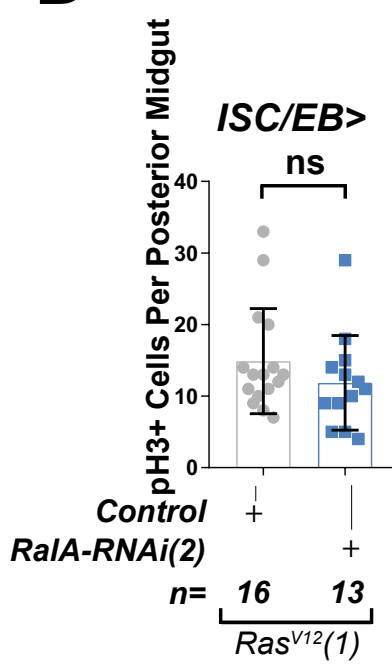

$E$

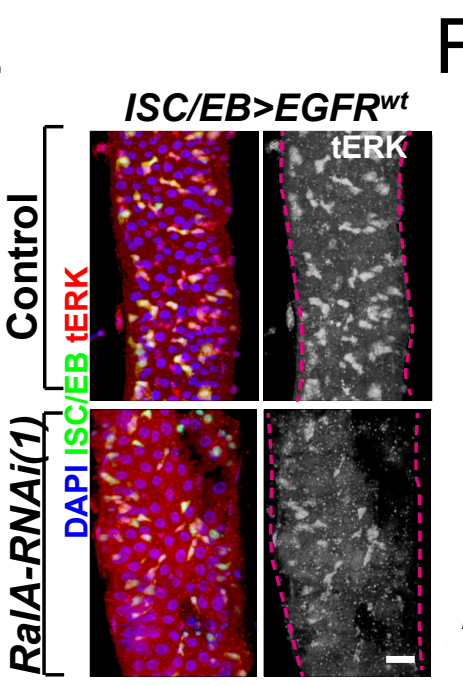

F

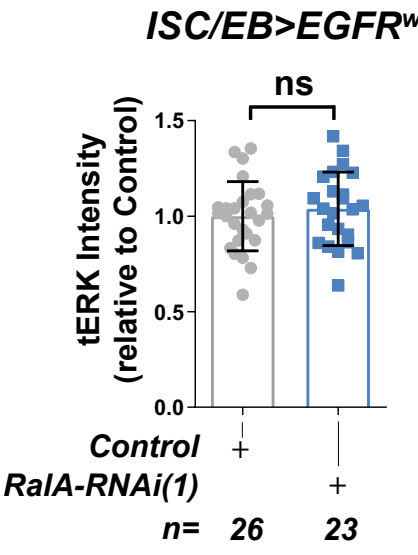

Fig 3-Supplement 1 
A DAPIISC/EB
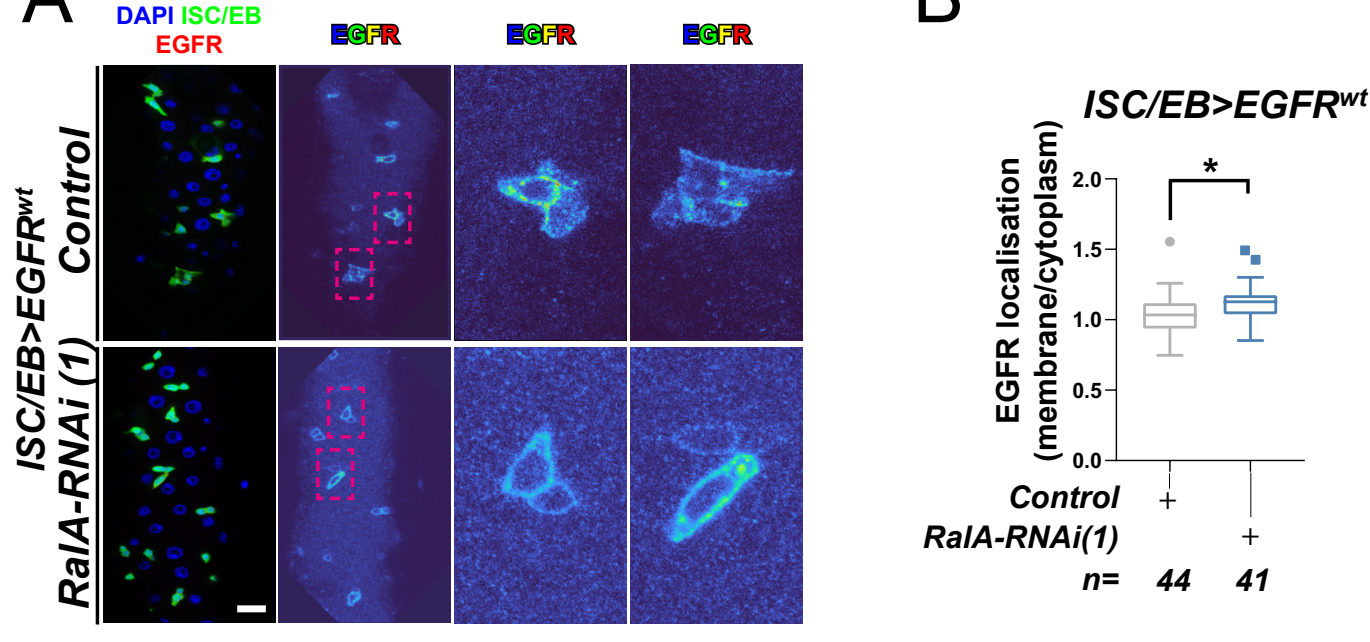

$\mathrm{C}$

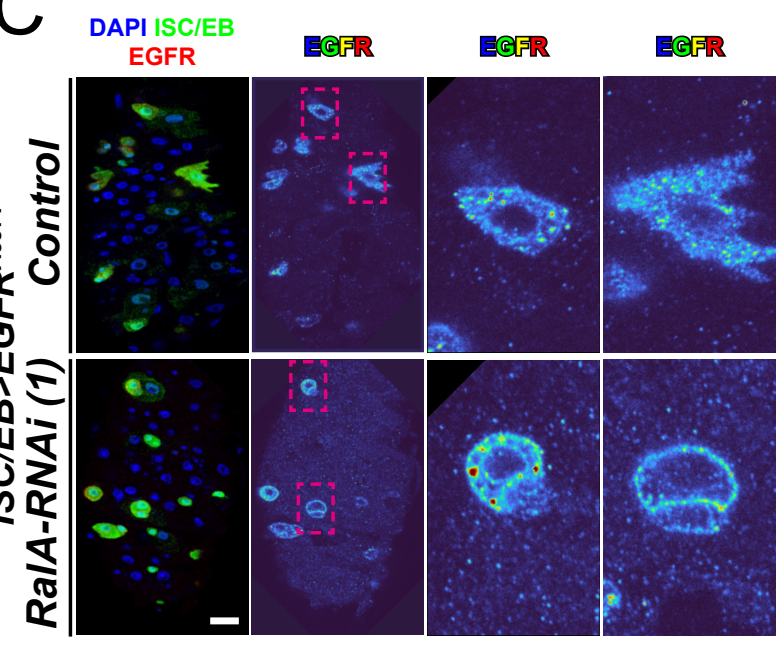

$D$
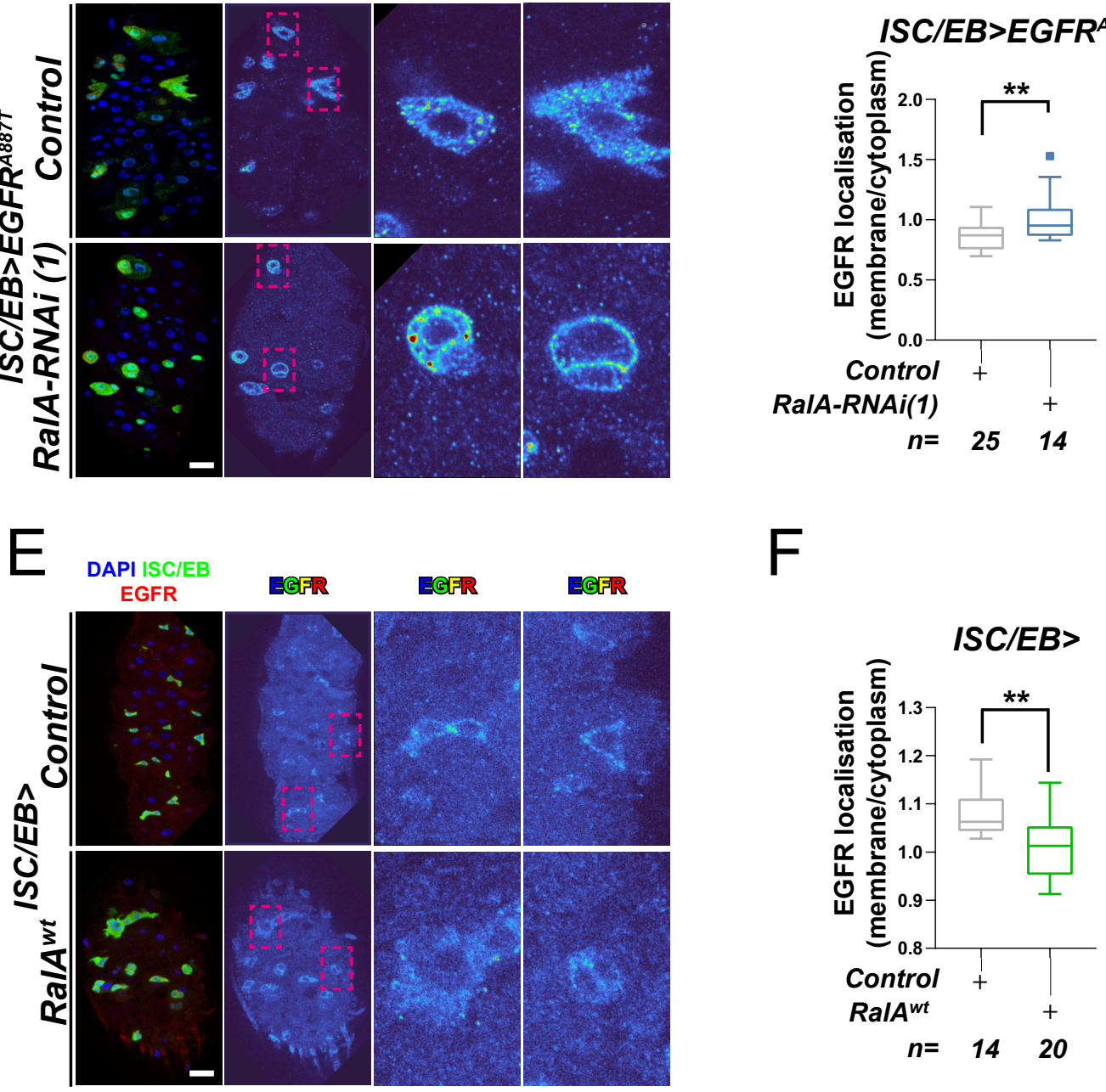

F

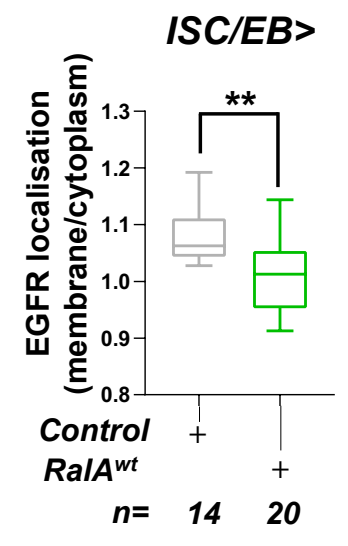

G

H1229 human lung cancer

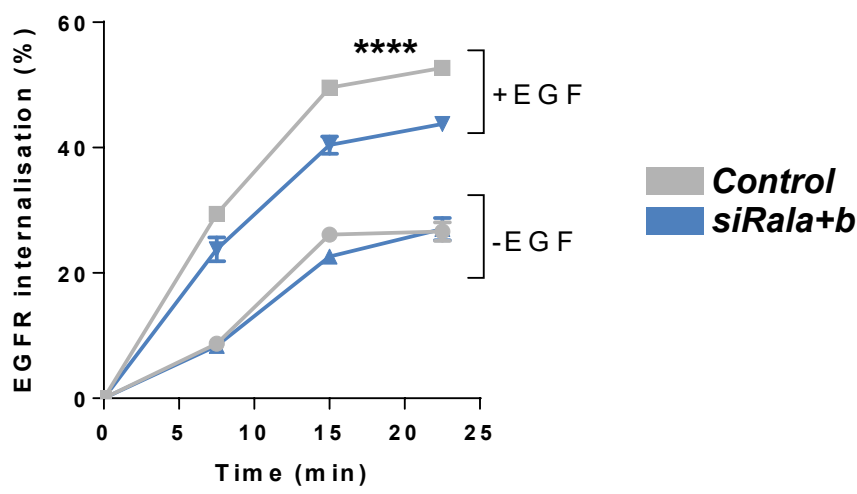

Fig 4 
A

DAPI ISC/EB EGFR

EGFR

EGFR

EGFR

B

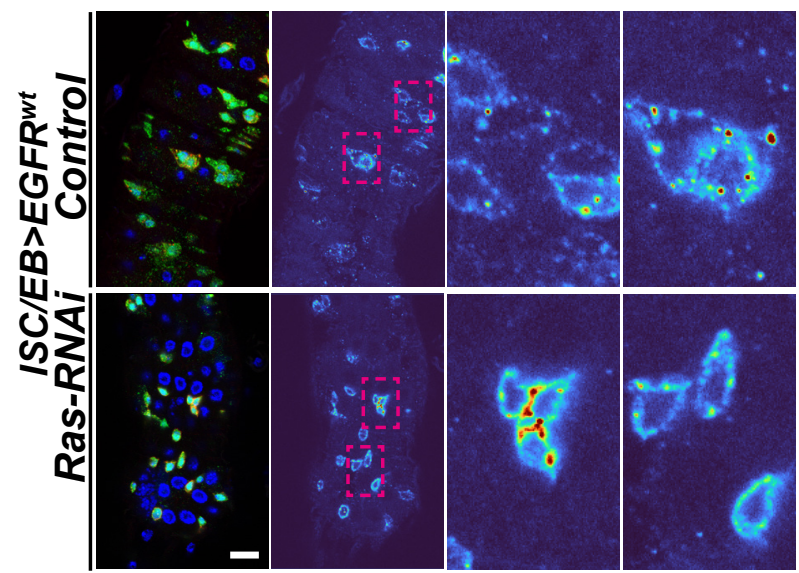

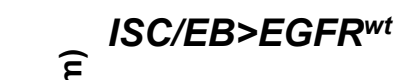
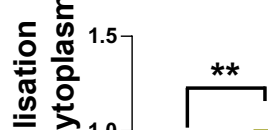

근 궁 1.0

ঠु

으 옹

똥

닌

ш

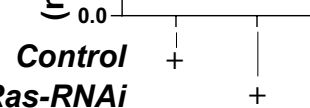

Ras-RNAi

$n=25 \quad 19$ 
bioRxiv preprint doi: https://doi.org/10.11 2020.10.07.329607; this version posted May 19, 202 The copyright holder for this preprint

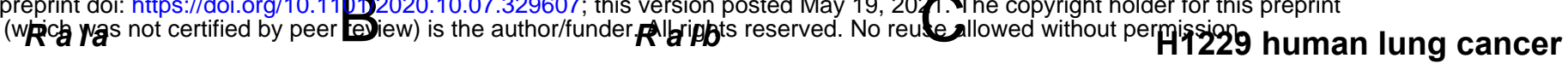
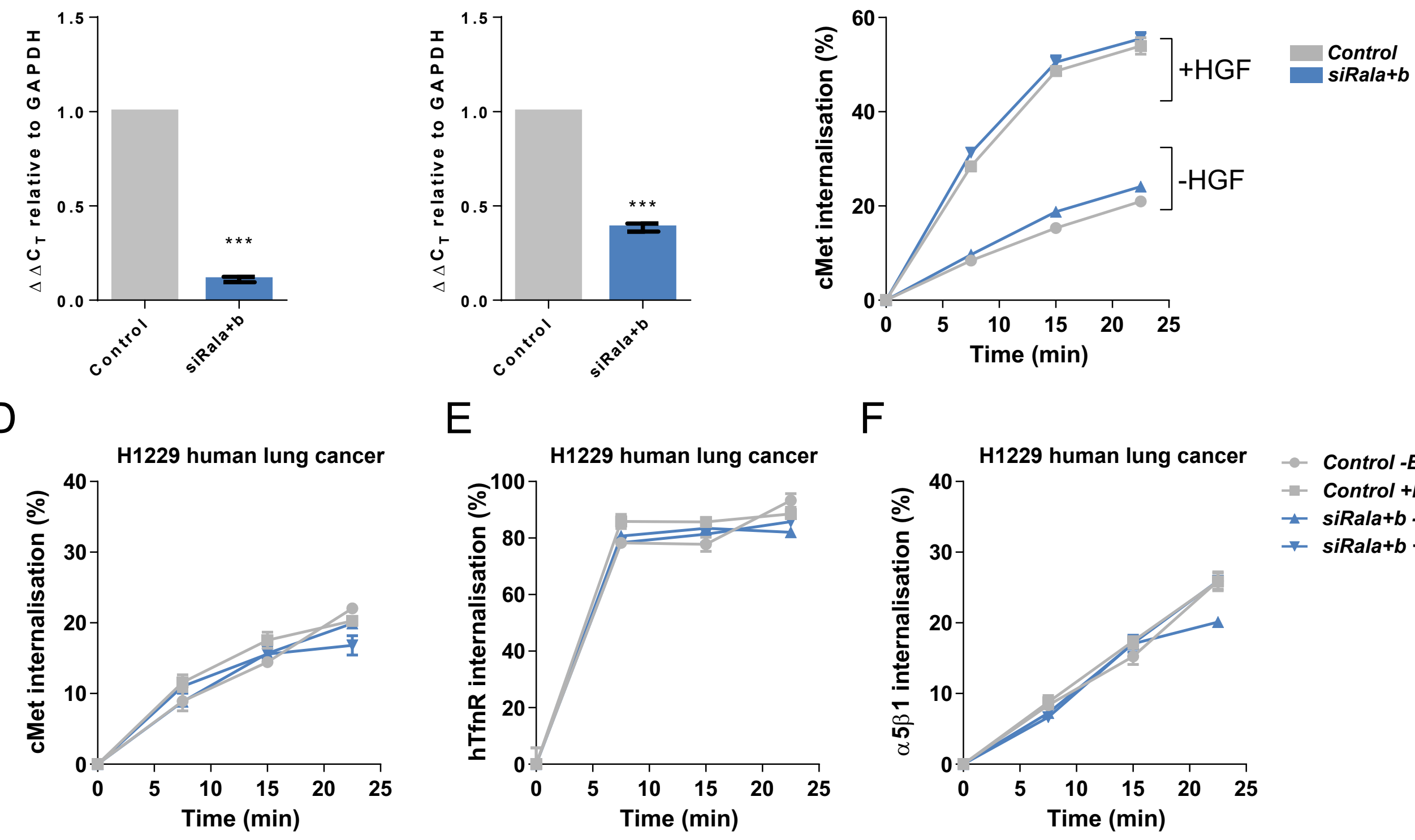

E

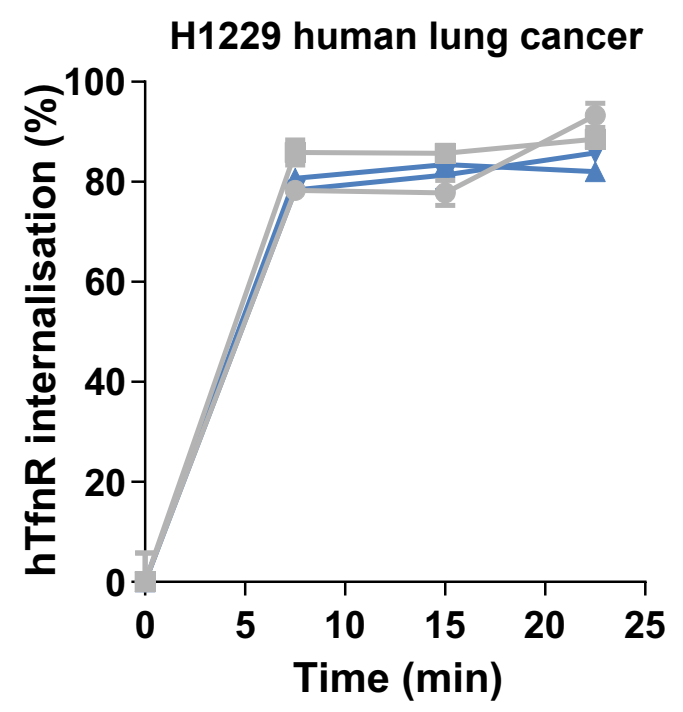

F

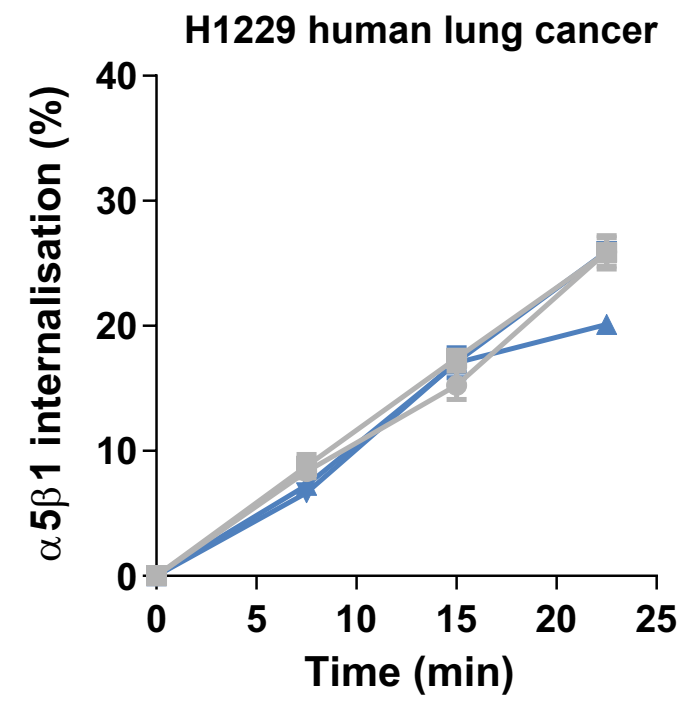

- Control -EGF

- Control +EGF

- siRala+b -EGF

$\rightarrow$ siRala+b +EGF

Fig 4-Supplement 3 
$\Delta \quad$ bioRxiv preprint doi: https://dgigrg/10.1101/2020.10.07.329607; thicersion posted May 19, 2021. The copyright holder for this preprint
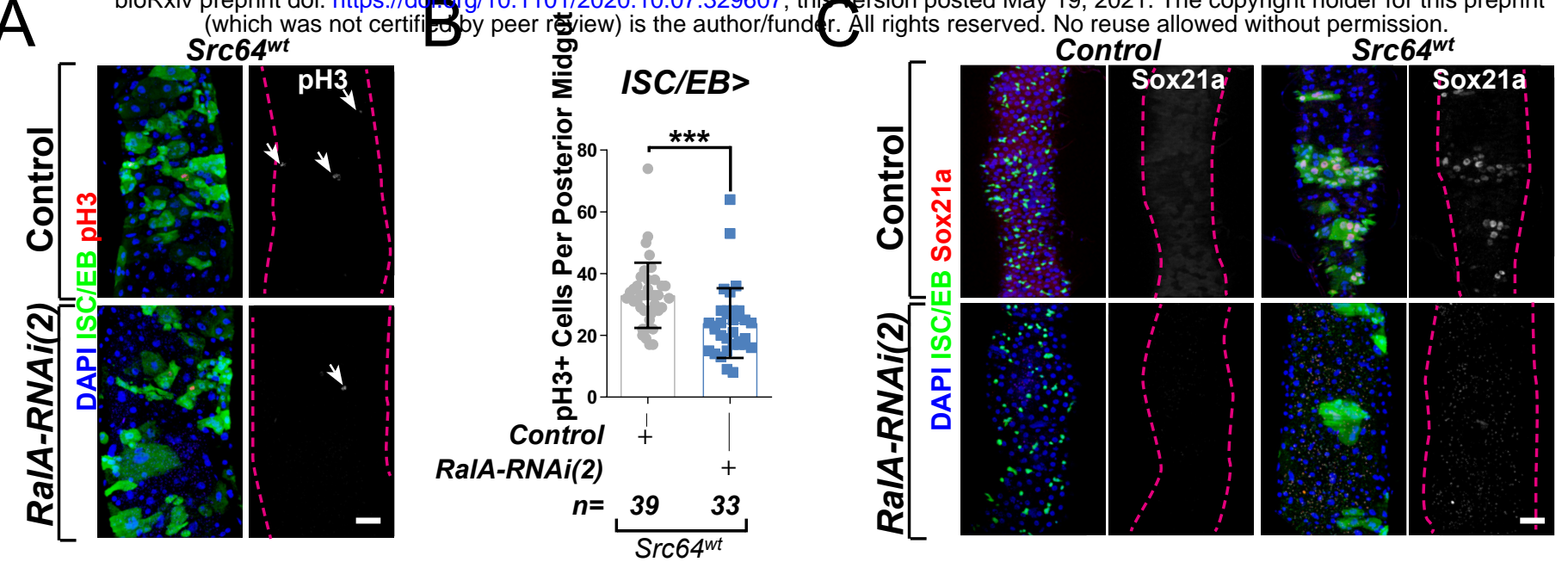

D
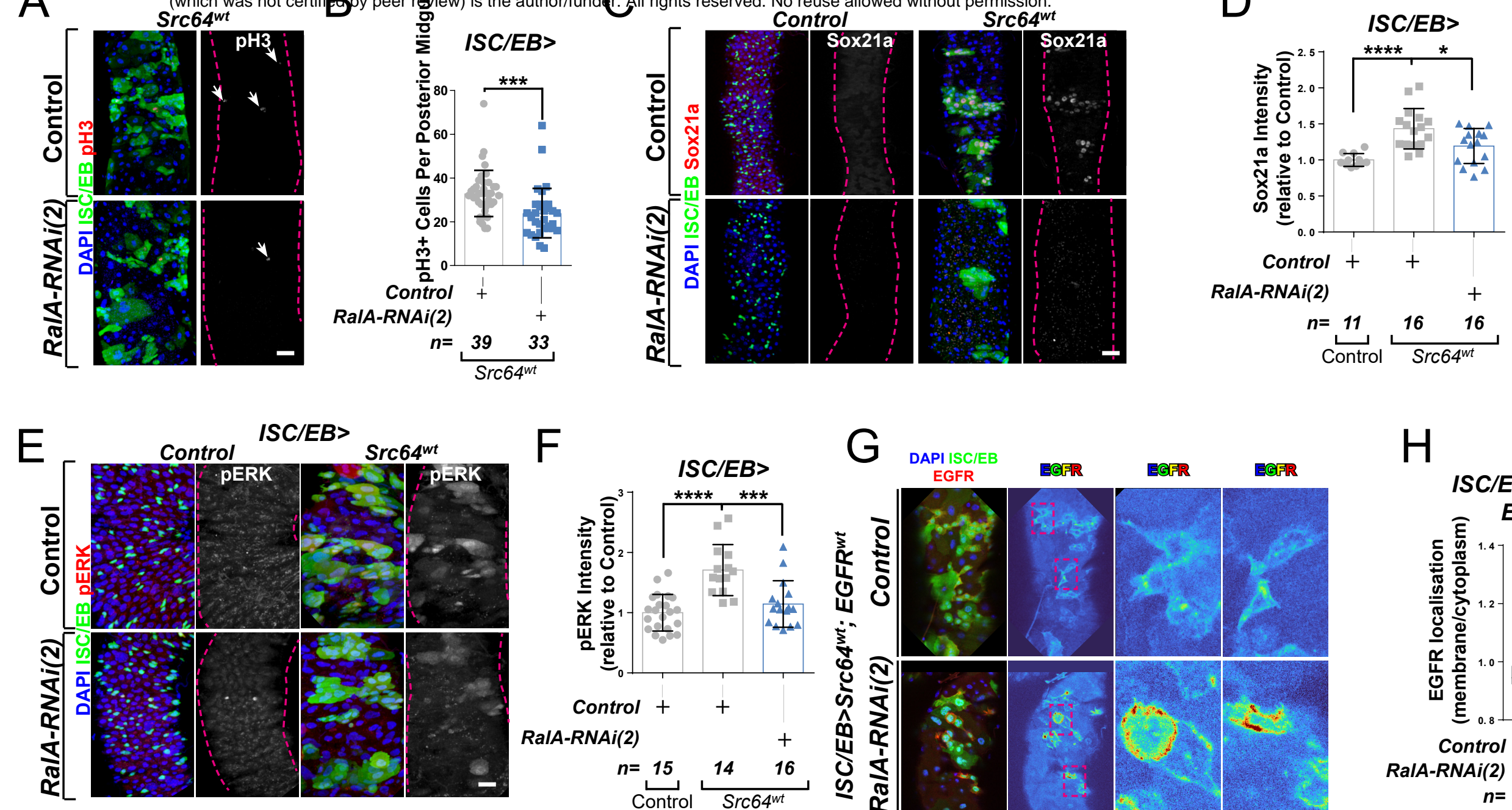

F
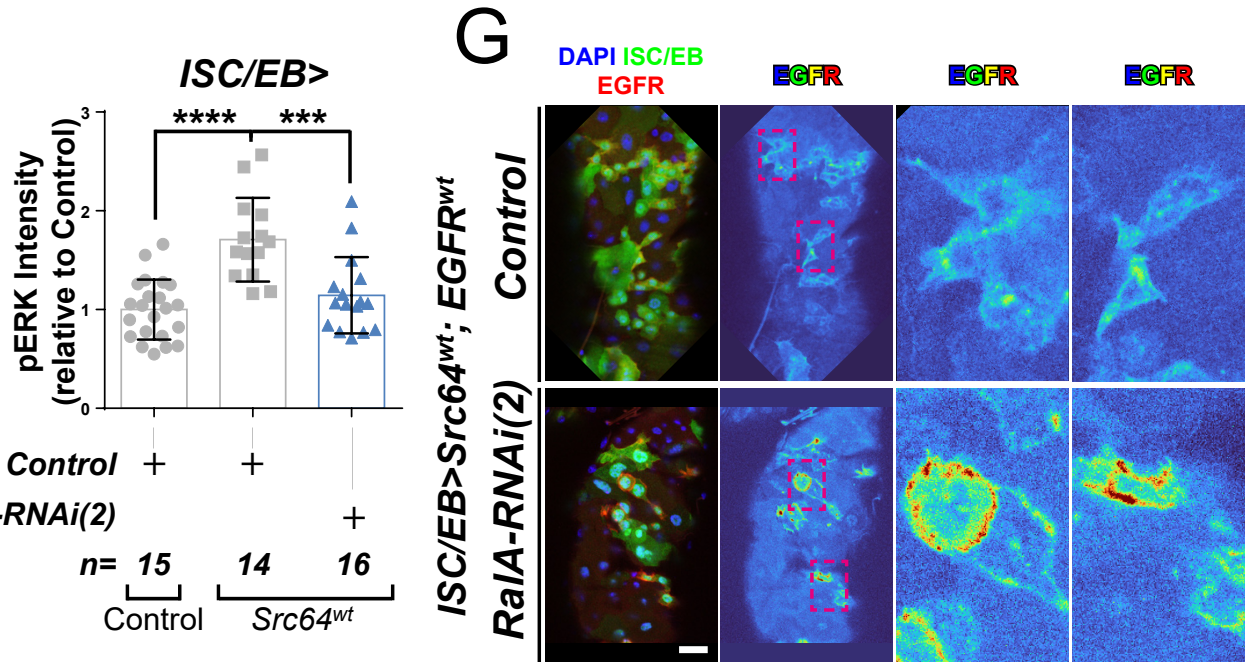

$\mathrm{H}$
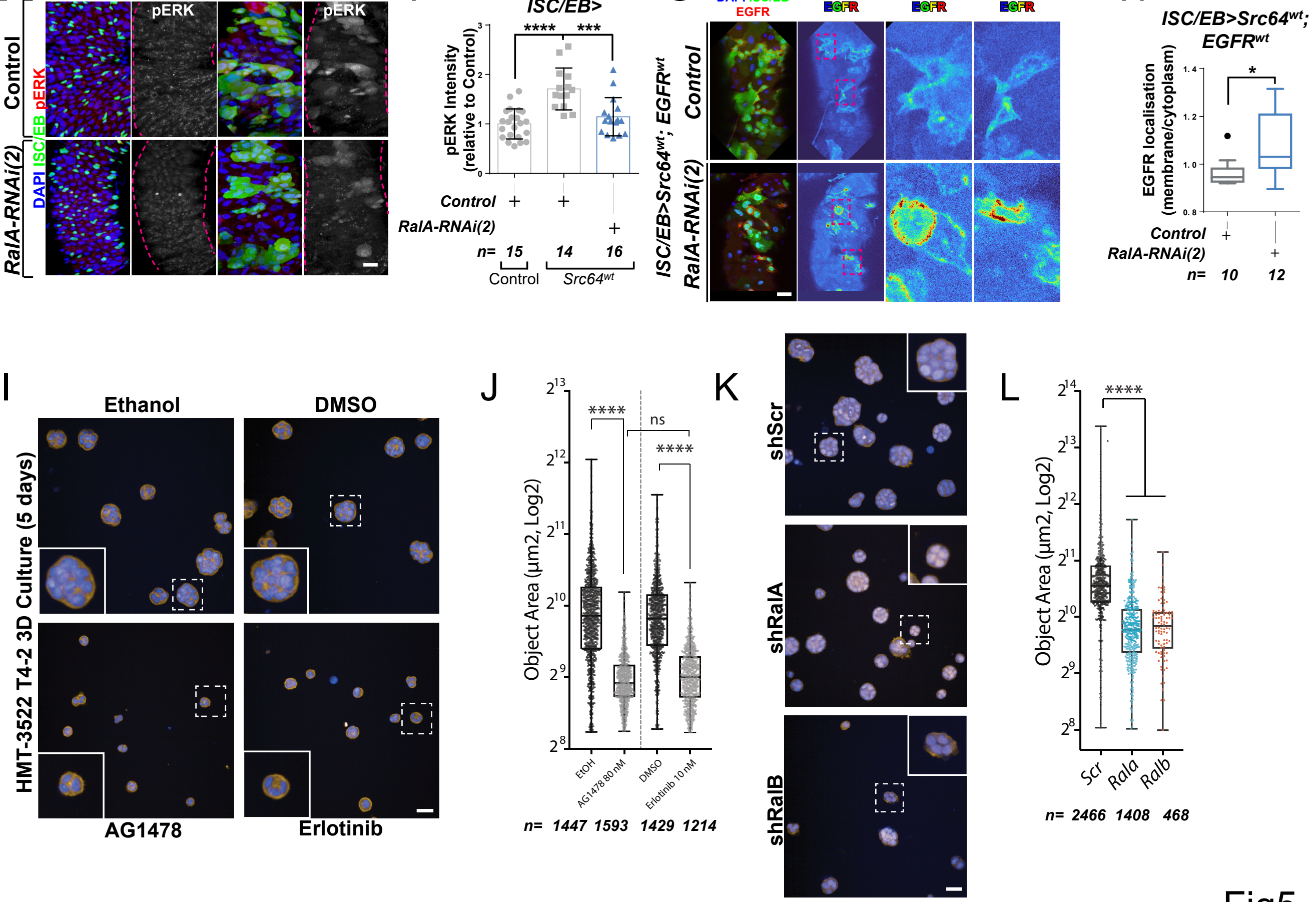

$n=24661408468$

Fig5 
